\title{
Misoprostol: An emerging technology for women's health-Report of a seminar
}

Caitlin S. Shannon

Population Council

Beverly Winikoff

Population Council

Follow this and additional works at: https://knowledgecommons.popcouncil.org/departments_sbsr-rh How does access to this work benefit you? Let us know!

\section{Recommended Citation}

Shannon, Caitlin S. and Beverly Winikoff (editors). 2004. "Misoprostol: An emerging technology for women's health-Report of a seminar." New York: Population Council. 


\section{isoprostol}

\section{An emerging technology for women's health}

Report of a seminar

\section{Caitlin S. Shannon}

Beverly Winikoff

Editors 
Misoprostol An emerging technology for women's health

Report of a seminar

7-8 May 2001

Population Council New York, New York

Caitlin S. Shannon

Beverly Winikoff

Editors

(2) Population Council 


\section{(f Population Council}

The Population Council is an international, nonprofit, nongovernmental organization that seeks to improve the well-being and reproductive health of current and future generations around the world and to help achieve a humane, equitable, and sustainable balance between people and resources. The Council conducts biomedical, social science, and public health research and helps build research capacities in developing countries. Established in 1952, the Council is governed by an international board of trustees. Its New York headquarters supports a global network of regional and country offices.

Population Council

One Dag Hammarskjold Plaza

New York, NY 10017 USA

212/339-0500; fax: 212/755-6052

e-mail: pubinfo@popcouncil.org

www.popcouncil.org

(C) 2004 by The Population Council, Inc.

Any part of this publication may be photocopied without permission from the authors or publisher, provided that publication credit is given and that copies are distributed free. Any commercial reproduction requires prior written permission from the Population Council. 


\section{O N T E N T S}

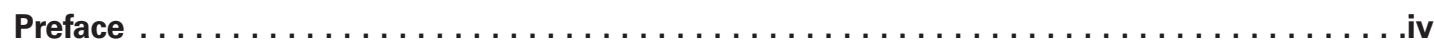

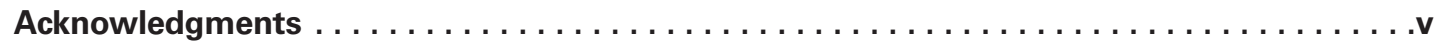

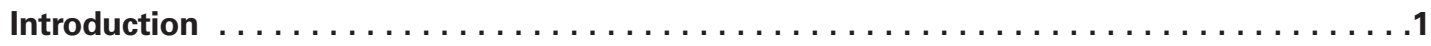

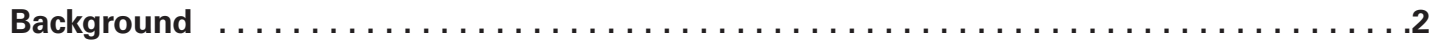

Current evidence in clinical research: Use of misoprostol for women's health indications $\ldots .5$

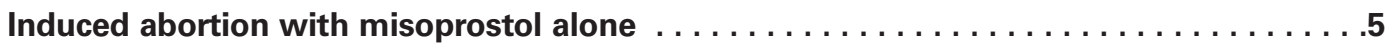

Uterine evacuation after pregnancy failure $\ldots \ldots \ldots \ldots \ldots \ldots \ldots \ldots \ldots \ldots \ldots \ldots \ldots$

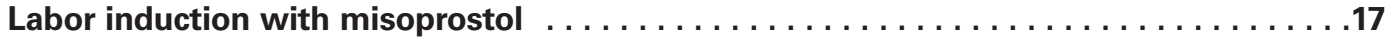

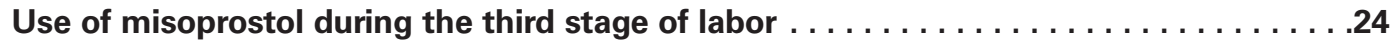

Cervical priming for obstetric and gynecological procedures $\ldots \ldots \ldots \ldots \ldots \ldots \ldots 29$

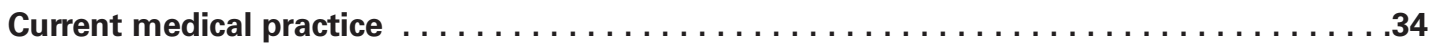

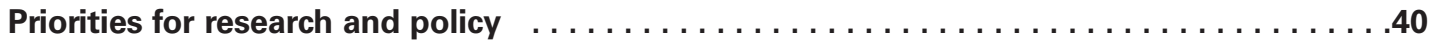

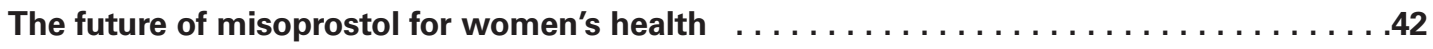

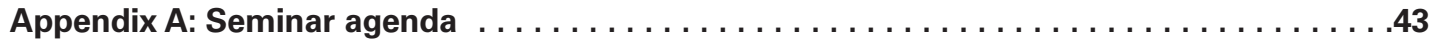

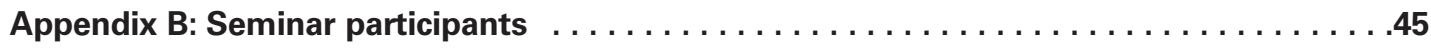

Appendix C: Bibliography of published articles on use of misoprostol

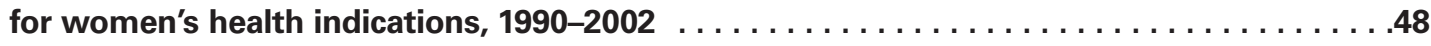


Pharmaceutical companies first marketed prostaglandins in the 1970s. Misoprostol (Cytotec ${ }^{\circledR}$ ), an orally active prostaglandin E1 analog, was approved in 1988 by the U.S. Food and Drug Administration for use in preventing gastric ulcers associated with use of nonsteroidal antiinflammatory drugs. For over a decade, however, researchers and clinicians have explored the use of this compound for a range of women's health indications. The literature on the subject is substantial, and anecdotal reports suggest that misoprostol is currently used for many indications.

Such use has become common for several reasons, including a need for better, simpler, and more cost-effective alternatives to standard treatments for incomplete abortion and labor induction. Moreover, development of nonsurgical interventions has high value, because such less-invasive interventions are often safer, preferable to patients, easier to deliver, and able to be provided by a range of health care practitioners. Use of misoprostol has also been motivated by the need to provide better health care for women in resourcepoor environments and to increase women's autonomy in health care decisionmaking everywhere.

The impetus for the meeting summarized in this report was the recognition that the large body of high-quality scientific work on misoprostol for women's health indications has not been synthesized in an accessible way. Scientists working to develop the potential of misoprostol have generally done so with very little collaboration or support from pharmaceutical companies or governmental research institutions. As a result, there has been no consensus on issues surrounding the use of misoprostol for women's health and no strategic agenda for continuing development, with most research proceeding in an ad hoc manner. Undeniably, impressive progress has been made in developing misoprostol for women's health indications despite unpromising circumstances. We realized, however, that there was much to be gained by coming together in order to summarize the current state of the field and to collaborate in planning for the future.

We have many hopes for misoprostol. We anticipate that a solid clinical base for use of misoprostol for women's health indications can be developed along with greater awareness of the science and importance of this drug. To this end, we hope to see more widespread, accurate, and appropriate dissemination of information on misoprostol, and misinformation dispelled. Finally, and perhaps most important, we look forward to seeing a dedicated product for women's health indications on the market. In many regards, this meeting was a call to action. The 58 participants-researchers, providers, women's health advocates, and educators-unanimously acknowledged misoprostol's promise to improve women's health. We hope that this report will motivate new strategic and collaborative efforts in research, advocacy, education, and regulatory matters to protect and to support this promise.

Note: This meeting was convened in May 2001. Given that many articles on the use of misoprostol for women's health have been published since, we have taken the liberty of updating the bibliography to include these recent publications.

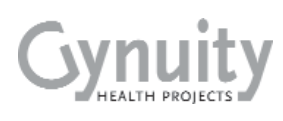

Beverly Winikoff, M.D., M.P.H.

President

Gynuity Health Projects

New York, NY, USA

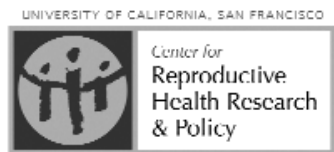

Felicia H. Stewart, M.D.

Co-director

Center for Reproductive Health

Research \& Policy

University of California, San Francisco

San Francisco, CA, USA
(2) Population Council

Caitlin Shannon, M.P.H. Program Coordinator Population Council NewYork, NY, USA 


\section{ACKNOW LE D G M E N T}

We are grateful to Shelley Clark, Antonia Polyn, Maria Alevrontas, and Jennifer Blum for organizing the seminar, and Tracy Weitz, Neena Philip, Batya Elul, and Peter Anderson for their assistance in producing this report.
We thank the Packard Foundation for its generous support of this meeting. Finally, we thank all of the seminar participants for their valuable and insightful comments, and for their continued efforts and dedication to developing this important women's health technology. 



\section{N T R O D U C T I O N}

On 7 and 8 May 2001, the Population Council and the Center for Reproductive Health Research \& Policy of the University of California, San Francisco, convened a technical seminar in New York City on the use of misoprostol for women's health indications. The seminar was designed to provide a forum for researchers, providers, women's health advocates, and educators to exchange information with the goal of advancing the potential of misoprostol to improve women's health. In presentations and question-and-answer sessions, participants discussed the state of the art in research, examined current clinical use of misoprostol, and created strategies for the future.

The three main objectives of the seminar were to:

- share research and clinical experience;

- identify promising regimens for use of misoprostol in women's health; and

- target priorities and potential strategies for research, education, policy, and information dissemination.

The first day focused on scientific and clinical aspects of misoprostol use. Leading experts discussed the current research for each indication, including dose, route of administration, regimens, efficacy, and side effects. Unpublished research (completed or in progress) also was discussed to ensure the most current understanding of the science.
The second day's discussion centered on the future of misoprostol for women's health, including identifying priorities for research and the role of provider groups and women's health and advocacy organizations in helping to ensure misoprostol's continued, appropriate use.

At the end of each session, discussion provided the group with an opportunity to share ideas and discuss unanswered questions.

This report covers the key issues raised by each speaker and highlights general areas of discussion among participants. Three main sections follow:

- a summary of available clinical research, which describes current research on each indication for which the use of misoprostol has been investigated, highlighting gaps in research and issues relevant for the transfer of the technology from research to practice;

- a summary of current medical practice, reviewing results of studies that investigated the use of misoprostol in women's health care, including providers' and women's knowledge of misoprostol and regimens and the indications most commonly used; and

- a list of priorities for research and policy. 


\section{Misoprostol's Importance for Women's Health}

Misoprostol is currently marketed by Pfizer Inc.* as Cytotec $^{\circledR}$ for the prevention of gastric ulcers induced by the use of nonsteroidal antiinflammatory drugs (NSAIDs). Cytotec ${ }^{\circledR}$ is registered for use in over 80 countries (see Figure 1). Several generic misoprostol products have recently become available for this indication.

A review of the literature reveals that research on misoprostol for women's health indications has been expanding rapidly since the beginning of the 1990s. The extensive body of published literature demonstrates misoprostol's potential for a range of women's health indications (see Box 1). These indications can be broadly categorized into one of three areas: abortion, uterine evacuation, and labor and delivery (see Box 2).

\section{Advantages of Misoprostol}

Misoprostol is inexpensive, easy to store, and widely available. Alternatives to misoprostol for certain indications include prostaglandins such as gemeprost and dinoprostone (Prostin ${ }^{\circledR}$, Prepidil $^{\circledR}$, and Cervidi $^{\circledR}$ ) and uterotonics such as oxytocin or Syntometrine ${ }^{\circledast}$ (oxytocin and ergometrine). These alternatives are more expensive, require refrigerated storage, and often are given by injection. Compared to these other products, misoprostol has the potential for widespread use, particularly in low-resource settings where the burden of reproductive mortality and morbidity is heaviest. Moreover, treatment with misoprostol is noninvasive, simple to provide, and may be preferable to women. It can be provided in a range of settings, including hospitals, family planning clinics, mobile units, and at home (see Boxes 3 and 4).

* From 1988 until 2000, Cytotec ${ }^{\circledast}$ (misoprostol) was marketed and distributed by G.D. Searle \& Company. Monsanto Company, including its G.D. Searle unit, merged with Pharmacia \& Upjohn in April 2000, creating Pharmacia Corporation. On 15 July 2002, Pharmacia Corporation and Pfizer Inc. announced that Pfizer would acquire Pharmacia. This merger was completed on 16 April 2003.

\section{FIGURE 1 Availability of misoprostol worldwide, July 2003}

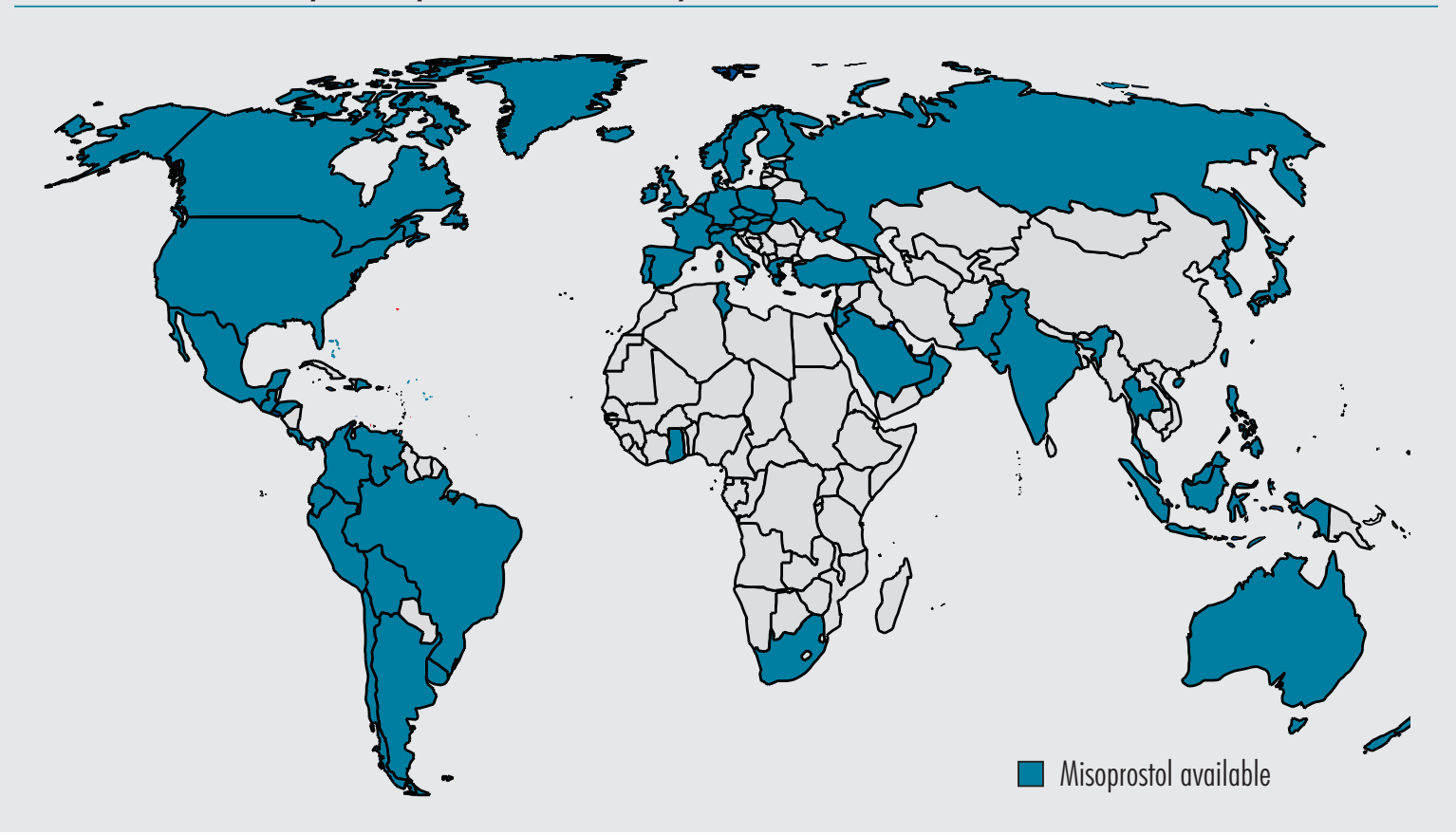




\section{BOX 1 State of current research on misoprostol}

Indications for which there is an extensive, well-established body of evidence

- First- and second-trimester pregnancy termination in conjunction with mifepristone or methotrexate

- Cervical ripening before first-trimester surgical pregnancy termination

- Labor induction with a viable fetus

Indications for which there is good evidence, including at least one published randomized, controlled trial, and that were discussed at the meeting

- First- and second-trimester pregnancy termination with misoprostol alone

- Management of miscarriage and incomplete abortion

- Labor induction for intrauterine fetal death

- Prevention and treatment of postpartum hemorrhage

- Cervical ripening before hysteroscopy and other gynecological procedures that require entry into the uterus

Indications for which there is anecdotal evidence or potential use but few published studies, and that were not discussed at the meeting

- Cervical ripening before second- and third-trimester dilation and evacuation

- IUD insertion or endometrial biopsy

- Enhancement of pregnancy rates with intrauterine insemination

\section{BOX 2 Women's health indications for misoprostol}

\section{Abortion}

Misoprostol is an effective abortifacient when used alone or in conjunction with other drugs such as mifepristone or methotrexate. It can be used to induce abortion at any point in gestation. At later gestational ages, misoprostol can be used either to induce labor or as part of a dilation and evacuation procedure. The drug is also used for cervical ripening prior to first-trimester aspiration abortion.

\section{Uterine evacuation}

Misoprostol may be instrumental in treating women who experience pregnancy failure requiring evacuation of the contents of the uterus.

Labor and delivery

Some providers use misoprostol to prime the cervix and augment other labor-inducing drugs such as oxytocin, while other providers use misoprostol alone to induce labor. Some studies have also suggested that misoprostol may prevent and treat postpartum hemorrhage.

\section{Obstacles to the Use of Misoprostol}

Despite misoprostol's promise, obstacles limit its widespread and appropriate use. There is reluctance within some health care delivery systems to make this compound widely available. Further, political controversy sometimes blocks access, and unanswered research questions render it difficult to develop clear guidelines for use. One of the most important obstacles, however, is that no commercial entity has registered misoprostol for its women's health indications, partly because of the political climate surrounding its abortifacient properties. As a result, research and development of misoprostol have proceeded in an ad hoc manner, with no formal development plan for its registration and introduction.

\section{BOX 3 Prostaglandins: A primer}

What are prostaglandins, and how do they work?

Prostaglandins are lipids made up of modified fatty acids attached to a five-member ring. There are about 20 naturally occurring compounds in this class. They act in a manner similar to that of hormones, stimulating target cells into action. However, they differ from hormones in that they act locally, near their site of synthesis, and are metabolized very rapidly. As a result, the same prostaglandins act differently in different tissues.

Naturally occurring prostaglandins are produced by many organs and tissues and have a wide range of action. For example, they can cause contractions of smooth muscles, such as in the uterus or intestines; cause dilation of blood vessels; or mediate the inflammatory response (aspirin and other NSAIDs act by blocking prostaglandin production). Prostaglandins are also involved in the production of mucus in the stomach, which provides protection against gastric acid.

Synthetic forms (analogs) of prostaglandins are used for a wide range of indications, including treatment of gastric ulcers; induction of labor and abortion, and treatment of bleeding after childbirth; and treatment of erectile dysfunction, congenital heart disease in babies, and glaucoma.

Commercially available prostaglandins with evidence-based uses for women's health indications

El analogs

- Misoprostol (Cytotec ${ }^{\circledR}$, Pfizer)

- Gemeprost (not commercially available in the United States)

- Sulprostone (no longer commercially available)

E2 analogs

- Dinoprostone (Prostin E2 ${ }^{\circledR}$, Pfizer) (preparations include Prepidil ${ }^{\circledR}$ [cervical gel], Propess-RS ${ }^{\circledR}$ [pessaries], and Prostin E2 ${ }^{\circledR}$ [oral tablets, vaginal tablets, solution, and vaginal gel])

F2-alpha analogs

- Dinoprost (Prostin F2 alpha ${ }^{\circledR}$, Pfizer) (not commercially available in the United States)

- Carboprost (Hemabate ${ }^{\circledR}$, Pfizer) 


\section{BOX 4 Overview of misoprostol}

\author{
What is misoprostol? \\ - Synthetic prostaglandin El analog \\ - Approved for prevention and treatment of gastric ulcers second- \\ ary to chronic treatment with NSAIDs \\ - Marketed and distributed worldwide by Pfizer
}

What properties make misoprostol useful for women's health indications?

- Its ability to contract the uterus and ripen the cervix

What are the possible women's health indications for misoprostol?

- Induction of labor

- Prevention of postpartum hemorrhage

- Cervical priming prior to obstetric and gynecological procedures

- Evacuation of the uterus after pregnancy failure (including treatment of incomplete abortion)

- Induction of abortion in the first, second, and third trimesters

What are the advantages of misoprostol?

Compared to traditional treatments, misoprostol has many advan-

tages, particularly in developing countries.

- Inexpensive

- Stable at room temperature

- Easy to administer

- Multiple modes of administration

- Widely available

What are the key policy and research issues?

- What will happen to the use of misoprostol in the future?

- What will be the role of the pharmaceutical industry?

- How can practitioners and hospital administrators be informed about its appropriate use?

- How can women's health organizations facilitate education and information dissemination?

- What should women know about the potential benefits and dangers of this drug?

Use of Cytotec $^{\circledR}$ (misoprostol) by pregnant women was contraindicated in the original U.S. Food and Drug Administration (FDA)-approved label for the drug. Recently, however, the widespread use of misoprostol for labor induction in the United States and its inclusion in the FDAapproved label for use with Mifeprex ${ }^{\circledR}$ (mifepristone) for early pregnancy termination were reflected in major changes to the label. These changes suggest tacit acknowledgment of misoprostol's various uses for women's health indications (see Box 5). Although there is an extensive body of highly technical literature on various off-label uses of misoprostol, regimens and practice guidelines have yet to be established for most women's health indications. Currently recommendations for use may come from several informal sources and may be inconsistent and contradictory, making it difficult for providers to choose an optimal regimen. Finally, apart from highly technical, scientific literature, it is difficult to find comprehensive, accurate information on misoprostol's use in women's health. The information that exists also tends to be contradictory and is not universally accessible. Nonetheless, use of misoprostol, including selfadministered use, is known to be widespread. Without proper patient and provider education, the potential for uninformed use is great, potentially resulting in poor outcomes and ineffective treatment while negatively affecting efforts to make the drug widely available and to standardize its use.

\section{Advancing Misoprostol's Potential}

The story of misoprostol is unique: Without any commercial drug development blueprint or strategy, and owing in great measure to the creativity and initiative of a dedicated cadre of physicians, scientists, and researchers, an enormous body of clinical literature on misoprostol has been created. Neither special investment nor sanctioned curriculum has driven this investigation. Indeed, it is rare to have a technology already at hand that could, with a relatively small amount of investment, reap such a large return for women's health around the globe.

\section{BOX 5 Recent changes to the U.S. FDA-approved label for Cytotec ${ }^{\circledR}$ (misoprostol)}

On 17 April 2002 the FDA announced a revision in the drug labeling of Cytotec ${ }^{\circledR}$. The changes include the following:

Revision of contraindications regarding and precautions for use in pregnant women

The label now states that misoprostol is contraindicated only for pregnant women who are using Cytotec $^{\circledR}$ to prevent NSAID-induced ulcers.

Creation of a new labor and delivery section of the labeling, and provision of safety information related to those uses Owing to FDA regulations, if a drug has a recognized use in labor and delivery, drug effect information must be stated, whether or not the use is stated in the indication section of the labeling.

Addition of new information on misoprostol use and uterine rupture The label states the uterine rupture following misoprostol use is known to be associated with risk factors such as advanced gestation, higher doses of the drug, prior cesarean delivery or uterine surgery, and having five or more previous pregnancies. 


\section{URRENT EVIDENCE IN CLIN ICAL RESEARCH: USEO F M ISOPROSTOL FOR WOMEN'S HEALTH INDICATIONS}

\section{Induced Abortion with Misoprostol Alone}

Access to safe and effective medical methods of abortion has the potential to reduce maternal mortality, especially in low-resource settings where safe provision of surgical services often is less feasible. The introduction of mifepristone in the 1980s was a seminal event in the availability of medical abortion technology. Use of this drug in conjunction with misoprostol is highly safe and effective for termination of pregnancies in women with gestations of up to nine weeks LMP (since last menstrual period). However, because of expense, commercial complexities, and the political climate surrounding the production and distribution of mifepristone, this drug may not be widely available for years, leaving women in many countries without access to medical abortion. Fortunately, researchers long ago acknowledged these potential barriers and for more than a decade have explored alternate methods of medical abortion, including administration of misoprostol alone. Because misoprostol has been available in many countries since the late 1980s, off-label use (clinic-based and self-administered) is now widespread for induction of both first- and second-trimester abortion.

\section{Synthesis of the Literature on First- and Second-Trimester Abortion Induction with Misoprostol Alone}

John Jain, University of Southern California, Los Angeles, CA, USA

\section{Abortion induction in the first trimester}

There is nearly a decade of published experience on the use of misoprostol alone for first-trimester abortion induction. Initial studies showed low efficacy $^{1-3}$ (see Table 1), but Carbonell's series of stud- ies using vaginally administered misoprostol built momentum for a misoprostol-alone regimen. ${ }^{4-7}$ Carbonell's regimen included placement of premoistened tablets in the vagina, followed by a three-hour recumbent period. Depending on the study, $800-\mu \mathrm{g}$ doses were repeated after 12,24 , or 48 hours for a maximum of four doses. At followup (14 days following the initial dosing), smaller doses were given to women who had evidence of incomplete abortion on ultrasound. Success rates ranged from $64 \%$ to $94 \%$ (see Table 2 ).

Based on the regimen developed by Carbonell, a series of small studies was conducted at the University of Southern California (USC). In all studies, four premoistened misoprostol tablets (200 $\mu \mathrm{g}$ each) were inserted in the posterior vaginal fornices, and women remained recumbent for 30 minutes. At 24 hours, if a gestational sac was seen on ultrasound, the $800-\mu \mathrm{g}$ dose was repeated. Success rates were quite high, ranging from $83 \%$ to $88 \%$, similar to the $94 \%$ success rate in a similar study of first-trimester pregnancy termination with mifepristone and misoprostol. ${ }^{8}$ Many more patients in the misoprostol-alone trial, however, displayed gastrointestinal side effects (such as vomiting and diarrhea) and fever.

Following the success of the above studies, a larger, randomized, placebo-controlled trial of 250 women comparing misoprostol alone to mifepristone and misoprostol was conducted in collaboration with the University of California, San Francisco. ${ }^{9}$ Women were given $200 \mathrm{mg}$ mifepristone or placebo followed two days later by $800 \mu \mathrm{g}$ vaginal misoprostol. If they failed to abort within 24 hours following the initial dose they were given up to two additional doses of $800 \mu \mathrm{g}$ vaginal misoprostol. At 24 hours the misoprostol-only group had $72 \%$ and $86 \%$ success after one and two doses, respectively, compared to $90 \%$ and $96 \%$, respectively, in the mifepristone-misoprostol group.

Bugalho and colleagues explored whether waiting one week to re-dose with misoprostol women who had not completely expelled the products of conception would change the efficacy of 
TABLE 1 Misoprostol alone for first-trimester pregnancy termination, early studies

\begin{tabular}{|c|c|c|c|c|}
\hline Study & Regimen & $\mathbf{N}$ & Gestational age (wks) & Success \\
\hline \multirow[t]{2}{*}{ Rabe et al. (1987)' } & $400 \mu \mathrm{g}$ oral misoprostol $\times 2$ & 100 & $9-12$ & $11 \%$ (at $24 \mathrm{hrs}$ ) \\
\hline & $200 \mu \mathrm{g}$ oral misoprostol $\times 2$ & 100 & $9-12$ & $9 \%$ (at 24 hrs) \\
\hline Norman et al. $(1991)^{2}$ & 200-600 $\mu \mathrm{g}$ oral misoprostol & 40 & $\leq 8$ & $5 \%$ \\
\hline Creinin and Vittinghoff (1994) & $\begin{array}{r}800 \mu \mathrm{g} \text { vaginal } \\
\text { misoprostol } \times 2 \mathrm{q} 24 \text { hrs }\end{array}$ & 30 & $\leq 8$ & $47 \%$ \\
\hline
\end{tabular}

misoprostol treatment. ${ }^{10}$ Women with gestations of less than six weeks LMP were administered $800 \mu \mathrm{g}$ vaginal misoprostol. Women returned to the clinic one week later for follow-up, and a second dose was administered at that time if a gestational sac was evident on ultrasound. At 24 hours following administration of the first dose of misoprostol nearly three-quarters of the women (72\%) had aborted, which is comparable to rates of completion after 24 hours found in other medical abortion studies. At the one-week follow-up only $13 \%$ of women required a second dose. At 24 hours following redosing, the overall efficacy for the study had increased from $87 \%$ to $92 \%$. Waiting to administer additional doses of misoprostol reduced the need for re-dosing without decreasing success rates.

Given the reported high rate of side effects with misoprostol-alone regimens, a recent study by Jain and colleagues tested the effectiveness of prophylaxis for reducing their frequency and severity. ${ }^{11}$ The experimental group was given 500 $\mathrm{mg}$ acetaminophen to control fever and pain and 4 mg loperamide for diarrhea and vomiting as needed. While the frequency of fever and chills was high in both groups, the incidence of diarrhea decreased significantly with prophylaxis (from $44 \%$ to $23 \%$, OR $0.38, p=0.003$ ). Moreover, prophylaxis was associated with decreased use of opiates.

The possible advantage of premoistening misoprostol tablets prior to vaginal administra- tion has also been investigated, although not thoroughly. In a study of misoprostol administered in combination with methotrexate, Creinin and colleagues found no decrease in efficacy with premoistened misoprostol. ${ }^{12}$ Ngai and colleagues found that premoistened misoprostol tablets inserted vaginally appeared slightly more effective than dry tablets, although the difference did not reach statistical significance. ${ }^{13}$

The teratogenic potential of misoprostol is of concern when treatment fails and a woman chooses to continue her pregnancy. Several published reports indicate a possible association between misoprostol exposure in utero and congenital defects. In one study, $50 \%$ of 96 infants with Möbius syndrome had been exposed in utero to misoprostol, as compared to $3 \%$ of babies with neural tube defect. ${ }^{14}$ In another study, Orioli and Castilla found that the frequency of limb and extremity malformation was higher in exposed neonates, but did not find an increase in Möbius syndrome. ${ }^{15}$ None of the published reports describes a consistent pattern of anomalies or a highly plausible mechanism of teratogenicity. Although these studies do not predict an absolute risk of congenital anomalies in infants exposed in utero to misoprostol, in the event of a failed abortion with misoprostol, surgical completion of the abortion is strongly recommended. ${ }^{16}$

TABLE 2 First-trimester induced abortion with misoprostol, studies by Carbonell and colleagues

\begin{tabular}{|c|c|c|c|c|}
\hline Study & $\begin{array}{l}\text { Gestational } \\
\text { age (wks) }\end{array}$ & $\mathbf{N}$ & Regimen & $\begin{array}{r}\text { Success } \\
(\% \text { on day } 7) \\
(95 \% \text { C.I.) }\end{array}$ \\
\hline Carbonell et al. (1997a) & $\leq 10$ & 141 & $800 \mu \mathrm{g}$ vaginal misoprostol $\times 3 q 48$ hrs & $94(90-98)$ \\
\hline Carbonell et al. $(1997 b)^{5}$ & $\leq 9$ & 175 & $800 \mu \mathrm{g}$ vaginal misoprostol $\times 3 q 48$ hrs (if necessary) & $92(87-96)$ \\
\hline Carbonell et al. $(2001)^{6}$ & $10-12$ & 150 & $800 \mu \mathrm{g}$ vaginal misoprostol $\times 3$ q 24 hrs & $84(77-89)$ \\
\hline Carbonell et al. $(2000)^{7}$ & $\leq 9$ & 90 & $600 \mu \mathrm{g}$ vaginal misoprostol $\times 3$ q 24 hrs & $64(53-74)$ \\
\hline
\end{tabular}


TABLE 3 Side effects reported following secondtrimester abortion induction with misoprostol $(\mathrm{N}=180)^{*}$

\begin{tabular}{lr}
\hline Side effect & $\%$ (n) \\
\hline Fever & $13(24)$ \\
Vomiting & $6(10)$ \\
Diarrhea & $2(3)$ \\
Moderate pain & $55(99)$ \\
Severe pain & $16(29)$ \\
\hline * Unpublished results from studies conducted by John Jain at USC. &
\end{tabular}

\section{Abortion induction in the second trimester}

In the United States, the most widely used method to terminate a second-trimester pregnancy medically is induction of labor with intravaginal administration of dinoprostone, an E2 prostaglandin. This treatment is highly effective, but it is associated with gastrointestinal side effects and chills. Like most prostaglandins, dinoprostone requires refrigeration and is expensive.

A study conducted at USC comparing the use of misoprostol (200 $\mu \mathrm{g}$ intravaginally every 12 hours) and dinoprostone (20 mg intravaginally every three hours) for termination of gestations between 12 and 22 weeks LMP found no statistically significant difference in success rates $181 \%$ and $89 \%$ of abortions were complete within 24 hours, respectively). ${ }^{17}$ After 48 hours, success rates in both groups were about $90 \%$. These rates were comparable to those found by Srisomboon and Pongpisuttinun, who tested a regimen of $200 \mu \mathrm{g}$ misoprostol inserted into the cervix every 12 hours for 48 hours. ${ }^{18}$ For both the misoprostol and dinoprostone arms in the USC study a shorter induction-to-abortion interval and a higher rate of complete abortion were associated with abortion of a dead fetus. In contrast, in cases with live fetuses use of misoprostol alone resulted in slightly fewer successful completions. Vomiting and fever were reported by fewer than $15 \%$ of women in the misoprostol group, and diarrhea was reported by only $2 \%$ (see Table 3).

Srisomboon and Pongpisuttinun, ${ }^{18}$ Herabutya and colleagues, ${ }^{19}$ and Wong and colleagues ${ }^{20}$ have published results of studies comparing different dosing regimens and routes of administration for misoprostol, but more work is necessary to determine the optimal route, dose, and dosing interval (see Table 4).

\section{First-Trimester Induced Abortion in India: Studies with Misoprostol Alone}

Kurus Coyaji, K.E.M. Hospital, Pune, India

A series of three unpublished studies conducted at K.E.M Hospital was designed to investigate the efficacy and safety of misoprostol when used alone for early pregnancy termination. Women enrolled had gestations of less than eight weeks LMP and sought medical pregnancy termination. The first study, essentially a dose-finding study, consisted of three study arms: (1) two oral 800- $\mu \mathrm{g}$

TABLE 4 Efficacy of second-trimester abortion induction with misoprostol

\begin{tabular}{|c|c|c|c|c|c|c|}
\hline Study & Regimen & N & $\begin{array}{r}\text { Status } \\
\text { of fetus }\end{array}$ & $\begin{array}{l}\text { Success at } \\
24 \text { hrs (\%) }\end{array}$ & $\begin{array}{l}\text { Success at } \\
48 \text { hrs }(\%)\end{array}$ & $\begin{array}{r}\text { Mean induction- } \\
\text { to-abortion } \\
\text { interval (hrs) }\end{array}$ \\
\hline \multirow[t]{2}{*}{ Jain (unpublished) } & \multirow[t]{2}{*}{$200 \mu \mathrm{g}$ vaginal misoprostol q 12 hrs } & \multirow[t]{2}{*}{180} & Live & 89 & 94 & 12 \\
\hline & & & Dead & 63 & 85 & 20 \\
\hline Srisomboon and & $200 \mu \mathrm{g}$ cervicovaginal misoprostol q 12 hrs & 50 & Live or dead & 54 & 92 & 28 \\
\hline $\begin{array}{l}\text { Pongpisuttinun } \\
(1998)^{18}\end{array}$ & & & & & & \\
\hline \multirow{3}{*}{$\begin{array}{l}\text { Herabutya et al. } \\
(2001)^{19}\end{array}$} & $200 \mu \mathrm{g}$ vaginal misoprostol q $12 \mathrm{hrs}$ & 51 & Live or dead & 45 & 71 & 45 \\
\hline & $400 \mu \mathrm{g}$ vaginal misoprostol q 12 hrs & 50 & Live or dead & 62 & 82 & 33 \\
\hline & $600 \mu \mathrm{g}$ vaginal misoprostol q $12 \mathrm{hrs}$ & 50 & Live or dead & 62 & 96 & 22 \\
\hline \multirow[t]{2}{*}{ Wong et al. $(2000)^{20}$} & $400 \mu \mathrm{g}$ vaginal misoprostol q 3 hrs & 74 & Live or dead & 73 & 91 & 24 \\
\hline & $400 \mu \mathrm{g}$ vaginal misoprostol q 6 hours & 74 & Live or dead & 61 & 76 & 43 \\
\hline
\end{tabular}


TABLE 5 Dose-finding studies of misoprostol alone for first-trimester abortion induction*

\begin{tabular}{lrrrr}
\hline Study & Regimen & Route & N & $\begin{array}{r}\text { Complete } \\
\text { abortion (\%) }\end{array}$ \\
\hline 1 & $800 \mu g \times 2$ & Oral & 4 & 75 \\
& $400 \mu g \times 4$ & Oral & 5 & 60 \\
& $600 \mu g \times 1$ & Vaginal & 11 & 54 \\
2 & $800 \mu g \times 2$ & Oral & 9 & 56 \\
& $800 \mu g \times 1$ & Vaginal & 6 & 50 \\
3 & $800 \mu g \times 1$ or 2 & Vaginal & 47 & 83 \\
\hline
\end{tabular}

* Unpublished results from studies conducted by Kurus Coyaii and the Population Council at K.E.M. Hospital, Pune, India.

doses six hours apart, (2) four 400- $\mu$ g oral doses

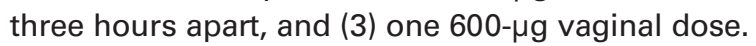
The second study compared two $800-\mu \mathrm{g}$ dose regimens: (1) two oral doses six hours apart, and (2) one vaginal dose. These two studies were discontinued when it became apparent that success rates were under $75 \%$ for each arm (see Table 5).

In a third study, a regimen of $800-\mu \mathrm{g}$ misoprostol, premoistened and inserted vaginally, demonstrated a significantly higher success rate. Nearly $83 \%$ of women (39 of 47 subjects) aborted completely (the rate was $87 \%$ with protocol violators excluded). In this study, although a majority of the women reported experiencing chills $(75 \%)$, fever (55\%), and gastrointestinal symptoms (47\%), acceptability was high. In fact, all of the women who had a successful abortion said they would recommend the method for pregnancy termination to a friend and $93 \%$ said they would choose it again (see Table 6).

$\begin{aligned} & \text { TABLE } 6 \\ & \text { misoprostol alone for first-trimester abortion induction }\end{aligned}$
(N=47)*

The results of this series of studies conducted at K.E.M. Hospital provide evidence that misoprostol can be used as a stand-alone method to terminate early gestations. Fine-tuning the regimen might further enhance the success rate. Additional doses of misoprostol could also be tried in women who have excessive bleeding. There is also good evidence that misoprostol can terminate effectively gestations in the second and third trimester. Research on late-first-trimester termination (9-13 weeks) with misoprostol, however, is lacking. Therefore, in addition to refining the regimen for early pregnancy termination with misoprostol, exploring methods for late-firsttrimester termination is an important goal of future research.

\section{Life-Table Analysis to Estimate the Efficacy of Misoprostol for First- Trimester Pregnancy Termination}

Bryna Harwood, University of Southern California, Los Angeles, CA, USA

The efficacy of misoprostol alone for medical abortion has not been estimated using consistent, comparable, or appropriate methods. Indeed, there are many factors that determine failure of medical abortion. The purpose of the following analysis is to determine the efficacy of misoprostol for medical abortion using a life-table analysis. Survival analyses were performed for perfect and typical use following administration of one, two, and three doses of misoprostol. The definitions and assumptions used for the analysis are outlined in Box 6.

\section{The studies}

Between 1996 and 2001, five trials conducted at the University of Southern California investigated the use of misoprostol for pregnancy termination in the first 56 days of pregnancy. Using the same regimen described by Jain (see above) and depending on the trial, women were offered either two or three 800-ug vaginal doses of misoprostol to terminate their early pregnancies. The overall completed abortion rate was between $88 \%$ and $93 \%$ in these studies. 


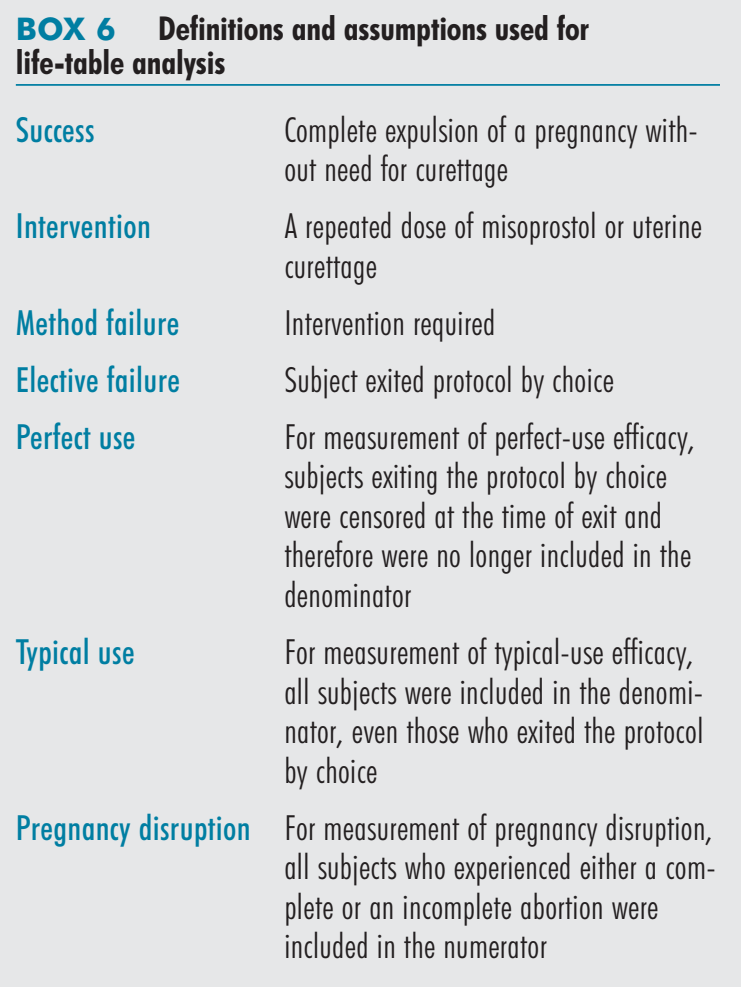

\section{Results}

Records of 365 women who had participated in these trials were examined. Across the trials the overall abortion rate was $89 \%$. That rate rose from $79 \%$ after one dose to $89 \%$ after two doses, and after the third dose efficacy increased to $91 \%$. Overall intervention rate was $9 \%$; of that rate, the rate intervention for subjects who requested to opt out of the protocol was only $3 \%$. Mean time to abortion was 2.9 days (see Table 7).

The appearance of the uterus and the extent of endometrial thickening post-medical abortion were also evaluated using life-table analysis. The literature considers normal an endometrial thickness of $15 \mathrm{~mm}$ or less for patients postabortion. In the life-table analysis endometrial thickness for women who had a successful abortion returned to "normal" after about ten days. Analysis of the data suggests that ultrasound follow-up is appropriate within two weeks of medical abortion, and it should be performed no sooner than three days following the final dose of misoprostol. Gravidity greater than 1 seemed to be a significant predictor for abortion success in both multiple regression models and life-table analysis.

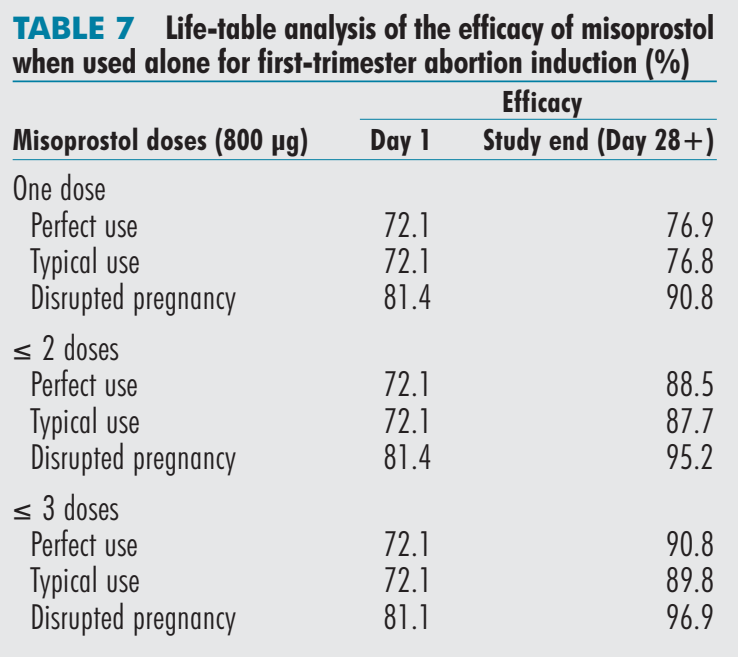

\section{Second-Trimester Induced Abortion in Thailand: Studies with Misoprostol Alone}

Yongyoth Herabutya, Ramathibodi Hospital, Bangkok, Thailand

Before 1990, hypertonic saline solution was the only method used for second-trimester pregnancy termination at Mahidol University. Between 1990 and 1994 investigators began to explore using prostaglandins, including Prostin ${ }^{\circledR}$ and misoprostol. Since 1995 misoprostol has been the sole method used for pregnancy termination at Mahidol University.

A dose-finding study conducted at the university between 1994 and 1996 compared three different doses of misoprostol $(200,400$, and $600 \mu \mathrm{g})$ administered vaginally every 12 hours for 48 hours for termination of gestations between 14 and 24 weeks LMP. ${ }^{21}$ All regimens demonstrated greater than $90 \%$ efficacy, with the highest dose $(600 \mu \mathrm{g})$ demonstrating the greatest success (96\%) at 48 hours (see Figure 2). Side effects-including fever, nausea, vomiting, diarrhea, and pain (as measured by need for analgesia) - reported by women appeared to increase with increasing doses of misoprostol. Differences among dose groups, however, were not statistically significant (see Table 8).

Based on these results, a second, larger study of 172 women tested a regimen of $600 \mu \mathrm{g}$ vaginal misoprostol every 12 hours as needed for termination of second-trimester gestations. ${ }^{22}$ In this study, there was no difference in either the mean time to abortion or the 48-hour completion rate between 
FIGURE 2 Cumulative abortion rate among women treated with various vaginal misoprostol doses for termination of gestations between 14 and 24 weeks $^{21}$

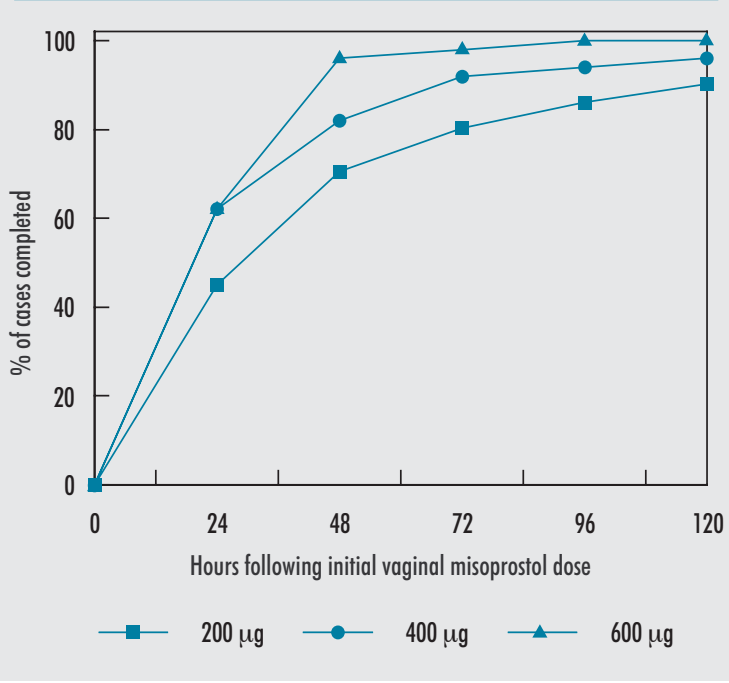

nulliparous and multiparous women. Gestational age, however, was significantly related to the induction-to-abortion time, with earlier gestations exhibiting a longer induction-to-abortion timeframe. Similar to the initial dose-finding study, complications and side effects were not severe.

Comparing the results of three studies ${ }^{19,20,22}$ that explored a range of doses from 400 to $800 \mu \mathrm{g}$ given vaginally every 3-12 hours suggests that, at 48 hours, $600 \mu \mathrm{g}$ every 6 hours appears to be the most effective dose for termination of pregnancies between 14 and 24 weeks' gestation. The completion rates with the misoprostol regimens tested were as high as $97 \%$ (see Table 9). Additionally, gravidity was not significantly associated with either mean time to abortion or the completion rate at 48 hours. Higher doses and shorter dosing

TABLE 8 Side effects following three vaginal misoprostol regimens for second-trimester abortion induction ${ }^{21}$

\begin{tabular}{|c|c|c|c|}
\hline \multirow[b]{2}{*}{ Side effect } & \multicolumn{3}{|c|}{$\begin{array}{l}\text { \% experiencing side effect with } \\
\text { misoprostol q } 12 \text { hrs (n) }\end{array}$} \\
\hline & $\begin{array}{l}200 \mu g \\
(n=51)\end{array}$ & $\begin{array}{l}400 \mu g \\
(n=50)\end{array}$ & $\begin{array}{l}600 \mu g \\
(n=50)\end{array}$ \\
\hline Temperature $>38^{\circ} \mathrm{C}$ & 0 & $2(1)$ & $28(14)$ \\
\hline Nausea/vomiting & $4(2)$ & $12(6)$ & $20(10)$ \\
\hline Diarrhea & $0(0)$ & $6(3)$ & 22 (11) \\
\hline Intramuscular analgesia & $16(8)$ & $16(8)$ & $22(11)$ \\
\hline Incomplete abortion & $35(18)$ & $28(14)$ & 22 (11) \\
\hline
\end{tabular}

intervals appear to be associated with more frequent reports of side effects, such as fever, vomiting, nausea, and diarrhea (see Table 10).

In a separate study, which tested three regimens (400 or $600 \mu \mathrm{g}$ vaginal misoprostol every six hours or $800 \mu \mathrm{g}$ vaginal misoprostol every 12 hours), the incidence of fever and the need for analgesia increased. This study showed, however, no difference in outcomes among the three regimens tested.

Among women undergoing second-trimester terminations with misoprostol, those who had had a previous cesarean section $(n=32)$ and those who had not $(n=387)$ experienced similar rates of complete abortion, abortion within 24 and 48 hours, and mean days of bleeding.

\section{Summary}

\section{First-trimester induced abortion with misoprostol alone}

Studies indicate that misoprostol alone can be highly effective when used for first-trimester termination. Regimens can have minimal side effects, and can be simple to use, feasible for introduction into a range of delivery settings, and desirable to women. Among the regimens tested, $800 \mu \mathrm{g}$ vaginal misoprostol appears be the best dose, yet the timing and number of doses necessary to achieve maximal efficacy is not yet clear. There is evidence that re-dosing can increase the likelihood of complete abortion, and by waiting a week or two to redose, fewer women will require a second or third dose. There may be no benefit to frequent or immediate re-dosing (i.e., in the first 24-48 hours after the initial dose). Finally, while most of the studies explored vaginal administration of misoprostol, oral regimens may also be effective and preferable for some women.

Factors to consider in creating a usable regimen are the efficacy and complexity of the regimen and the severity of side effects and their impact on patient acceptability. Future goals for developing the method include reducing the pain women experience and the incidence of side effects, particularly gastrointestinal complaints. However, while many providers are concerned about reducing gastrointestinal side effects related to use of misoprostol, there is little evidence that these particular side effects correlate with decreased acceptability. In fact, the most important predictors of finding the procedure acceptable are 
TABLE 9 Comparison of effectiveness of vaginal misoprostol alone for second-trimester abortion induction ${ }^{19,20,22}$

TABLE 10 Comparison of side effects following use of vaginal misoprostol alone for second-trimester abortion induction ${ }^{19,20,22}$

\begin{tabular}{|c|c|c|c|c|c|}
\hline & \multicolumn{5}{|c|}{ Misoprostol regimen } \\
\hline & $\begin{array}{l}400 \mu \mathrm{g} \\
\mathrm{q} 3 \mathrm{hrs} \\
(\mathrm{n}=74)\end{array}$ & $\begin{array}{l}400 \mu \mathrm{g} \\
q 6 \text { hrs } \\
(\mathrm{n}=74)\end{array}$ & $\begin{array}{l}600 \mu \mathrm{g} \\
\mathrm{q} 6 \mathrm{hrs} \\
(\mathrm{n}=52)\end{array}$ & $\begin{array}{r}600 \mu \mathrm{g} \\
q 12 \text { hrs } \\
(\mathrm{n}=172)\end{array}$ & $\begin{array}{l}800 \mu \mathrm{g} \\
q 12 \mathrm{hrs} \\
(\mathrm{n}=76)\end{array}$ \\
\hline Temperature $>38^{\circ} \mathrm{C}(\%)$ & 32.4 & 12.2 & 59.6 & 41.3 & 71.1 \\
\hline Nausea/vomiting (\%) & 10.8 & 12.2 & 5.8 & 14.6 & 6.6 \\
\hline Diarrhea $>3$ days (\%) & 5.4 & 2.7 & 26.9 & 20.3 & 10.5 \\
\hline Need for intramuscular analgesia (\%) & 33.8 & 36.5 & 30.8 & 17.4 & 27.6 \\
\hline
\end{tabular}

success with the method, satisfaction with the quality of care provided, and low levels of pain. Analgesic, antidiarrheal, and antiemetic medications are all useful for helping women manage the procedure. Most important, greater attention should be paid to improving efficacy of the method and reducing its complexity.

Finally, it is important to explore what women are willing to tolerate in terms of side effects and failure rates. Most researchers and providers believe that treatment with mifepristone-misoprostol is superior to misoprostol alone for termination of first-trimester pregnancies. In several studies, however, misoprostol-alone regimens have demonstrated success rates comparable to those of mifepristone-misoprostol regimens. For some women a $90 \%$ or even an $80 \%$ chance of avoiding a surgical procedure is highly desirable. Therefore, in countries where mifepristone is not available (i.e., the majority of countries in the world) misoprostol alone offers an important, viable alternative to surgery for first-trimester abortion.

\section{Second-trimester induced abortion with misoprostol alone}

Misoprostol can also be used for medical termination of second-trimester pregnancy. While misoprostol-alone regimens for abortion induction in the second trimester have been shown to be safe and effective, total dose, dosing interval, and route of administration have not been clearly established. Because the sensitivity of the uterus to prostaglandins increases dramatically over the course of the second trimester, regimens should vary by gestational age. In addition, fetal status (e.g., whether the fetus is live or dead at the start of the procedure) may alter uterine sensitivity to misoprostol, which may influence regimens. These issues should be studied further.

The risk of uterine rupture increases for women with advanced gestations (i.e., those greater than 16 weeks LMP). Caution is also advised when treating women who have had previous cesarean deliveries. Use of misoprostol for termination of advanced gestations is not recommended for women with either classical-vertical or low-vertical incisions. For women with low-transverse incisions, termination with misoprostol may be safe.

\section{References}

1 Rabe, T., H. Basse, H. Thuro, L. Kiesel, and B. Runnebaum. 1987. "Effect of the PGE1 methyl analog misoprostol on the pregnant uterus in the first trimester," Geburtshilfe Frauenheilkd 47(5): 324-331.

2 Norman, J.E., K.J. Thong, and D.T. Baird. 1991. “Uterine contractility and induction of abortion in early pregnancy by misoprostol and mifepristone," Lancet 338(8777): 1233-1236. 
3 Creinin, M.D. and E. Vittinghoff. 1994. "Methotrexate and misoprostol vs misoprostol alone for early abortion: A randomized controlled trial," Journal of the American Medical Association 272(15): 1190-1195.

4 Carbonell, J.L., L. Varela, A. Velazco, and C. Fernandez. 1997a. "The use of misoprostol for termination of early pregnancy," Contraception 55(3):165-168.

5 Carbonell, J.L., L. Varela, A. Velazco, C. Fernandez, and C. Sanchez. 1997b. "The use of misoprostol for abortion at < or $=9$ weeks' gestation," European Journal of Contraception and Reproductive Health Care 2(3): 181-185.

6 Carbonell, J.L., A. Velazco, L. Varela, R. Tanda, C. Sanchez, S. Barambio, S. Chami, F. Valero, S. Aragon, and J. Mari. 2001. "Misoprostol for abortion at 9-12 weeks' gestation in adolescents," European Journal of Contraception and Reproductive Health Care 6(1): 39-45.

7 Carbonell, J.L., L. Varela, A. Velazco, R. Tanda, S. Barambio, and S. Chami. 2000. “Vaginal misoprostol 600 microg for early abortion," European Journal of Contraception and Reproductive Health Care 5(1): 46-51.

8 Jain, J.K., K.R. Meckstroth, and D.R. Mishell, Jr. 1999. "Early pregnancy termination with intravaginally administered sodium chloride solution-moistened misoprostol tablets: Historical comparison with mifepristone and oral misoprostol," American Journal of Obstetrics and Gynecology 181(6): 1386-1391.

9 Jain, J.K., C. Dutton, B. Harwood, K.R. Meckstroth, and D.R. Mishell, Jr. 2002. “A prospective randomized, doubleblinded, placebo-controlled trial comparing mifepristone and vaginal misoprostol to vaginal misoprostol alone for elective termination of early pregnancy," Human Reproduction 17(6): 1477-1482.

10 Bugalho, A., S. Mocumbi, A. Faundes, and E. David. 2000. "Termination of pregnancies of $<6$ weeks gestation with a single dose of 800 microg of vaginal misoprostol," Contraception 61(1): 47-50.

11 Jain, J.K., B. Harwood, K.R. Meckstroth, and D.R. Mishell, Jr. 2001. “Early pregnancy termination with vaginal misoprostol combined with loperamide and acetaminophen prophylaxis," Contraception 63(4): 217-221.

12 Creinin, M.D., J.L. Carbonell, J.L. Schwartz, L. Varela, and R. Tanda. 1999. "A randomized trial of the effect of moistening misoprostol before vaginal administration when used with methotrexate for abortion," Contraception 59(1): 11-16.
13 Ngai, S.W., O.S. Tang, Y.M. Chan, and P.C. Ho. 2000. "Vaginal misoprostol alone for medical abortion up to 9 weeks of gestation: Efficacy and acceptability," Human Reproduction 15(5): 1159-1162.

14 Pastuszak, A.L., L. Schuler, C.E. Speck-Martins, K.E. Coelho, S.M. Cordello, F. Vargas, D. Brunoni, I.V. Schwarz, M. Larrandaburu, H. Safattle, V.F. Meloni, and G. Koren. 1998. "Use of misoprostol during pregnancy and Möbius' syndrome in infants," New England Journal of Medicine 338(26): 1881-1885.

15 Orioli, I.M. and E.E. Castilla. 2000. “Epidemiological assessment of misoprostol teratogenicity," British Journal of Obstetrics and Gynaecology 107(4): 519-523.

16 Philip, N.M., C. Shannon, and B. Winikoff (eds.). 2003. “Misoprostol and teratogenicity: Reviewing the evidence-Report of a meeting," Robert H. Ebert Program on Criticial Issues in Reproductive Health Publication Series. New York: Population Council.

17 Jain, J.K. and D.R. Mishell, Jr. 1994. "A comparison of intravaginal misoprostol with prostaglandin E2 for termination of second-trimester pregnancy," New England Journal of Medicine 331(5): 290-293.

18 Srisomboon, J. and S. Pongpisuttinun. 1998. "Efficacy of intracervicovaginal misoprostol in second-trimester pregnancy termination: A comparison between live and dead fetuses," Journal of Obstetric and Gynaecological Research 24(1): 1-5.

19 Herabutya, Y., B. Chanrachakul, and P. Punyavachira. 2001. "Second trimester pregnancy termination: A comparison of 600 and 800 micrograms of intravaginal misoprostol," Journal of Obstetric and Gynaecological Research 27(3): 125-128.

20 Wong, K.S., C.S. Ngai, E.L. Yeo, L.C. Tang, and P.C. Ho. 2000. "A comparison of two regimens of intravaginal misoprostol for termination of second trimester pregnancy: A randomized comparative trial," Human Reproduction 15(3): 709-712.

21 Herabutya, Y. and P. 0-Prasertsawat. 1998. “Second trimester abortion using intravaginal misoprostol," International Journal of Gynaecology and Obstetrics 60(2): 161-165.

22 Herabutya, Y., B. Chanrachakul, and P. Punyavachira. 2000. "Vaginal misoprostol in termination of second trimester pregnancy," Journal of Obstetric and Gynaecological Research 26(2): 121-125. 


\section{Uterine Evacuation After Pregnancy Failure}

Approximately $10 \%-20 \%$ of clinically recognized pregnancies are not carried to term, with most failures occurring within the first 12 weeks of gestation. ${ }^{1}$ Early failures often resolve spontaneously without treatment. Providers - often without regard for clinical necessity-have typically resorted to surgical interventions to quickly resolve incomplete or missed abortions, risking uterine perforation, cervical tears, infection, and bleeding. Only recently have expectant management (i.e., not treating women immediately upon presentation) and noninvasive (i.e., medical) techniques begun to replace surgical intervention for pregnancy failure. Expeditious resolution of pregnancy failure may be desirable for psychological and medical reasons, with safe and effective noninvasive treatment being particularly desirable. Given its pharmacological properties, misoprostol has emerged as a promising candidate to fill this role.

For pregnancy failure in the second and third trimesters (usually referred to as intrauterine fetal death, or IUFD) either labor is induced and the fetus is delivered vaginally or dilation and evacuation (D\&E) is performed, depending on gestational age. As with treatment of early pregnancy failure, there is no true gold standard for treatment of IUFD, and researchers continue to explore new methods.

\section{Misoprostol and Miscarriage}

Salina M.W. Pang and Tony K.H. Chung, Chinese University of Hong Kong, Hong Kong, China

In Hong Kong, surgical evacuation of retained products of conception (POCs) has been considered the gold standard of treatment for women presenting with spontaneous abortions. Patients undergoing such procedures in the past have occupied approximately $18 \%$ of gynecology beds at the Prince of Wales Hospital at the Chinese University of Hong Kong. The development of transvaginal ultrasound imaging, however, has allowed for use of a nonsurgical protocol for evacuation of retained POCs (see Figure 3).

Pilot studies conducted at the Prince of Wales Hospital indicated that a one-to-two-day course of treatment with a prostaglandin (either misoprostol or gemeprost) might be an alternative to surgical

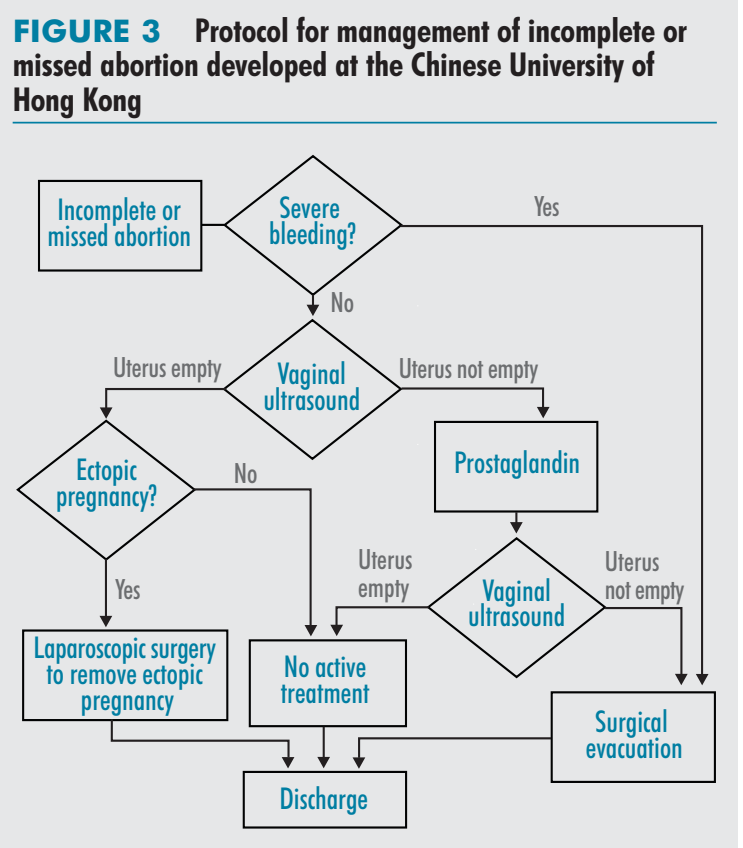

intervention. Based on this premise, a series of small observational studies with misoprostol were conducted at the hospital. Results demonstrated that in $50 \%$ of cases treated with misoprostol retained POCs were expelled without surgery.

A randomized, placebo-controlled trial in 767 subjects subsequently compared surgery and treatment with one dose of $800 \mu \mathrm{g}$ misoprostol for management of incomplete abortion. ${ }^{2}$ Results from the trial indicated that patients treated with misoprostol had fewer short- and long-term complications, although the average duration of treatment was longer in the misoprostol group. This latter difference, however, is probably due to the study protocol, which required all patients to be hospitalized until retained POCs were expelled or evacuated surgically (although in actual medical practice, patients treated with misoprostol typically would not require hospitalization). The average number of days of bleeding was similar between the two groups (9.1 days for misoprostol vs. 9.3 for surgery; $p=0.48$ ). There were higher rates of infection and need for a secondary evacuation in the surgical group compared to the misoprostol group (see Table 11). However, women who underwent surgical evacuation after misoprostol treatment experienced no complications. This last result is of particular note, as the cervical-priming effect of misoprostol might reduce the rate of complications following any necessary surgical evacuation. 


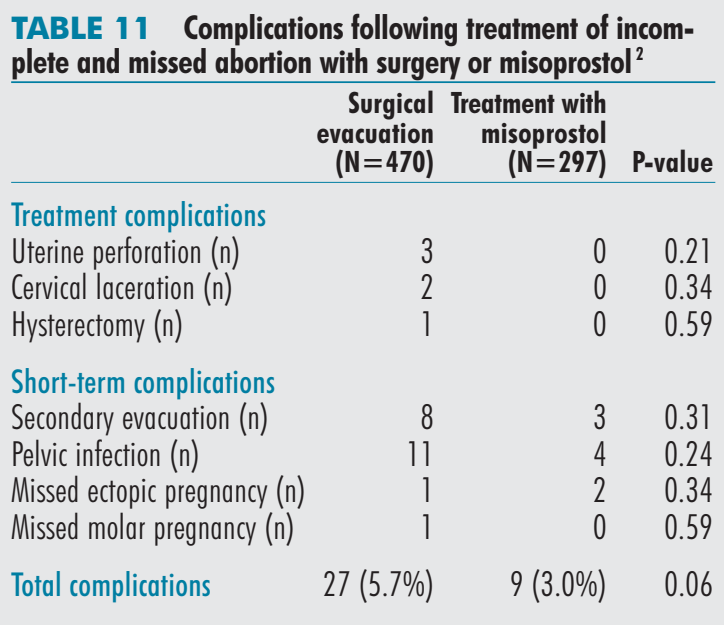

Following the success of that trial, a second randomized, placebo-controlled trial of 201 women was conducted to compare the efficacy and side effects of vaginal and oral misoprostol in the management of incomplete abortion. ${ }^{3} \mathrm{An} 800 \mu \mathrm{g}$ dose of misoprostol was administered either vaginally or orally to women presenting with retained POCs. A second dose was repeated four hours later if the POCs had not been expelled. Rates of complete uterine evacuation were similar in the two groups (64.4\% following oral administration of misoprostol vs. $61.1 \%$ following vaginal administration). There was significantly less diarrhea among vaginal misoprostol users compared to those who took the medication orally ( $13.6 \%$ vs. $65.3 \%, p<0.001)$. No other significant differences in side effects were observed.

This series of studies indicates that medical management of incomplete abortion with misoprostol, given either orally or vaginally, is a safe and effective alternative to surgical evacuation. Treatment-related complications occur less frequently in women treated with misoprostol than in those treated surgically. In addition, treatment with misoprostol reduced the need for surgery as well as the frequency of complications in cases requiring subsequent surgical completion.

\section{Misoprostol and the Management of Intrauterine Fetal Death (IUFD) in the Second and Third Trimesters}

Hazem el-Refaey, Chelsea and Westminster Hospital, London, UK

Standards for the management of IUFD in the second and third trimester are not well specified in the literature; however, some guidance is available. First, mifepristone combined with misoprostol, where available, is commonly used to manage IUFD. Second, protocols for management have been adapted primarily from experience with second- and third-trimester pregnancy termination in patients with either live or dead fetuses; protocols have not been specifically developed for patients with IUFDs.

The use of mifepristone in combination with misoprostol for the induction of second- and thirdtrimester terminations in women with and without IUFD is fairly well established. ${ }^{4-11}$ However, it has not been established whether mifepristone is an important adjunct to treatment with misoprostol or whether misoprostol could be used by itself. Mifepristone disrupts the decidua, ripens the cervix, and, perhaps most important, increases the sensitivity of the uterine myometrium to exogenous prostaglandins. In addition, treatment with mifepristone may be associated with fewer overall side effects, which may explain why a combined therapy of mifepristone and misoprostol, as opposed to misoprostol alone, has become popular in the management of second- and thirdtrimester terminations.

Reducing the duration of treatment for women who have experienced an IUFD is important, and the results of a recent study that explored two regimens for second- and third-trimester pregnancy termination called into question the advantage of mifepristone with misoprostol over misoprostol alone. El-Refaey and Templeton compared the induction-to-abortion interval in women receiving either mifepristone or a placebo prior to administration of misoprostol for second- or thirdtrimester pregnancy termination in cases where fetuses were either live or dead. Among those women who had experienced IUFD prior to the procedure, the use of mifepristone demonstrated no significant advantage over misoprostol alone with regard to time to abortion. ${ }^{10}$ Given these results a misoprostol-alone regimen may be preferable as it eliminates the 24-48-hour waiting period between the administration of mifepristone and misoprostol, effectively decreasing the length of the procedure, and is much less expensive.

The route of misoprostol administration may influence acceptability of regimens for secondand third-trimester terminations. Research has indicated that women tend to prefer oral misoprostol, in part because they do not have to be subjected to vaginal examination. Also, in later 
pregnancy termination the release of amniotic fluid may decrease misoprostol's bioavailability when administered vaginally. Nonetheless, elRefaey and Templeton suggest that in the majority of patients a combined vaginal/oral misoprostol regimen may be both highly effective and acceptable because such a regimen combines the pharmacokinetic properties of the two routes (which together may confer the maximal benefit) and reduces the number of times a woman may be required to undergo vaginal examination and administration of drug.

At the University of Aberdeen, a randomized, controlled trial tested such a regimen. Seventy women with either live or dead fetuses who sought second- or third-trimester uterine evacuation were given $600 \mathrm{mg}$ oral mifepristone followed 24-48 hours later by $600 \mu \mathrm{g}$ vaginal misoprostol. ${ }^{10}$ After the initial dose of misoprostol, women were randomized to receive additional doses of $400 \mu \mathrm{g}$ misoprostol orally or vaginally every three hours. The mean induction-to-abortion interval was the same for both groups (about six hours), and most women required only one or two doses of misoprostol. The frequency of gastrointestinal side effects, however, was high and not comparable to similar studies, with $57 \%$ of women in both groups combined reporting vomiting and $29 \%$ reporting diarrhea.

\section{Summary}

\section{Treatment of incomplete and missed abortion}

Research suggests that misoprostol may be an important alternative to surgical interventions in the treatment of missed or incomplete abortion. Although use of misoprostol for evacuating retained POCs may not be $100 \%$ effective, and therefore some women will still require surgical evacuation, the cost and simplicity of offering misoprostol as a "first-line" treatment has tremendous benefits. First, misoprostol can be used where access to surgery is limited. Second, it can greatly reduce the burden of surgical procedures on hospitals, in both cost and time. Third, acceptability research indicates that many women prefer avoiding surgery when possible. Nonetheless, if women with missed or incomplete abortions were managed expectantly (i.e., not given any treatment on intake), many abortions would resolve without treatment. Research to explore the benefits and risks of expectant management compared to both surgical and medical management is warranted.

Based on medical abortion research, we know that success with a method is highly correlated to satisfaction. We also know that many women will choose a medical method to avoid surgery. Yet we do not know what level of efficacy women would find acceptable for treatment of incomplete or missed abortion with misoprostol. Furthermore, the optimal regimen may not have been discovered, as there has been no true pharmaceutical development testing a range of dosages, timing, and route of administration. Finally, to maximize efficacy it may be important to develop different regimens for treatment of incomplete versus missed abortion with misoprostol, and there is some evidence that misoprostol may not be equally effective in these two different circumstances.

Although further research may help refine regimens to optimize treatment, guidelines based on published data could be developed, as there is evidence that more providers are beginning to offer misoprostol as an alternative to surgical evacuation.

\section{Treatment of intrauterine fetal death}

Misoprostol is also a promising treatment for late pregnancy failure, often referred to as IUFD. Although regimens tested appear effective, there are few published studies and, in all studies, sample sizes are small. Additional data could help direct the development of treatment guidelines. In particular, published studies on misoprostol for treatment of IUFD have tested only one regimen for a very wide range of gestations. Therefore, despite tremendous physiological differences in the uterus at different stages of gestation, failures of both early-second-trimester and late-thirdtrimester gestations are treated similarly. It may be more appropriate to have regimens based on narrower gestational age limits. Also, because the literature reports only on regimens in which misoprostol is administered vaginally, it would be useful to explore regimens that make use of other routes of administration. 
1 Cunningham, G. (ed). 1996. Williams Obstetrics, 20th ed. New York: McGraw-Hill Professional.

2 Chung, T.K., D. Lee, L. Cheung, C. Haines, and A. Chang. 1999. “Spontaneous abortion: A randomized, controlled trial comparing surgical evacuation with conservative management using misoprostol," Fertility and Sterility 71(6): 1054-1059.

3 Pang, M.W., T.S. Lee, and T.K. Chung. 2001. “Incomplete miscarriage: A randomized controlled trial comparing oral with vaginal misoprostol for medical evacuation," Human Reproduction 16(11): 2283-2287.

4 Bartley, J. and D.T. Baird. 2002. "A randomised study of misoprostol and gemeprost in combination with mifepristone for induction of abortion in the second trimester of pregnancy," British Journal of Obstetrics and Gynaecology 109(11): 1290-1294.

5 le Roux, P.A., G.S. Pahal, L. Hoffman, R. Nooh, H. el-Refaey, and C.H. Rodeck. 2001. "Second trimester termination of pregnancy for fetal anomaly or death: Comparing mifepristone/misoprostol to gemeprost," European Journal of Obstetrics, Gynecology, and Reproductive Biology 95(1): 52-54.

6 Ngai, S.W., O.S. Tang, and P.C. Ho. 2000. “Randomized comparison of vaginal (200 microg every $3 \mathrm{~h}$ ) and oral (400 microg every $3 \mathrm{~h}$ ) misoprostol when combined with mifepristone in termination of second trimester pregnancy," Human Reproduction 15(10): 2205-2208.

7 Webster, D., G.C. Penney, and A. Templeton. 1996. “A comparison of 600 and $200 \mathrm{mg}$ mifepristone prior to second trimester abortion with the prostaglandin misoprostol," British Journal of Obstetrics and Gynaecology 103(7): 706-709.

8 Ho, P.C., Y.F. Chan, and W. Lau. 1996. “Misoprostol is as effective as gemeprost in termination of second trimester pregnancy when combined with mifepristone: A randomised comparative trial," Contraception 53(5): 281-283.

9 Hinshaw, K., H. el-Refaey, R. Rispin, and A. Templeton. 1995. "Mid-trimester termination for fetal abnormality: Advantages of a new regimen using mifepristone and misoprostol," British Journal of Obstetrics and Gynaecology 102(7): 559-560.

10 el-Refaey, H. and A. Templeton. 1995. "Induction of abortion in the second trimester by a combination of misoprostol and mifepristone: A randomized comparison between two misoprostol regimens," Human Reproduction 10(2): 475-478.

11 el-Refaey, H., K. Hinshaw, and A. Templeton. 1993. “The abortifacient effect of misoprostol in the second trimester: A randomized comparison with gemeprost in patients pretreated with mifepristone (RU486)," Human Reproduction 8(10): 1744-1746 


\section{Labor Induction with Misoprostol}

The frequency of labor induction has varied historically as well as geographically. For example, in the 1970s in the United Kingdom nearly 50\% of labors were induced. In the 1980s, rates fell considerably and then rose slightly in the 1990s. That rise may have been due in part to a Canadian study on post-term pregnancies published in 1992 indicating that labor induction reduced the rate of cesarean sections and did not increase neonatal morbidity. ${ }^{1}$ In recent years changes in the indications for induction (i.e., recommendations by professional organizations such as the American College of Obstetricians and Gynecologists, the Royal College of Obstetricians and Gynaecologists, and the Society of Obstetricians and Gynaecologists of Canada) may be responsible for lower rates of inductions in some countries.

Compared to women who experience spontaneous deliveries, a higher percentage of all women whose labors are induced require cesarean sections. One reason for this is that many women with medical indications for inductions are not at term and have highly unfavorable cervixes (i.e., Bishop scores <4). Nonetheless, labor induction may be preferable to an immediate cesarean section and can result in better outcomes for mother and infant. Methods of induction include amniotomy (deliberate rupture of the fetal membranes, carried out only when the cervix is favorable) and administration of either oxytocin (usually administered after amniotomy) or prostaglandins (usually series $\mathrm{E}$ analogs).
Review of Labor Induction with Misoprostol: Route of Administration, Efficacy, Safety, and Potential Concerns

Allan Templeton, University of Aberdeen, Aberdeen, UK

In 1997, Sanchez-Ramos published a meta-analysis of labor induction with misoprostol. ${ }^{2}$ His analysis showed that, compared to other prostaglandins, oxytocin, or placebo, induction with misoprostol led to shorter induction-to-delivery intervals and lower rates of cesarean section with no difference in neonatal outcomes (such as admission to a neonatal intensive care unit). However, induction with misoprostol resulted in slightly higher rates of uterine tachysystole (more than five contractions every ten minutes for at least 20 minutes) and uterine hyperstimulation (a contraction lasting at least two minutes). The differences were not statistically significant. From this review, it appears that misoprostol is effective at inducing labor, yet certain precautions should be taken.*

Safe and effective doses of misoprostol for labor induction are much lower after 24 weeks' gestation, perhaps related to shifts in progesterone levels. In a randomized comparative trial completed at Aberdeen Maternity Hospital, a low dose of misoprostol ( $50 \mu \mathrm{g}$ given vaginally every four hours to a maximum of $200 \mu \mathrm{g}$ ) resulted in a significant reduction in the median induction-to-delivery interval and in the need for oxytocin augmentation compared to administration of dinoprostone vaginal gel ( $1 \mathrm{mg}$ every six hours to a maximum of 3 $\mathrm{mg}){ }^{3}$ Moreover, women given misoprostol delivered within 12-24 hours and after only one dose (see Table 12). There were no adverse neonatal events. In order to observe possible rare adverse events, however, additional large trials would be required.

* In 1999 the American College of Obstetricians and Gynecologists published a specific guideline on induction of labor with misoprostol (see Box 7, p. 22). The Royal College of Obstetricians and Gynaecologists and the Society of Obstetricians and Gynaecologists of Canada also recently published guidelines on induction that are more general but include misoprostol.

TABLE 12 Misoprostol compared to dinoprostone for labor induction at term ${ }^{3}$

\begin{tabular}{|c|c|c|c|}
\hline & $\begin{array}{r}\text { Misoprostol } 50 \mu \mathrm{g} \mathrm{q} 4 \text { hrs } \\
(\max 4 \text { doses) }(\mathrm{N}=105)\end{array}$ & $\begin{array}{r}\text { Dinoprostone } 1 \mathrm{mg} \mathrm{q} 6 \text { hrs } \\
(\text { max } 3 \text { doses) }(\mathrm{N}=106)\end{array}$ & P-value \\
\hline Induction-to-delivery interval (mean hrs) & 14.4 & 22.9 & $<0.00001$ \\
\hline Women requiring one dose (\%) & 77 & 49 & $<0.0001$ \\
\hline Need for oxytocin augmentation (\%) & 21 & 47 & $<0.0001$ \\
\hline
\end{tabular}


Indeed, while the extensive published literature indicates that misoprostol is effective for inducing labor, dosage is a key issue that remains unresolved both practically and theoretically. The benefits of a lower dose of misoprostol (i.e., 25-50 $\mu \mathrm{g})$, particularly in relation to reduced rates of uterine hyperstimulation, have become clear. The delivery of that lower dose, however, remains an issue, as only 100 - or $200-\mu g$ tablets are available. Oral suspensions of the drug are an alternative dosing strategy, but it is difficult to deliver exact doses reliably. Similarly, splitting tablets is not a precise method of delivering lower doses.

The literature also does not indicate the appropriate route of administration. A trial recently completed at Aberdeen Maternity Hospital compared two doses of oral misoprostol, $50 \mu \mathrm{g}$ and $100 \mu \mathrm{g}$, repeated every fours hours for a maximum of five doses. ${ }^{4}$ Results indicated no difference in the number of cesarean deliveries for fetal distress or in neonatal outcomes between the two dose groups. Although the mean induction-to-delivery interval was longer in the $50-\mu \mathrm{g}$ group ( 26.8 hours in the $100-\mu$ g group vs. 33.7 hours in the $50-\mu$ g group), this difference was not statistically significant. The percentage of failed inductions, however, was significantly higher in the low-dose group (12.7\% vs. $4.8 \%)$. The study suggests that oral misoprostol administration may be safe and effective, and that a 100- $\mu \mathrm{g}$ dose may be as safe and effective as a 50$\mu \mathrm{g}$ dose. Moreover, because $100-\mu \mathrm{g}$ tablets are the smallest dose available, and the rate of failed induction was lower in the 100- $\mu$ g group with no increase in adverse events such as uterine hyperstimulation, this route may be preferred for labor induction regimens with misoprostol. Larger trials, however, are warranted to explore further the safety and efficacy of this regimen (see Table 13).
It is important to consider the differences between oral and vaginal administration of misoprostol. The fact that vaginally delivered drug reaches the target tissues before being metabolized by the liver results in a substantial and perhaps important difference in the pharmacokinetics of the two routes. The local effects of the drug on the uterus, including on the cervix, may also differ between the two routes. No study comparing these effects, however, has been published, and they are not well understood.

Induction of labor by sublingual misoprostol may be a viable alternative to either vaginal or oral administration as it theoretically combines the liver-bypass effect seen with vaginal administration with the safer level of uterine stimulation seen with oral administration. The results of a study, also recently completed at Aberdeen Maternity Hospital, comparing sublingual to oral administration indicate that the induction-to-delivery interval was shorter with the sublingual route. ${ }^{5}$ There were no differences in neonatal outcomes between the two groups, but there was one case of hyperstimulation with sublingual misoprostol (see Table 14).

\section{Medically Indicated Induction of Labor with Misoprostol and Induction of Labor in Women with Previous Cesarean Section}

\author{
Luis Sanchez-Ramos, University of Florida, \\ Jacksonville, FL, USA
}

Many clinicians have begun to use misoprostol to induce labor in order to improve obstetric and neonatal outcomes for women with medical indications for labor induction. Prelabor rupture of

\section{TABLE 13 Comparison of $50 \mu \mathrm{g}$ and $100 \mu \mathrm{g} \mathrm{oral} \mathrm{misoprostol} \mathrm{for} \mathrm{labor} \mathrm{induction} \mathrm{at} \mathrm{term}{ }^{4}$}

\begin{tabular}{|c|c|c|c|}
\hline Outcome & 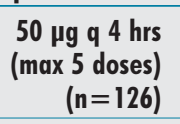 & $\begin{array}{r}100 \mu \mathrm{g} \mathrm{q} 4 \text { hrs } \\
\text { (max } 5 \text { doses) } \\
(n=125)\end{array}$ & $\begin{array}{r}\text { Mean difference) } \\
\text { relative risk } \\
(95 \% \text { C.I.) }\end{array}$ \\
\hline Misoprostol doses ( $\mathrm{n} \pm$ S.D.) & $2.3 \pm 1.5$ & $1.8 \pm 1.2$ & $0.5(0.2-0.8)$ \\
\hline Oxytocin augmentation (\%) & 53.2 & 46.5 & $0.9(0.7-1.1)$ \\
\hline Cesarean delivery (\%) & 26.2 & 22.4 & $0.9(0.6-1.3)$ \\
\hline Cesarean deliver for fetal concerns (\%) & 6.3 & 8.8 & $1.4(0.6-3.3)$ \\
\hline Uterine hyperstimulation (\%) & 0.0 & 1.6 & $5.0(0.2-108)$ \\
\hline Induction-to-delivery interval (hrs \pm S.D.) & $33.7 \pm 26.2$ & $26.8 \pm 19.0$ & $6.9(0.4-13)$ \\
\hline Delivery within 24 hours (\%) & 44.0 & 53.6 & $1.5(0.8-2.6)$ \\
\hline 5-minute Apgar (median [range]) & $9(6-9)$ & $9(6-9)$ & - \\
\hline NICU admission (\%) & 9.5 & 12.0 & $1.3(0.6-2.6)$ \\
\hline
\end{tabular}


TABLE 14 Comparison of sublingual and oral misoprostol for labor induction at term ${ }^{5}$

\begin{tabular}{|c|c|c|c|}
\hline Outcome & $\begin{array}{r}50 \mu \mathrm{g} \text { sublingual } \\
\text { q } 4 \text { hrs (max } 5 \text { doses) } \\
(\mathrm{n}=125)\end{array}$ & $\begin{array}{r}100 \mu \mathrm{g} \text { oral } \\
\text { q } 4 \text { hrs (max } 5 \text { doses) } \\
(n=125)\end{array}$ & $\begin{array}{r}\text { Mean difference/ } \\
\text { relative risk } \\
(95 \% \text { C.I. })\end{array}$ \\
\hline Misoprostol doses ( \pm \pm S.D.) & $1.5 \pm 0.9$ & $1.6 \pm 0.9$ & $0.1(-0.13-0.33)$ \\
\hline Oxytocin augmentation (\%) & 46.4 & 51.6 & $0.9(0.7-1.2)$ \\
\hline Cesarean delivery (\%) & 24.8 & 25.8 & $1.0(0.6-1.5)$ \\
\hline Cesarean delivery for fetal concerns (\%) & 11.2 & 1.6 & $1.3(0.6-2.7)$ \\
\hline Uterine hyperstimulation (\%) & 1.6 & 0.0 & $1.0(0.1-6.9)$ \\
\hline Induction-to-delivery interval (hrs \pm S.D.) & $21.8 \pm 14.6$ & $24.1 \pm 16$ & $2.3(-2.2-6.7)$ \\
\hline Delivery within 24 hours (\%) & 62.8 & 59.0 & $1.1(0.6-2.1)$ \\
\hline 5-minute Apgar <7 (\%) & 0.8 & 4.0 & $0.2(0.02-1.7)$ \\
\hline NICU admission (\%) & 12.0 & 9.5 & $1.3(0.6-2.6)$ \\
\hline
\end{tabular}

membranes at term and severe pre-eclampsia remote from term are two common indications for which misoprostol has been tested. Misoprostol has also been used to induce labor in women attempting vaginal delivery after cesarean section.

\section{Induction of labor for prelabor rupture of membranes at term}

Prelabor rupture of membranes at term (term-PROM) occurs in approximately $10 \%$ of term pregnancies, and $95 \%$ of affected women deliver within 72 hours without intervention. It is not clear from the literature whether expectant management or labor induction leads to better overall outcomes for mother and infant. Results from the TERMPROM study demonstrated that expectant management resulted in fewer cesarean deliveries, an equal number of neonatal infections, and more maternal infections compared to induction of labor. ${ }^{6}$ Results of the study also indicated that women viewed induction of labor more favorably than expectant management.

Six randomized trials of misoprostol for induction of labor following term-PROM studied deliveries of singleton pregnancies in cephalic presentation with comparable gestational ages. ${ }^{7-12}$ Women with a history of previous cesarean section, multifetal pregnancy, infection, or who were in active labor were excluded. The trials compared a range of misoprostol doses and regimens to either oxytocin or placebo. The overall cesarean rate for women treated with misoprostol was $11 \%$ compared to $13 \%$ in the control groups. This difference was not statistically significant. Approximately three-quarters of the women (73\%) delivered after a single dose of misoprostol $(25-200 \mu \mathrm{g})$, and the mean induction-to-delivery interval was 9.4 hours. About one-quarter of the women (26\%) required augmentation with oxytocin (see Table 15).

Comparing the results of studies by SanchezRamos and colleagues ${ }^{8}$ (which compared $50 \mu \mathrm{g}$ vaginal misoprostol to oxytocin infusion) and Wing and $\mathrm{Paul}^{9}$ (which compared $25 \mu \mathrm{g}$ vaginal misoprostol to oxytocin infusion), there do not appear to be significant differences in the overall rate of cesarean delivery or the frequency of cesarean deliveries because of fetal heart rate abnormalities following administration of either dose of misoprostol. The higher dose was associated with a decreased induction-to-delivery interval and lower frequency of infection, but an increased frequency of tachysystole and uterine hyperstimulation (see Table 16).

A significantly larger proportion of neonates born after labors induced with the lower dose of misoprostol were admitted to the neonatal intensive care unit ( $26 \%$ vs. $7 \%$ of neonates whose labors were induced with the higher dose). This difference may be related to the fact that, on average, the induction-to-delivery period following induction with $25 \mu \mathrm{g}$ vaginal misoprostol was longer, or it may be due to varying NICU admission criteria in the two study hospitals. The percentage of neonates with Apgar scores $<7$ at five minutes, however, was similar in both studies.

Labor induction with misoprostol in termPROM patients appears to be as effective and safe as induction with oxytocin infusion. In addition, the rate of cesarean section following induction with misoprostol may be lower. Although several effective regimens have been tested, data are not sufficient to suggest an optimal dose and route of 
TABLE 15 Six randomized controlled trials of misoprostol for labor induction in women with prelabor rupture of membranes at term

\begin{tabular}{|c|c|c|c|c|c|c|c|c|}
\hline \multirow[b]{2}{*}{ Study } & \multirow[b]{2}{*}{ N } & \multicolumn{4}{|c|}{ Misoprostol regimen } & \multicolumn{3}{|c|}{ Comparison regimen } \\
\hline & & $\mathbf{n}$ & Route & Regimen & $\begin{array}{r}\text { Cesarean } \\
\text { deliveries (\%) }\end{array}$ & n & Agent & $\begin{array}{r}\text { Cesarean } \\
\text { deliveries (\%) }\end{array}$ \\
\hline $\begin{array}{l}\text { Ngai et al. } \\
(1996)^{7}\end{array}$ & 80 & 39 & Oral & $200 \mu \mathrm{g} \mathrm{q} 12 \mathrm{hrs}$ & 7.7 & 41 & Placebo (vitamin B6) & 7.3 \\
\hline $\begin{array}{l}\text { Sanchez-Ramos et al. } \\
(1997)^{8}\end{array}$ & 141 & 70 & Vaginal & $\begin{array}{l}50 \mu \mathrm{g} \mathrm{q} 4 \text { hrs } \\
(\max 600 \mu \mathrm{g})\end{array}$ & 11.4 & 71 & Oxytocin & 12.7 \\
\hline $\begin{array}{l}\text { Wing and Paul } \\
(1998)^{9}\end{array}$ & 197 & 98 & Vaginal & $\begin{array}{r}25 \mu \mathrm{g} \mathrm{q} 6 \text { hrs } \\
(\max 50 \mu \mathrm{g})\end{array}$ & 13.3 & 99 & Oxytocin & 17.1 \\
\hline $\begin{array}{l}\text { Butt et al. } \\
(1999)^{10}\end{array}$ & 108 & 55 & Oral & $50 \mu \mathrm{g} \mathrm{q} 4$ hrs & 14.5 & 53 & Oxytocin & 13.2 \\
\hline $\begin{array}{l}\text { Ngai et al. } \\
(2000)^{11}\end{array}$ & 80 & 40 & Oral & $\begin{array}{r}100 \mu \mathrm{g} \mathrm{q} 4 \text { hrs } \\
(\max 300 \mu \mathrm{g})\end{array}$ & 5.0 & 40 & Oxytocin & 7.5 \\
\hline $\begin{array}{l}\text { Hoffmann et al. } \\
(2001)^{12}\end{array}$ & 96 & 47 & Oral & $\begin{array}{l}100 \mu \mathrm{gq} 6 \mathrm{hrs} \\
(\max 200 \mu \mathrm{g})\end{array}$ & 8.5 & 49 & $\begin{array}{l}1 \text { mg vaginal prostaglandin } \\
\text { E2 q } 6 \text { hrs (max } 2 \mathrm{mg}) \\
\text { Placebo (vitamin C) }\end{array}$ & 9.6 \\
\hline
\end{tabular}

administration. Increasing the dose of misoprostol to more than $25 \mu \mathrm{g}$ may lead to faster deliveries but also to more unpredictable or uncontrollable uterine stimulation. The effect of this tradeoff on maternal and neonatal outcomes is unclear.

\section{Severe pre-eclampsia remote from term}

Remote from term, the unfavorable state of the cervix makes uncomplicated vaginal delivery after induction less likely than at term. Therefore, the care of women with severe pre-eclampsia remote

\begin{tabular}{|c|c|c|}
\hline Outcome & $\begin{array}{l}\text { Wing and Paul } \\
(1998)^{9}\end{array}$ & $\begin{array}{r}\text { Sanchez-Ramos et al. } \\
(1997)^{8}\end{array}$ \\
\hline Chorioamnionitis (\%) & 28.6 & 5.7 \\
\hline $\begin{array}{l}\text { Interval to delivery } \\
\text { (min } \pm \text { S.D.) }\end{array}$ & $901 \pm 558$ & $416 \pm 276$ \\
\hline Tachysystole (\%) & 6.1 & 28.6 \\
\hline Uterine hyperstimulation (\%) & 0.0 & 8.6 \\
\hline Cesarean delivery (\%) & 13.3 & 11.4 \\
\hline $\begin{array}{l}\text { Cesarean deliver for fetal } \\
\text { heart rate abnormalities (\%) }\end{array}$ & 4.1 & 4.3 \\
\hline 5-minute Apgar score $<7(\%)$ & 2.0 & 1.4 \\
\hline NICU admission (\%) & 25.5 & 7.1 \\
\hline
\end{tabular}

from term must take into account the risks of continuing the pregnancy and the risks of inducing labor or performing a cesarean section. Unfortunately, there is little guidance for practice in the published literature.

An unpublished retrospective analysis from the University of Florida of the management of severe pre-eclampsia remote from term compared outcomes of cases of induced labor before $(n=78)$ and after ( $n=62$ ) misoprostol became available for use in labor induction in 1991 (see Table 17). Both the frequency of cesarean delivery and the average time to delivery after misoprostol became available were lower, although these differences were not statistically significant. In fact, patients with highly unfavorable cervixes (i.e., Bishop scores $<4$ ) were more likely to be induced during the period when misoprostol was available.

Analysis of unpublished data from a community hospital compared outcomes of labor inductions using misoprostol $(n=114)$ and oxytocin $(n=95)$ in women with severe pre-eclampsia remote from term. The frequency of cesarean delivery in the misoprostol group was higher than it was in the oxytocin group ( $15 \%$ vs. $10 \%, p=0.29$ ), although this difference was not statistically significant. Delivery within 12 hours following induction was more common in women who had been administered oxytocin $(71 \%$ vs. $47 \%$ of women in the misoprostol group, $p=0.007)$. The percentage of women with highly unfa- 
TABLE 17 Use of misoprostol to induce labor in women with severe pre-eclampsia remote from term*

\begin{tabular}{lrrrr}
\hline & \multicolumn{3}{c}{ Time period evaluated } & \\
\cline { 2 - 4 } Outcome & 1988-91 & 1992-96 & P-value \\
\hline Patients having labor induction (N) & 41 & 44 & \\
Cesarean delivery (\%) & 46.3 & 29.5 & 0.12 \\
Assisted vaginal delivery (\%) & 17.1 & 9.1 & 0.17 \\
Vaginal delivery $\leq$ 24 hrs (\%) & 39.0 & 50.0 & 0.90 \\
Induction-to-delivery interval (min) & $945 \pm 740$ & $1,078 \pm 674$ & 0.26 \\
\hline
\end{tabular}

*Unpublished data from a community hospital in Florida aggregated by Luis SanchezRamos at the University of Florida, Jacksonville.

vorable cervixes, however, was significantly higher in the misoprostol group (69\% vs. $54 \%$ in the oxytocin group, $\mathrm{p}=0.03$ ) and could have contributed to the higher frequency of cesarean delivery and the longer induction-to-delivery interval in that group.

In conclusion, misoprostol appears to be safe and effective at inducing labor in women with severe pre-eclampsia remote from term, but not necessarily superior to oxytocin. More information on this subject, controlling for cervical dilation, would help guide practice.

\section{Induction of labor in women previously delivered by cesarean section}

It is fairly common practice in the United States for women who have previously delivered by cesarean section to attempt vaginal delivery subsequently, and most women attempting labor have a successful vaginal birth (referred to as vaginal birth after cesarean, or VBAC). ${ }^{13}$ A major concern of women attempting VBAC is uterine rupture, the frequency of which varies with the type of cesarean scar. Rupture occurs in $0.2 \%-1.5 \%$ of women with low-transverse scars, between $1 \%$ and $7 \%$ of those with low-vertical incisions, and between $4 \%$ and $9 \%$ of those with classical-vertical incisions.

It is uncertain whether induction of labor-as opposed to spontaneous delivery-in women attempting VBAC increases that risk. The literature on this topic is inconsistent, particularly with regard to comparability of study populations and use of standard definitions for analysis (e.g., the terms "cervical ripening," "labor induction," and "labor augmentation" are often poorly defined). There is also an important difference, not always delineated, between complete rupture and dehiscence (i.e., partial separation of the uterine scar).
The former is far more serious as it is more likely to lead to maternal and neonatal morbidity and mortality. Finally, it is important to consider that during elective repeat cesarean section (without a trial of labor) there is also a risk of uterine rupture $(0.2 \%$ of deliveries), albeit lower than the risk associated with attempted VBAC. ${ }^{14}$

Determining whether uterine rupture (or dehiscence) is more common among women with previous cesarean sections induced with misoprostol as compared with other methods of induction or with spontaneous delivery would require a very large randomized trial (according to one calculation such a trial would require 1,600 subjects in each study arm). While a trial of this magnitude has not been conducted, several smaller, uncontrolled trials have been completed. An unpublished review of 15 studies of misoprostol induction in women with previous cesarean section (ten articles and five abstracts) netted 641 cases in which the frequency of scar disruption was $2.8 \%$.

In a trial conducted at USC that enrolled 38 women attempting VBAC who received oxytocin infusion or misoprostol, two patients in the misoprostol arm experienced scar disruption. ${ }^{15}$ The overall frequency of scar disruptions was deemed too high, and the trial was discontinued.

In an unpublished study at the University of Florida, 72 women who had one or two previous cesarean sections were enrolled and received either $50 \mu \mathrm{g}$ vaginal misoprostol every six hours $(n=37)$ or oxytocin infusion for induction of labor $(n=35)$. There was no difference between the groups with regard to maternal demographics, indications for prior cesarean sections, indications for induction, frequency of failed induction, or maternal postpartum complications. There were no uterine ruptures in the misoprostol group and one in the oxytocin group. There was one case of dehiscence in the misoprostol group and four in the oxytocin group.

Several small, randomized trials have compared spontaneous VBAC patients and women with previous cesarean in whom labor was induced (with oxytocin, dinoprostone, or misoprostol). A meta-analysis indicated that while induction with oxytocin does not significantly increase the risk of uterine rupture compared to spontaneous labor, induction with prostaglandins (dinoprostone and misoprostol) does. The evidence does not support use of misoprostol for induction of labor in women attempting VBAC, 
TABLE 18 Comparison of safety of spontaneous delivery and labor induction with misoprostol in women with previous cesarean attempting vaginal birth

\begin{tabular}{lrrr}
\hline & \multicolumn{2}{c}{ Uterine ruptures per study group (n/N) } & \\
\cline { 2 - 3 } Study & Induction with misoprostol & Spontaneous delivery & Odds ratio (95\% C.I.) \\
\hline Plaut et al. (1999) & $5 / 89$ & $0 / 364$ & $47(2.6-867)$ \\
Cunha et al. (1999) & $2 / 57$ & $0 / 57$ & $5.2(0.2-110)$ \\
Butt et al. (1999) & $3 / 39$ & $13 / 560$ & $3.5(0.9-13)$ \\
Total & $10 / 285$ & $13 / 1,096$ & $3.03(1.3-7.0)$
\end{tabular}

particularly where oxytocin is available and widely used (see Table 18).

\section{Summary}

Induction of labor with misoprostol appears to be a safe and effective alternative to other modern methods of labor induction, such as other prostaglandins or oxytocin. However, the way misoprostol stimulates contractions of the uterus may be less predictable, and the frequency of tachysystole and uterine hyperstimulation may be higher in induction with misoprostol than with oxytocin.

The use of misoprostol seems appropriate for induction of labor in women with term-PROM and severe pre-eclampsia remote from term. It may also be the preferred method for women with very unfavorable cervixes. There are precautions for use, however. The use of misoprostol in women who are attempting VBAC is not recommended because of a possible increased risk of uterine rup-

BOX 7 American College of Obstetricians and Gynecologists (ACOG) guidelines for induction of labor with misoprostol

"Given the current evidence, intravaginal misoprostol tablets appear effective in inducing labor in pregnant women who have unfavorable cervixes." (ACOG Practice Guideline, November 1999)

- If misoprostol is to be used for cervical ripening or labor induction in the third trimester, one-quarter of a 100- $\mu \mathrm{g}$ tablet (approximately $25 \mu \mathrm{g}$ ) should be considered for the initial dose.

- Doses should not be administered more frequently than every 3-6 hours.

- Oxytocin should not be administered less than 4 hours after the last misoprostol dose.

- Misoprostol should not be used in patients with a previous cesarean delivery or prior major uterine surgery. ture or scar dehiscence. The frequency of uterine rupture during an attempted vaginal birth in women with previous cesarean varies by type of uterine scar, and labor induction with misoprostol may be safe in women with low-transverse scars, although additional data are needed before making this recommendation.

Several professional obstetrician and gynecologist groups have developed guidelines for labor induction with misoprostol (see Box 7). These guidelines will need to be refined as new data become available. In particular, new data may help determine whether certain treatment criteria would reduce the frequency of more serious maternal and fetal/neonatal complications (see Box 8).

Several other issues warrant further exploration. For instance, the optimal dose and dosing interval may not have yet been identified. Several meta-analyses indicate that vaginal doses of 25-50 $\mu \mathrm{g}$ or oral doses of 50-100 $\mu \mathrm{g}$ are safe and effective. Published guidelines recommend vaginal dosing, but the benefit of vaginal versus oral administration has not been fully evaluated. It may

BOX 8 Major considerations for labor induction with misoprostol

1. What dose should be used?

2. What is an appropriate dosing interval?

3. Is misoprostol use appropriate for women with prelabor rupture of membranes?

4. Is misoprostol use appropriate for women who have had a prior cesarean section?

5. Is oral administration of misoprostol appropriate?

6. Can misoprostol be used for outpatient cervical ripening?

7. What is the best mechanism for ensuring the delivery of $<100 \mu \mathrm{g}$ doses? 
be that oral and vaginal administration are both safe and effective, in which case the choice of route may be left to the discretion of the patient and provider. On the other hand, pharmacokinetic differences in the two routes may mean that one is safer or more effective than the other. These differences should be explored further-either with new studies or through meta-analysis of existing datato improve guidelines for use. In addition, recent studies have explored buccal and sublingual administration of misoprostol. The potential benefits of these new routes of administration merit further study and inclusion in meta-analyses, and may warrant revision of treatment guidelines.

\section{References}

1 Hannah, M.E., W.J. Hannah, J. Hellmann, S. Hewson, R. Milner, A. Willan, and the Canadian Multicenter Post-term Pregnancy Trial Group. 1992. "Induction of labor as compared with serial antenatal monitoring in post-term pregnancy," New England Journal of Medicine 326(24): 1587-1592.

2 Sanchez-Ramos, L., A.M. Kaunitz, R.L. Wears, I. Delke, and F.L. Gaudier. 1997. "Misoprostol for cervical ripening and labor induction: A meta-analysis," Obstetrics and Gynecology 89(4): 633-642.

3 Danielian, P., B. Porter, N. Ferri, J. Summers, and A. Templeton. 1999. "Misoprostol for induction of labour at term: A more effective agent than dinoprostone vaginal gel," British Journal of Obstetrics and Gynaecology 106(8): 793-797.

4 Shetty, A., R. Martin, P. Danielian, and A. Templeton. 2002. "A comparison of two dosage regimens of oral misoprostol for labor induction at term," Acta Obstetricia et Gynecologica Scandinavica 81(4): 337-342.

5 Shetty, A., L. Mackie, P. Danielian, P. Rice, and A. Templeton. 2002. "Sublingual compared with oral misoprostol in term labour induction: A randomized controlled trial," British Journal of Obstetrics and Gynaecology 109(6): 645-650.

6 Hannah, M.E., A. Ohlsson, D. Farine, S.A. Hewson, E.D. Hodnett, T.L. Myhr, E.E. Wang, J.A. Weston, and A.R. Willam. 1996. "Induction of labor compared with expectant management for prelabor rupture of the membranes at term: TERMPROM Study Group," New England Journal of Medicine 334(16): 1005-1010.
7 Ngai, S.W., W.K. To, T. Lao, and P.C. Ho. 1996. “Cervical priming with oral misoprostol in pre-labor rupture of membranes at term," Obstetrics and Gynecology 87(6): 923-926.

8 Sanchez-Ramos, L., A.H. Chen, A.M. Kaunitz, F.L. Gaudier, and I. Delke. 1997. "Labor induction with intravaginal misoprostol in term premature rupture of membranes: $A$ randomized study," Obstetrics and Gynecology 89(6): 909-912.

9 Wing, D.A. and R.H. Paul. 1998. "Induction of labor with misoprostol for premature rupture of membranes beyond thirty-six weeks' gestation," American Journal of Obstetrics and Gynecology 179(1): 94-99.

10 Butt, K.D., K.A. Bennett, J.M. Crane, D. Hutchens, and D.C. Young. 1999. "Randomized comparison of oral misoprostol and oxytocin for labor induction in term prelabor membrane rupture," Obstetrics and Gynecology 94(6): 994-999.

11 Ngai, S.W., Y.M. Chan, S.W. Lam, and T.T. Lao. 2000. “Labour characteristics and uterine activity: Misoprostol compared with oxytocin in women at term with prelabour rupture of the membranes," British Journal of Obstetrics and Gynaecology 107(2): 222-227.

12 Hoffmann, R.A., J. Anthony, and S. Fawcus. 2001. “Oral misoprostol vs. placebo in the management of prelabor rupture of membranes at term," International Journal of Gynaecology and Obstetrics 72(3): 215-221.

13 American College of Obstetricians and Gynecologists (ACOG). 1999. Induction of Labor: ACOG Practice Bulletin 10. Washington, DC: ACOG.

14 Rageth, J.C., C. Juzi, and H. Grossenbacher for the Swiss Working Group of Obstetricians and Gynecologists. 1999. “Delivery after previous cesarean: A risk evaluation," Obstetrics and Gynecology 93(3): 332-337.

15 Wing, D.A., K. Lovett, and R.H. Paul. 1998. “Disruption of prior uterine incision following misoprostol for labor induction in women with previous cesarean delivery," Obstetrics and Gynecology 91(5 pt 2): 828-830.

16 Plaut, M.M., M.L. Schwartz, and S.L. Lubarsky. 1999. "Uterine rupture associated with the use of misoprostol in the gravid patient with a previous cesarean section," American Journal of Obstetrics and Gynecology 180(6 Pt 1): 1535-1542.

17 Cunha, M., A. Bugalho, C. Bique, and S. Bergstrom. 1999. "Induction of labor by vaginal misoprostol in patients with previous cesarean delivery," Acta Obstetricia et Gynecologica Scandinavica 78(7): 653-654. 


\section{Use of Misoprostol During the Third Stage of Labor}

The third stage of labor carries the highest risk of mortality and morbidity for the mother because of the potential for postpartum hemorrhage (PPH), which accounts for about one-quarter of maternal deaths worldwide. ${ }^{1}$ Hemorrhage requires prompt treatment in order to avoid blood transfusions and/or major surgical interventions. Prevention and treatment of PPH can help decrease mortality and morbidity rates in the postpartum period.

Agents traditionally used to treat PPH, such as methylergometrine or oxytocin, may not be appropriate for use in a range of delivery settings and sometimes are not effective. Misoprostol is a promising alternative for treatment and prevention of PPH in low-resource settings. It can also be used in women with pre-eclampsia, as, in contrast to other available prostaglandins, its use is not contraindicated in women with high blood pressure. ${ }^{2}$ Finally, misoprostol can be considered an adjunct treatment when oxytocin and methylergometrine fail to control hemorrhage.

The first study on the use of misoprostol for the prevention of PPH was published by el-Refaey and colleagues in $1996{ }^{3}$ Since then, the results of nearly 20 more trials comparing misoprostol (administered either orally or rectally) to placebo and to standard treatments have been published. ${ }^{4-22}$ There are, however, significant methodological challenges to understanding the true effectiveness of misoprostol for treatment and prevention of PPH. First, there is no gold standard that can be used as an indicator for rates of PPH. Typically blood loss is used as an indicator, yet its measurement, most often by visual estimation, is imprecise. Furthermore, there is no consensus on the level of blood loss associated with negative maternal outcomes, although amounts exceeding $500 \mathrm{~mL}$ or $1,000 \mathrm{~mL}$ have been used as study endpoints. Other indicators, such as mean change in hemoglobin, mean blood loss, and need for additional oxytocics, have also been used as indicators of PPH.

Second, while several large clinical trials have been conducted on $\mathrm{PPH}$, comparison of results is difficult, as the studies employed different methodologies, definitions, and measurement techniques. Some studies have investigated small samples, with the result that the data are not sufficient to draw conclusions about the benefit of misoprostol over standard treatments for prevention or treatment of PPH.

\section{Use of Misoprostol to Prevent Postpartum Hemorrhage: The WHO Third Stage of Labor Trial ${ }^{23}$}

\author{
A. Metin Gulmezoglu, World Health Organization, Geneva, \\ Switzerland
}

$\mathrm{PPH}$ is a leading cause of maternal mortality and morbidity. In many parts of the world in an effort to reduce the incidence of severe hemorrhage, active management of the third stage of labor recently has become a standard aspect of obstetric care, and misoprostol has emerged as one promising treatment alternative. A pilot trial, conducted in Thailand and South Africa, determined that a $600-\mu \mathrm{g}$ oral dose of misoprostol ensures maximal efficacy with acceptable tolerability. ${ }^{24}$ The subsequent WHO trial was powered to compare the rates of two primary outcomes in the two study groups: (1) postpartum blood loss of $1,000 \mathrm{~mL}$ or more and (2) the need for additional uterotonics. Secondary outcomes included postpartum blood loss of more than $500 \mathrm{~mL}$, need for blood transfusion, manual removal of the placenta, delayed PPH (i.e., later than one hour postpartum), and treatment for severe hemorrhage (including bimanual compression and hysterectomy). Data on side effects were also collected.

Nine centers worldwide participated, enrolling 18,530 women (see Table 19 for participant characteristics). Women were randomized prior to labor, but treatment packs were dispensed only when it was certain that vaginal delivery would occur (i.e.,

\begin{tabular}{|c|c|c|}
\hline & $\begin{array}{r}\text { Misoprostol } \\
(600 \mu \mathrm{g} \text { oral) }\end{array}$ & $\begin{array}{l}\text { Oxytocin } \\
\text { (10 l.U.) }\end{array}$ \\
\hline Maternal age (yrs) (mean \pm S.D.) & $26.5 \pm 5.5$ & $26.3 \pm 5.4$ \\
\hline Parity $=0(\%)$ & 44.8 & 45.8 \\
\hline Parity $\geq 5(\%)$ & 5.2 & 5.2 \\
\hline Gestational age $<37$ wks & 12.2 & 11.7 \\
\hline $\begin{array}{l}\text { Oxytocin or prostaglandin before } \\
\text { delivery }(\%)\end{array}$ & 38.0 & 37.8 \\
\hline Epidural analgesia (\%) & 6.2 & 6.0 \\
\hline Assisted vaginal delivery (\%) & 9.1 & 8.2 \\
\hline Perineal suturing (\%) & 66.4 & 66.1 \\
\hline
\end{tabular}




\section{TABLE 20 Primary and secondary outcomes of the WHO trial}

\begin{tabular}{|c|c|c|c|c|}
\hline & Misoprostol $(600 \mu \mathrm{g})$ & Oxytocin (10 I.U.) & Relative risk (95\% C.I.) & P-value \\
\hline \multicolumn{5}{|l|}{ Primary outcome } \\
\hline Blood loss $\geq 1,000 \mathrm{~mL}(\%)$ & 4 & 3 & $1.39(1.19-1.63)$ & $<0.0001$ \\
\hline Use of additional uterotonics (\%) & 15 & 11 & $1.40(1.29-1.51)$ & $<0.0001$ \\
\hline \multicolumn{5}{|l|}{ Secondary outcome } \\
\hline Blood loss $\geq 500 \mathrm{~mL}(\%)$ & 20 & 14 & $1.44(1.35-1.54)$ & $<0.0001$ \\
\hline Need for blood transfusion (\%) & 0.8 & 1 & $0.74(0.55-1.01)$ & 0.06 \\
\hline Manual removal of placenta (\%) & 2 & 2 & $1.02(0.85-1.23)$ & 0.88 \\
\hline Delayed postpartum hemorrhage (\%) & 0.4 & 0.3 & $1.19(0.74-1.92)$ & 0.54 \\
\hline Exploration under general anesthesia (\%) & 0.9 & 0.9 & $1.05(0.77-1.43)$ & 0.81 \\
\hline Bimanual compression (\%) & 0.8 & 0.7 & $1.15(0.82-1.62)$ & 0.48 \\
\hline Hysterectomy (\%) & 0.04 & 0.09 & $0.50(0.15-1.66)$ & 0.39 \\
\hline Admission to intensive care (\%) & 0.04 & 0.05 & $0.80(0.22-2.98)$ & 1.00 \\
\hline Maternal death (\%) & 0.02 & 0.02 & $1.00(0.14-7.10)$ & 1.00 \\
\hline
\end{tabular}

during the second stage of labor). $600 \mu \mathrm{g}$ oral misoprostol or 10 I.U. oxytocin given intramuscularly or intravenously (and matching placebo) was administered after delivery of the baby and the cutting of the cord. Prior to participation in the study, providers at all centers practiced some form of active management of the third stage of labor.

The frequency of blood loss of $1,000 \mathrm{~mL}$ or more was low in both groups, $4 \%$ in the misoprostol group and $3 \%$ in the oxytocin group. Significant intercenter variation, however, was observed. Overall, additional uterotonics were more likely to be administered to women in the misoprostol group ( $15 \%$ vs. $11 \%$ in the oxytocin group). Both of these aggregate differences were significant, and the relative risk was similar (about 1.4) (see Table 20).

The aggregate frequency of blood loss of 500 $\mathrm{mL}$ or more was also significantly different across the two study groups $(20 \%$ in the misoprostol group vs. $14 \%$ in the oxytocin group). Few women in either group required transfusions, yet fewer in the misoprostol group required transfusions than in the oxytocin group. All other outcomes appeared similar with respect to study group (see Table 20). These outcomes were rare, however, and the sample was inadequate to detect differences in the rates. Significant differences in side effects observed within one hour of misoprostol or oxytocin administration included higher rates of observed shivering and fever with misoprostol as compared to oxytocin (see Table 21).

Two study centers in Nigeria and Thailand collected data on side effects for 24 hours. ${ }^{25}$ The frequency of shivering decreased significantly between two and six hours (from $18 \%$ at one hour to $3 \%$ in the 2-6-hour period) and fell to almost zero 7-12 hours later. Fever exhibited a different trend, however; its frequency increased in the 2-6hour period (from $6 \%$ at one hour to $11 \%$ in the 2-6-hour period). Reports of diarrhea showed a similar trend, with the frequency rising to $5 \%$ at 2-6 hours and falling to near zero by $13-18$ hours.

TABLE 21 Side effects observed within one hour of misoprostol or oxytocin administration in the WHO trial

\begin{tabular}{lrr}
\hline Side effect & Misoprostol (600 $\mathrm{\mu g})$ & Oxytocin (10 I.U.) \\
\hline Any shivering (\%) & 18 & 5 \\
Severe shivering (\%) & 1 & 0.2 \\
Body temperature $>38^{\circ} \mathrm{C}(\%)$ & 6 & 0.8 \\
Body temperature $>40^{\circ} \mathrm{C}(\%)$ & 0.1 & 0 \\
Nausea (\%) & 0.8 & 0.4 \\
Vomiting (\%) & 0.7 & 0.3 \\
Diarrhea (\%) & 0.4 & 0.1
\end{tabular}


In summary, use of $600 \mu \mathrm{g}$ oral misoprostol in the third stage of labor, as compared to $10 \mathrm{I} . \mathrm{U}$. oxytocin administered intramuscularly or intravenously, is associated with an increased frequency of blood loss of $1,000 \mathrm{~mL}$ or more and use of additional uterotonics. Compared to oxytocin, the frequency of observed side effects with misoprostol is higher, but side effects subside 2-6 hours after treatment. Therefore, in hospitals and other tertiary-care settings where active management of the third stage of labor is the norm and oxytocin is available, the results of the trial do not support the use of misoprostol in its stead.

\section{A Randomized, Controlled Trial of Misoprostol and Oral Ergometrine in the Management of the Third Stage of Labor in a Home-Delivery Setting in Rural Gambia}

Gijs Walraven, Medical Research Council, Farafenni, Gambia

Home birth is preferred by and is often the only option for many women in the developing world. In fact, $60 \%$ of births in the developing world occur outside a tertiary health care facility. Presence of a skilled birth attendant at delivery and access to emergency obstetric care are among the most crucial interventions to decrease maternal morbidity and mortality. In settings where the current provision of skilled obstetric care remains limited there is a particular need to consider the role of community-based, traditional birth attendants (TBAs) in improving safe motherhood.

Results from the WHO trial described above may be applicable to deliveries in tertiary-care settings, but they are not applicable to the homedelivery setting where the use of injectable medications is not feasible. There is need, therefore, to identify a method such as oral misoprostol that can be used for prevention and treatment of PPH in a rural or community-based setting. To date there have been no trials of misoprostol for $\mathrm{PPH}$ prevention or treatment in these settings.

Gambia, a primarily rural country in western Africa, provides a unique opportunity to explore the potential forTBAs to help reduce maternal morbidity and mortality. In the early 1980s, TBA training programs were developed and implemented. In addition to an initial six-week training course, community health nurse midwives provide trainedTBAs with continuing education and supervision.
In a recent study ofTBA knowledge of PPH in the Farafenni region of Gambia, 20 out of 22TBAs demonstrated a high level of knowledge about current PPH treatment standards (i.e., they were able to describe the steps for active management of the third stage of labor). Interestingly, although all TBAs thought that ergometrine (the current standard treatment in the region) could help prevent excessive blood loss, five TBAs suggested that more potent drugs are needed. The TBAs also were eager to improve their knowledge and to participate in further training.

Given the results of this study, implementation of a large-scale, community-based study of PPH prevention using TBAs in Farafenni seemed feasible. The Population Council and the Medical Research Council of the United Kingdom began a collaboration in 2001 to examine the potential of misoprostol to prevent PPH at the community level. This randomized, double-blind, placebo-controlled trial is designed to compare the safety and efficacy of $600 \mu \mathrm{g}$ oral misoprostol and $2 \mathrm{mg}$ oral ergometrine in the prevention of $\mathrm{PPH}$.

The primary endpoint of this study is blood loss of more than $500 \mathrm{~mL}$. Secondary endpoints include blood loss of more than $1,000 \mathrm{~mL}$, mean blood loss, and mean change in pre- and postpartum hemoglobin levels. The sample size $(\mathrm{N}=1,200)$ is sufficient to detect (with $80 \%$ power) a $35 \%$ reduction in blood loss of $500 \mathrm{~mL}$ or more after use of misoprostol compared to ergometrine, assuming a $15 \%$ incidence of such blood loss in women treated with ergometrine and allowing for missing data and multivariate analysis. Recruitment for the study began in August 2001. To date over 600 women have been enrolled. It is anticipated that recruitment will end in 2004.

\section{The Pharmacokinetics of Rectal Misoprostol When Used to Prevent Postpartum Hemorrhage}

Anthony Bamigboye, University of the Witwatersrand, Nelspruit, South Africa

In a randomized trial comparing the use of $400 \mu \mathrm{g}$ rectal misoprostol and $10 \mathrm{I} . \mathrm{U}$. intramuscular syntometrine in the third stage of labor, the rates of hemorrhage greater than $500 \mathrm{~mL}$ and mean blood loss were similar between the two groups. ${ }^{5}$ ElRefaey and colleagues found that compared with placebo, $400 \mu \mathrm{g}$ oral misoprostol was associated with a statistically lower rate of hemorrhage. ${ }^{12}$ 
The results of two other studies, O'Brien and colleagues ${ }^{18}$ and Diab and colleagues, ${ }^{26}$ support the possibility that the rectal route of misoprostol administration may be preferable as it is associated with less shivering and fever than the oral route.

There is a dearth of studies, however, on the pharmacokinetics of misoprostol in pregnant women. Zieman and colleagues ${ }^{27}$ studied misoprostol's pharmacokinetics after oral and vaginal administration in 20 pregnant women. Serum levels of the principal metabolite after administration of $400 \mu \mathrm{g}$ were measured at various intervals. Results indicated that the extent of absorption was statistically different among the oral and vaginal groups, suggesting a possible explanation for the observed difference in clinical efficacy. As this study did not examine alternative routes of administration (i.e., rectal), further studies are needed.

There are three approaches to investigating the pharmacokinetics of a molecule such as misoprostol: (1) gas chromatography/mass spectrometry, (2) radioimmunoassay, or (3) enzyme-linked immunosorbent assay (ELISA). Original pharmacokinetic data on misoprostol measured by gas chromatography are available from its development as a gastric treatment for peptic ulcers, but the expensive, laborious nature of this technique makes it impractical for use by independent researchers. The presence of an ELISA for misoprostol free acid (the breakdown product of misoprostol) is a more cost-effective alternative.

\section{Summary}

Active management of the third stage of labor has become a standard means for preventing $\mathrm{PPH}$. Nonetheless, PPH remains a leading cause of maternal mortality worldwide, disproportionately affecting women in low-resource settings. For this reason, development of a prophylactic uterotonic agent that is easily administered, affordable, and heat stable is essential. Furthermore, as no preventive measure is completely effective, a treatment for uncontrolled hemorrhage that is easy to use and cost-effective may have important benefits. Misoprostol has emerged as a promising alternative for both indications and, given the current body of literature, a case can be made for its use in settings where standard oxytocics are not available or where their use is not feasible.

The results of the WHO trial, however, indicate that in hospitals and other tertiary-care settings where active management of the third stage of labor is the norm and oxytocin is available, the use of misoprostol is not warranted. Nonetheless, there is much to be learned from the enormous amount of data carefully collected during this trial. Most important, the results suggest that oxytocin may offer only a small clinical advantage over misoprostol, as there was only a $1 \%$ difference in the frequency of blood loss of more than $1,000 \mathrm{~mL}$ between the two study groups. If oxytocin prophylaxis prevents an important number of hemorrhages, then misoprostol prophylaxis must also be deemed beneficial.

Depending on the circumstance, misoprostol and standard oxytocics may have equal value in preventing hemorrhage. As the majority of the world's women deliver at home or outside a hospital setting, without skilled attendants and without access to standard oxytocic therapies, misoprostol could reduce the global burden of PPH. This possibility underscores the need for additional trials evaluating misoprostol's use for both prevention and treatment of hemorrhage.

The experience of and results from the WHO trial underscore the need to move forward with new research on the use of misoprostol in the third stage of labor. Most important, appropriate endpoints should be chosen and researchers should consider how best these endpoints could be measured. While it may be more feasible methodologically to choose a proxy measure for mortality (e.g., blood loss of more than $1,000 \mathrm{~mL}$ ), there is no consensus that this particular measure is the best one. There is no evidence that this level of blood loss is correlated most closely with morbidity or mortality and therefore should be the gold standard. One might argue that preventing blood loss of 2,000 $\mathrm{mL}$ or more or the need for blood transfusions is more important. In fact, in the WHO trial transfusion rates were higher in the oxytocin group, although this difference was not statistically significant. It may be necessary to design studies with adequate power to detect differences in rare but potentially more informative endpoints, such as need for blood transfusion or death. It also may be useful to design future studies that explore the interaction between treatment with misoprostol and the use of additional oxytocics.

\section{References}

1 World Health Organization. 1996. Revised 1990 Estimates of Maternal Mortality: A New Approach by WHO and UNICEF. Geneva: World Health Organization.

2 Sifton, D.W. (ed). 2003. Physician's Desk Reference, 57th ed. Montvale: Medical Economics Company. 
3 el-Refaey, H., P. O'Brien, W. Morafa, J. Walder, and C. Rodeck. 1996. "Misoprostol for third stage of labour," Lancet 347(9010): 1257.

4 Amant, F., B. Spitz, D. Timmerman, A. Corremans, and F.A. Van Assche. 1999. “Misoprostol compared with methylergometrine for the prevention of postpartum haemorrhage: A double-blind randomised trial," British Journal of Obstetrics and Gynaecology 106(10): 1066-1070.

5 Bamigboye, A.A., G.J. Hofmeyr, and D.A. Merrell. 1998. "Rectal misoprostol in the prevention of postpartum hemorrhage: A placebo-controlled trial," American Journal of Obstetrics and Gynecology 179(4): 1043-1046.

6 Bamigboye, A.A., D.A. Merrell, G.J. Hofmeyr, and R. Mitchell. 1998. "Randomized comparison of rectal misoprostol with syntometrine for management of third stage of labor," Acta Obstetricia et Gynecologica Scandinavica 77(2): 178-181.

7 Bugalho, A., A. Daniel, A. Faundes, and M. Cunha. 2001. "Misoprostol for prevention of postpartum hemorrhage," International Journal of Gynaecology and Obstetrics 73(1): 1-6.

8 Caliskan, E., B. Dilbaz, M.M. Meydanli, N. Ozturk, M.A. Narin, and A. Haberal. 2003. "Oral misoprostol for the third stage of labor: A randomized controlled trial," Obstetrics and Gynecology 101(5 Pt 1): 921-928.

9 Caliskan, E., M.M. Meydanli, B. Dilbaz, B. Aykan, M. Sonmezer, and A. Haberal. 2002. "Is rectal misoprostol really effective in the treatment of third stage of labor? A randomized controlled trial," American Journal of Obstetrics and Gynecology 187(4): 1038-1045.

10 Cook, C.M., B. Spurrett, and H. Murray. 1999. "A randomized clinical trial comparing oral misoprostol with synthetic oxytocin or syntometrine in the third stage of labour," Australian and New Zealand Journal of Obstetrics and Gynaecology 39(4): 414-419.

11 el-Refaey, H., R. Nooh, P. O'Brien, M. Abdalla, M. Geary, J. Walder, and C. Rodeck. 2000. “The misoprostol third stage of labour study: A randomised controlled comparison between orally administered misoprostol and standard management," British Journal of Obstetrics and Gynaecology 107(9): 1104-1110.

12 el-Refaey, H., P. O'Brien, W. Morafa, J. Walder, and C. Rodeck. 1997. "Use of oral misoprostol in the prevention of postpartum haemorrhage," British Journal of Obstetrics and Gynaecology 104(3): 336-339.

13 Gerstenfeld, T.S. and D.A. Wing. 2001. “Rectal misoprostol versus intravenous oxytocin for the prevention of postpartum hemorrhage after vaginal delivery," American Journal of Obstetrics and Gynecology 185(4): 878-882.

14 Hofmeyr, G.J., V.C. Nikodem, M. de Jager, and B.R. Gelbart. 1998. "A randomised placebo controlled trial of oral misoprostol in the third stage of labour," British Journal of Obstetrics and Gynaecology 105(9): 971-975.

15 Karkanis, S.G., D. Caloia, M.E. Salenieks, J. Kingdom, M. Walker, F. Meffe, and R. Windrim. 2002. “Randomized con- trolled trial of rectal misoprostol versus oxytocin in third stage management," Journal of Obstetrics and Gynaecology Canada 24(2): 149-154.

16 Kundodyiwa, T.W., F. Majoko, and S. Rusakaniko. 2001. "Misoprostol versus oxytocin in the third stage of labor," International Journal of Obstetrics and Gynaecology 75(3): 235-241.

17 Ng, P.S., A.S. Chan, W.K. Sin, L.C.Tang, K. Cheung, and P.M. Yuen. 2001. "A multicentre randomized controlled trial of oral misoprostol and I.M. syntometrine in the management of the third stage of labour," Human Reproduction 16(1): 31-35.

18 O'Brien, P., H. el-Refaey, A. Gordon, M. Geary, and C.H. Rodeck. 1998. "Rectally administered misoprostol for the treatment of postpartum hemorrhage unresponsive to oxytocin and ergometrine: A descriptive study," Obstetrics and Gynecology 92(2): 212-214.

19 Oboro, V.O. and T.0. Tabowei. 2003. "A randomised controlled trial of misoprostol versus oxytocin in the active management of the third stage of labour," Journal of Obstetrics and Gynaecology 23(1): 13-16.

20 Ramsey, P.S., K.D. Ramin, and S.S. Bradley. 1999. “Rectal misoprostol in the prevention of postpartum hemorrhage," American Journal of Obstetrics and Gynecology 180/6 Pt 1): 1601-1602.

21 Surbek, D.V., P.M. Fehr, I. Hosli, and W. Holzgreve. 1999. “Oral misoprostol for third stage of labor: A randomized placebocontrolled trial," Obstetrics and Gynecology 94(2): 255-258.

22 Walley, R.L., J.B. Wilson, J.M. Crane, K. Matthews, E. Sawyer, and D. Hutchens. 2000. "A double-blind placebo controlled randomised trial of misoprostol and oxytocin in the management of the third stage of labour," British Journal of Obstetrics and Gynaecology 107(9): 1111-1115.

23 Gulmezoglu, A.M., J. Villar, N.T.N. Ngoc, G. Piaggio, G. Carroli, L.M. Adetoro, H. Abdel-Aleem et al. 2001. “WHO multicentre randomized trial of misoprostol in the management of the third stage of labour," Lancet 358(9283): 689-695.

24 Lumbiganon, P., J. Hofmeyr, A.M. Gulmezoglu, A. Pinol, and J. Villar. 1999. "Misoprostol dose-related shivering and pyrexia in the third stage of labour: WHO Collaborative Trial on Misoprostol in the Management of the Third Stage of Labour," British Journal of Obstetrics and Gynaecology 106(4): 304-308.

25 Lumbiganon, P., J. Villar, G. Piaggio, A.M. Gulmezoglu, L. Adetoro, and G. Carroli. 2002. "Side effects of oral misoprostol during the first 24 hours after administration in the third stage of labour," British Journal of Obstetrics and Gynaecology 109(11): 1222-1226.

26 Diab, K.M., A.R. Ramy, and M.A. Yehia. 1999. “The use of rectal misoprostol as active pharmacological management of the third stage of labor," Journal of Obstetric and Gynaecological Research 25(5): 327-332.

27 Zieman, M., S.K. Fong, N.L. Benowitz, D. Bankster et al. 1997. "Absorption kinetics of misoprostol with oral or vaginal administration," Obstetrics and Gynecology 90(1): 88-92. 


\section{Cervical Priming for Obstetric and Gynecological Procedures}

Many common gynecological procedures require entry into the uterus through the cervix. These include surgical abortion, hysteroscopy, endometrial biopsy, and insertion of an intrauterine device (IUD). Complications, including pain, cervical lacerations, or uterine perforations, encountered during these procedures are usually related to difficulties in passing instruments through the cervical os. These complications occur most commonly in nulliparous or postmenopausal women or during procedures, such as hysteroscopy, that require relatively wide cervical dilation. For procedures such as hysteroscopy and endometrial biopsy, difficulty in instrumentation has been a major cause of procedure failure. ${ }^{1}$

Although mechanical methods have been preferred for cervical dilation, pharmacologic agents have been developed more recently to "prime" (dilate or soften) the cervix (see Box 9). Stimulated by these agents, cervical tissue becomes more elastic and less resistant. These same changes also cause the cervical os to dilate and may facilitate passage of instruments through the cervix, thereby reducing the frequency of complications.

Because paracervical blocks are often necessary to reduce the discomfort of mechanical dilation, use of pharmacologic agents to dilate the cervix also may reduce the need for anesthetics. Moreover, such agents may reduce the time needed to perform a procedure and increase the ease with which the procedure is carried out. The major advantages of misoprostol over other pharmacologic agents are cost and convenience. Misoprostol also can be self-administered (either orally or vaginally) at home prior to arrival at the clinic or hospital.

The cervical-priming effect of misoprostol has been observed in pregnant and nonpregnant women of reproductive age, but not yet in postmenopausal women whose hormone levels differ from those of women of reproductive age. Basic cellular research is beginning to elucidate specific pathways of cervical remodeling by misoprostol. It is believed that this process is mediated by hormonally regulated cytokinases (proteins found inside and outside of cells that break down other proteins). Misoprostol is thought to bind with extracellular steroids (estrogen and gonadotropinreleasing hormone primarily) and extracellular
BOX 9 Methods of cervical priming
Physiological agents

By stimulating physiological changes in the cells of the cervix, these agents make the cervix more elastic and widen its opening.

- Relaxin

- Prostaglandins (E1, E2, F2-alpha)

Mechanical methods

By exerting a mechanical force on the cervix, these methods widen the opening of the cervix.

- Hygroscopic dilators (Hanks, Hegar, Kleegman, Pratt)

- Osmotic dilators (laminaria tents [made from an aquatic plant])

membrane steroid receptors to facilitate release of estrogen and progesterone into cervical cells. In turn, these steroids bind to their respective intracellular receptors, stimulating DNA transcription of key proteins. These proteins have been shown to modify the collagen matrix of the cervix, leading to greater tissue elasticity. Misoprostol also may exert its cervical-ripening effect through a similar but nonsteroid-dependent pathway.

\section{Cervical Priming Prior to Surgical Abortion}

Gillian Penney, University of Aberdeen, Aberdeen, UK

Multiple trials have demonstrated that pharmacologic methods of cervical priming are comparable to mechanical methods, including laminaria tents. Prostaglandins tested for this purpose include E1, E2, and F2-alpha analogs (see Table 22). ${ }^{2-6}$ Use of mifepristone for cervical priming prior to surgical abortion has also been investigated and, in fact, the drug is registered for this indication in Europe.

Results of several published studies indicate that prostaglandins, administered either orally or vaginally, render surgical terminations in the first trimester both easier for providers to perform and more acceptable to patients (see Table 23). ${ }^{7-10}$ Comparison of misoprostol to both gemeprost and mifepristone suggests that misoprostol is at least as effective as measured by cervical dilation (see Table 24). ${ }^{11-15}$ Data from Aberdeen, Hong Kong, and Singapore show that the optimal current priming regimen for misoprostol is $400 \mu \mathrm{g}$ orally administered three hours before the procedure. 
TABLE 22 Benefits of cervical priming prior to surgical abortion: Results of cohort and randomized clinical studies

\begin{tabular}{|c|c|c|c|}
\hline & $\mathbf{N}$ & Outcome & Conclusion \\
\hline \multicolumn{4}{|l|}{ Large cohort studies } \\
\hline Schulz et al. $(1983)^{2}$ & $\begin{array}{r}15,438 \\
(\leq 12 \text { wks })\end{array}$ & $\begin{array}{l}\text { Overall risk of cervical } \\
\text { injury }=1.03 \%\end{array}$ & $\begin{array}{l}\text { Cervical priming (laminaria vs. none) } \\
=\text { relative risk of } 0.19\end{array}$ \\
\hline Kafrissen et al. $(1984)^{3}$ & $\begin{array}{r}67,175 \\
(13-24 \mathrm{wks})\end{array}$ & $\begin{array}{l}\text { Overall risk of uterine } \\
\text { perforation }=0.09 \%\end{array}$ & $\begin{array}{l}\text { Cervical priming (laminaria vs. none) } \\
=\text { relative risk of } 0.17\end{array}$ \\
\hline Ferris et al. $(1996)^{4}$ & $\begin{array}{r}83,469 \\
(\leq 20 \text { wks })\end{array}$ & $\begin{array}{l}\text { Overall risk of immediate } \\
\text { complications }=0.7 \%\end{array}$ & $\begin{array}{l}\text { Cervical priming (laminaria vs. none) } \\
=\text { odds ratio of } 0.3\end{array}$ \\
\hline \multicolumn{4}{|c|}{ Randomized, controlled trials } \\
\hline WHO $(1981)^{5}$ & $\begin{array}{r}1,001 \\
(8-12 \text { wks })\end{array}$ & \multicolumn{2}{|c|}{$\begin{array}{l}\text { Cervical priming with prostaglandin results in significantly easier dilation, } \\
\text { lower blood loss, reduced need for re-evacuation, and reduced infection }\end{array}$} \\
\hline de Jonge et al. $(2000)^{6}$ & $\begin{array}{r}278 \\
(\leq 12 \mathrm{wks})\end{array}$ & \multicolumn{2}{|c|}{$\begin{array}{l}\text { Cervical priming with misoprostol results in significantly easier dilation, } \\
\text { shorter procedure, and reduced incidence of treatment failure }\end{array}$} \\
\hline
\end{tabular}

\section{TABLE 23 Mechanical vs. pharmacological agents used for cervical priming prior to surgical abortion}

\begin{tabular}{|c|c|c|c|c|}
\hline Study & N & $\begin{array}{r}\text { Mechanical } \\
\text { primer }\end{array}$ & $\begin{array}{r}\text { Pharmacological } \\
\text { primer }\end{array}$ & Results \\
\hline Krishna et al. (1986) ${ }^{7}$ & 627 & Laminaria & $\begin{array}{r}4 \text { prostaglandin } \\
\text { regimens }\end{array}$ & $\begin{array}{l}\text { - Prostaglandin analogs comparable to laminaria } \\
\text { - No skill needed to administer prostaglandin analogs }\end{array}$ \\
\hline Helm et al. (1988) & 78 & Lamicel $^{\circledR}$ & Gemeprost & $\begin{array}{l}\text { - Gemeprost results in easier dilation and a faster, } \\
\text { less uncomfortable procedure compared to } \text { Lamicel }^{\circledR}\end{array}$ \\
\hline \multirow[t]{2}{*}{ Gupta and Johnson (1992) } & 64 & Lamicel $^{\circledR}$ & Prostaglandin & $\begin{array}{l}\text { - Lamice }{ }^{\circledR} \text {, prostaglandins, and mifepristone } \\
\text { equally effective }\end{array}$ \\
\hline & & & $\begin{array}{l}\text { Mifepristone } \\
\text { Placebo }\end{array}$ & $\begin{array}{l}\text { - Oral mifepristone results in easiest } \\
\text { dilation with fewest side effects }\end{array}$ \\
\hline Maclsaac et al. $(1999)^{10}$ & 106 & Laminaria & $\begin{array}{l}\text { Oral and vaginal } \\
\text { misoprostol }\end{array}$ & $\begin{array}{l}\text { - Vaginal misoprostol more effective than oral } \\
\text { - Misoprostol, oral or vaginal, results in equal } \\
\text { dilation and less pain compared to laminaria }\end{array}$ \\
\hline
\end{tabular}

\section{TABLE 24 Misoprostol compared to other pharmacological agents for cervical priming prior to surgical abortion}

\begin{tabular}{|c|c|c|c|c|}
\hline Study & N & $\begin{array}{r}\text { Misoprostol } \\
\text { regimen }\end{array}$ & $\begin{array}{r}\text { Comparison } \\
\text { regimen }\end{array}$ & Conclusion \\
\hline el-Refaey et al. (1994)" & 90 & Vaginal & $\begin{array}{r}\text { Gemeprost } \\
\text { Placebo }\end{array}$ & - Equal efficacy \\
\hline Ngai et al. $(1995)^{12}$ & 64 & Oral & Gemeprost & $\begin{array}{l}\text { - Misoprostol is cheaper, more effective, and } \\
\text { more convenient }\end{array}$ \\
\hline Ngai et al. (1996) & 100 & Oral & Mifepristone & $\begin{array}{l}\text { - Equal efficacy } \\
\text { - Misoprostol is cheaper and more convenient }\end{array}$ \\
\hline Henry and Haukkamaa (1999) & 199 & Vaginal & Gemeprost & $\begin{array}{l}\text { - Equal efficacy } \\
\text { - Misoprostol has fewer side effects than gemeprost }\end{array}$ \\
\hline Ashok et al. $(2000)^{15}$ & 90 & Vaginal & Mifepristone & $\begin{array}{l}\text { - Mifepristone is more effective, but costs } \\
\text { more and is less available }\end{array}$ \\
\hline
\end{tabular}




\begin{tabular}{|c|c|c|c|c|}
\hline & Lawrie et al. $(1996)^{16}$ & Ngai et al. (1999) $)^{17}$ & Singh et al. $(1999 a)^{18}$ & Singh ef al. $(1999 b)^{19}$ \\
\hline N & 60 & 225 & 120 & 180 \\
\hline \multicolumn{5}{|l|}{ Regimen } \\
\hline 1 Route & Oral & Oral & Vaginal & Vaginal (3 hrs prior) \\
\hline Dose & $400 \mu \mathrm{g}$ & $200 \mu \mathrm{g}$ & $200 \mu g$ & $400 \mu \mathrm{g}$ \\
\hline 2 Route & Vaginal & Oral & Vaginal & Vaginal (2 hrs prior) \\
\hline Dose & $800 \mu \mathrm{g}$ & $400 \mu \mathrm{g}$ & $400 \mu \mathrm{g}$ & $600 \mu \mathrm{g}$ \\
\hline 3 Route & - & Vaginal & Vaginal & Vaginal (2 hrs prior) \\
\hline Dose & - & $200 \mu g$ & $600 \mu \mathrm{g}$ & $800 \mu \mathrm{g}$ \\
\hline 4 Route & - & Vaginal & Vaginal & - \\
\hline Dose & - & $400 \mu \mathrm{g}$ & $800 \mu g$ & 一 \\
\hline Conclusion & $\begin{array}{l}\text { Doses demonstrate efficacy, yet } \\
\text { oral action unpredictable }\end{array}$ & $\begin{array}{l}400 \mu \mathrm{g} \text { oral dose } 3 \text { hours } \\
\text { prior to surgery recommended }\end{array}$ & $\begin{array}{r}400 \mu \mathrm{g} \text { vaginal dose } \\
\text { recommended }\end{array}$ & $\begin{array}{r}400 \mu \mathrm{g} \text { dose } 3 \text { hours prior } \\
\text { to surgery more effective } \\
\text { than larger dose administered } \\
\text { closer to procedure }\end{array}$ \\
\hline
\end{tabular}

Administration of misoprostol more than 12 hours before surgical abortion can result in incomplete abortion or heavy vaginal bleeding while the patient is still at home, which could significantly affect acceptability. Misoprostol administration less than three hours preprocedure, even with doses higher than $400 \mu \mathrm{g}$ administered orally or vaginally, has been shown to result in less of a priming effect, as measured by cervical dilation and ease of insertion of instruments (see Table 25). ${ }^{16-19}$

\section{Cervical Priming Prior to Hysteroscopy and Other Gynecological Procedures}

Suk Wai Ngai, University of Hong Kong, Hong Kong, China

Use of misoprostol for cervical priming prior to labor induction and surgical abortion is described extensively in the literature. In contrast, very few studies have been published on its use prior to gynecolog- ical procedures such as IUD insertion and hysteroscopy, yet the majority of published studies support its efficacy. ${ }^{20-24}$ Cervical priming with misoprostol has the potential to reduce the incidence of cervical tearing and uterine perforation during gynecological procedures. Researchers at Queen Mary Hospital in Hong Kong, China, have undertaken several studies to examine the cervical priming effect of misoprostol in nonpregnant women.

In the first study, women admitted for hysteroscopy (generally women of reproductive age with fertility problems) were randomized to receive either $400 \mu \mathrm{g}$ oral misoprostol or a placebo 12 hours prior to the procedure. ${ }^{22}$ This dose of misoprostol was chosen based on its successful use for cervical softening prior to first-trimester surgical evacuation in previous trials conducted at Queen Mary Hospital. Results indicated that cervixes of women treated with misoprostol required significantly less force for dilation than those of women in the placebo group (see Table 26).

TABLE 26 Use of misoprostol for cervical priming prior to hysteroscopy ${ }^{22}$

\begin{tabular}{lrrr}
\hline & Misoprostol $(\mathbf{n = 2 1 )}$ & Placebo ( $\mathbf{n = 2 3 )}$ & P-value (95\% C.I.) \\
\hline Age in years (mean \pm S.D.) & $34.5 \pm 8.0$ & $32.5 \pm 5.0$ & - \\
Fertility problems $(\mathrm{n})$ & 19 & 21 & - \\
Failed endometrial aspiration $(\mathrm{n})$ & 1 & 1 & - \\
Recurrent vaginal bleeding $(\mathrm{n})$ & 1 & 1 & - \\
Baseline cervical dilation (mean mm \pm S.D.) & $6.0 \pm 1.3$ & $3.2 \pm 1.3$ & $0.001(1.98-3.7)$ \\
Cumulative force required for dilation to 8 mm (mean N \pm S.D.) & $40.1 \pm 20.6$ & $103.7 \pm 41.7$ & $0.001(43.3-83.3)$
\end{tabular}


The use of misoprostol in postmenopausal women was also explored. Because the cervixes of postmenopausal women are typically small and stenotic, a method of softening the cervix in this population might help reduce the pain and complications associated with procedures such as hysteroscopy. To test the usefulness of misoprostol for this indication, 34 postmenopausal women were randomized to receive either $400 \mu \mathrm{g}$ oral misoprostol or placebo three hours prior to hysteroscopy. ${ }^{23}$ The mean ages of two groups differed statistically (56 years in the misoprostol group vs. 67 years in the placebo group); weight, height, and body mass ratio, however, were similar. There were no statistical differences observed in mean cervical dilation immediately preprocedure, cumulative force necessary to dilate the cervix, or blood loss between the two groups (see Table 27). Reported side effects following misoprostol administration were minimal and included slight fatigue and vaginal bleeding. From these results, it does not appear that misoprostol is useful as a cervical priming agent in postmenopausal women. The sample size was small, however.

\section{Summary}

Preprocedure administration of misoprostol appears to be a worthwhile adjunct to gynecological and obstetric procedures that require dilation

\begin{tabular}{lrr}
$\begin{array}{l}\text { TABLE } 27 \\
\text { Use of misoprostol for cervical priming prior }\end{array}$ \\
$\begin{array}{lrr}\text { Mo hysteroscopy in postmenopausal women }{ }^{23} \\
\text { Misoprostol } \\
(\mathbf{n}=\mathbf{1 8})\end{array}$ & $\begin{array}{r}\text { Placebo } \\
(\mathbf{n}=16)\end{array}$ \\
\hline Baseline cervical dilation (mm) & & \\
Mean \pm S.D. & $4.2 \pm 1.7$ & $4.4 \pm 1.6$ \\
Median & 5.0 & 5.0 \\
Range & $0-6$ & $0-6$ \\
Cumulative force (N) & & \\
Mean \pm S.D. & $27.7 \pm 23.3$ & $21.8 \pm 11.8$ \\
Median & 24.0 & 19.0 \\
Range & $2-101$ & $8-50$ \\
Duration of operation (min) & & \\
Mean \pm S.D. & $11.7 \pm 10.8$ & $6.4 \pm 4.2$ \\
Median & 7.0 & 5.0 \\
Range & $4-41$ & $2-15$ \\
Blood loss (ml) & & \\
Mean \pm S.D. & $21.7 \pm 50.0$ & $6.9 \pm 12.3$ \\
Median & 5.0 & 3.0 \\
Range & $0-20$ & $0-50$ \\
& &
\end{tabular}

of the cervix and entry into the uterus, perhaps with the exception of procedures among postmenopausal women. Several published studies have demonstrated that pretreatment with misoprostol can reduce short-term complications associated with these procedures, including cervical lacerations and uterine perforations. Moreover, use of misoprostol may reduce subsequent morbidity caused by cervical stenosis.

Studies suggest that misoprostol is at least as effective as commonly used methods of mechanical and pharmacologic dilation and has the added benefit of being inexpensive, convenient, and acceptable to patients. Although studies differ in their findings, the optimal priming regimen based on current data appears to be $400 \mu \mathrm{g}$ administered orally three hours prior to a procedure. In women who are nulliparous, have had previous traumatic injuries to the cervix, or are postmenopausal, misoprostol may be less effective, as their cervixes are likely to be more resistant to dilation. Further studies in these populations are warranted because current information is limited, with few published studies and small sample sizes.

Additional research could help answer other important questions. Most studies have focused on the use of misoprostol for cervical ripening prior to first-trimester terminations with the patient usually self-administering misoprostol before coming to the clinic. This type of preprocedure treatment, if safe, could benefit women seeking second-trimester terminations, as dilation of the cervix during this period takes longer and can be more painful. The efficacy, safety, and acceptability of this procedure, however, are not wellresearched and have yet to be established.

The extent of dilation caused by misoprostol is less predictable than that with mechanical dilation and therefore overdilation may be more frequent. Overdilation prior to the insertion of an IUD may result in higher expulsion rates, or, for hysteroscopic procedures, an inadequate seal around the hysteroscope. Larger studies testing a broader range of doses and dosing intervals of misoprostol for this indication may help to fine-tune its use.

For women who present at clinics for same-day procedures, waiting three hours for cervical dilation may not be practical or acceptable. Further research is needed to investigate whether a particular dose and route of administration would be effective over a shorter time interval with tolerable side effects.

Finally, basic laboratory research exploring the actions of prostaglandins on collagenase and 
other collagenolytic proteases thought to be involved in cervical remodeling may be useful. Descriptions of the interaction of gonadosteriods and estrogen with misoprostol could also be informative. This type of research, however, is quite costly and may not be of highest priority.

\section{References}

1 Scottish Hysteroscopy Audit Group. 1996. “A Scottish audit of hysteroscopic surgery for menorrhagia: Compliance and follow-up," British Journal of Obstetrics and Gynaecology 102(3): 249-254.

2 Schulz, K.F., D.A. Grimes, and W. Cates, Jr. 1983. “Measures to prevent cervical injury during suction curettage abortion," Lancet 1(8335): 1182-1185.

3 Kafrissen, M.E., K.F. Schulz, D.A. Grimes, and W. Cates, Jr. 1984. “Midtrimester abortion: Intra-amniotic instillation of hyperosmolar urea and prostaglandin F2 alpha v. dilatation and evacuation," Journal of the American Medical Association 251(7): 916-919.

4 Ferris, L.E., M. McMain-Klein, N. Colodny, N.F. Fellows, and J. Lamont. 1996. "Factors associated with immediate abortion complications," Canadian Medical Association Journal 154(11): 1677-1685.

5 World Health Organization. 1981. “Vaginal administration of 15-methyl-PGF2 alpha methyl ester for preoperative cervical dilatation," Contraception 23(3): 251-259.

6 de Jonge, E.T., R. Jewkes, J. Levin, and H. Rees. 2000. “Randomised controlled trial of the efficacy of misoprostol used as a cervical ripening agent prior to termination of pregnancy in the first trimester," South African Medical Journal 90(3): 256-262.

7 Krishna, U., A.N. Gupta, H.K. Ma, I. Manuilova, V. Hingorani, R.N. Prasad, M. Bygdeman, J. Herczeg, D. Obersnel-Kveder, A. Losa et al. 1986. “Randomized comparison of different prostaglandin analogues and laminaria tent for preoperative cervical dilatation. World Health Organization Special Programme of Research, Development and Research Training in Human Reproduction: Task Force on Prostaglandins for Fertility Regulation," Contraception 34(3): 237-251.

8 Helm, C.W., N. Davies, and R.J. Beard. 1988. “A comparison of gemeprost (Cervagem) pessaries and Lamicel tents for cervical preparation for abortion by dilatation and suction," British Journal of Obstetrics and Gynaecology 95(9): 911-915.

9 Gupta, J.K. and N. Johnson. 1992. “Should we use prostaglandins, tents or progesterone antagonists for cervical ripening before first trimester abortion?" Contraception 46(5): 489-497.

10 Maclsaac, L., D. Grossman, E. Balistreri, and P. Darney. 1999. "A randomized controlled trial of laminaria, oral misoprostol, and vaginal misoprostol before abortion," Obstetrics and Gynecology 93(5 Pt 1): 766-770.
11 el-Refaey, H., L. Calder, D.N. Wheatley, and A. Templeton. 1994. "Cervical priming with prostaglandin E1 analogues, misoprostol and gemeprost," Lancet 343(8907): 1207-1209.

12 Ngai, S.W., K.C. Yeung, T. Lao, and P.C. Ho. 1995. “Oral misoprostol versus vaginal gemeprost for cervical dilatation prior to vacuum aspiration in women in the sixth to twelfth week of gestation," Contraception 51(6): 347-350.

13 . 1996. “Oral misoprostol versus mifepristone for cervical dilatation before vacuum aspiration in first trimester nulliparous pregnancy: A double blind prospective randomised study," British Journal of Obstetrics and Gynaecology 103(11): 1120-1123.

14 Henry, A.M. and M. Haukkamaa. 1999. “Comparison of vaginal misoprostol and gemeprost as pre-treatment in first trimester pregnancy interruption," British Journal of Obstetrics and Gynaecology 106(6): 540-543.

15 Ashok, P.W., G.M. Flett, and A. Templeton. 2000. "Mifepristone versus vaginally administered misoprostol for cervical priming before first-trimester termination of pregnancy: A randomized, controlled study," American Journal of Obstetrics and Gynecology 183(4): 998-1002.

16 Lawrie, A., G. Penney, and A. Templeton. 1996. "A randomised comparison of oral and vaginal misoprostol for cervical priming before suction termination of pregnancy," British Journal of Obstetrics and Gynaecology 103(11): 1117-1119.

17 Ngai, S.W., Y.M. Chan, O.S. Tang, and P.C. Ho. 1999. “The use of misoprostol for pre-operative cervical dilatation prior to vacuum aspiration: A randomized trial," Human Reproduction 14(8): 2139-2142.

18 Singh, K., Y.F. Fong, R.N. Prasad, and F. Dong. 1999a. "Evacuation interval after vaginal misoprostol for preabortion cervical priming: A randomized trial," Obstetrics and Gynecology 94(3): 431-434.

19 . 1999b. "Vaginal misoprostol for pre-abortion cervical priming: Is there an optimal evacuation time interval?" British Journal of Obstetrics and Gynaecology 106(3): 266-269.

20 Fung, T.M., M.H. Lam, S.F. Wong, and L.C. Ho. 2002. “A randomised placebo-controlled trial of vaginal misoprostol for cervical priming before hysteroscopy in postmenopausal women," British Journal of Obstetrics and Gynaecology 109(5): 561-565.

21 Ngai, S.W., Y.M. Chan, and P.C. Ho. 2001. "The use of misoprostol prior to hysteroscopy in postmenopausal women," Human Reproduction 16(7): 1486-1488.

22 Ngai, S.W., Y.M. Chan, K.L. Liu, and P.C. Ho. 1997. “Oral misoprostol for cervical priming in non-pregnant women," Human Reproduction 12(11): 2373-2375.

23 Preutthipan, S. and Y. Herabutya. 1999. “A randomized controlled trial of vaginal misoprostol for cervical priming before hysteroscopy," Obstetrics and Gynecology 94(3): 427-430.

24 - 2000. “Vaginal misoprostol for cervical priming before operative hysteroscopy: A randomized controlled trial," Obstetrics and Gynecology 96(6): 890-894. 
In most developing countries, access to new drug therapies is limited, especially where drugs are expensive or require sophisticated technologies or skills. Little research and funding have been devoted to finding effective and inexpensive technologies that are appropriate to low-resource settings. Consequently, providers often modify standard regimens to suit their own needs or develop their own treatments based on available drugs. One example of this is the off-label use of misoprostol for a host of reproductive health indications.

Misoprostol is especially well-suited for use in developing countries and has several important advantages over other available treatment options. Despite these advantages, there are no standard or labeled regimens for any of these indications. Instead, providers have relied on the medical literature and colleagues in the field, as well as their own experience, for information on effective regimens. Consequently, both in the medical literature and in clinical practice there is considerable variation in the regimens used.

\section{The Use of Misoprostol to Improve Gynecological and Obstetric Health in Brazil, Jamaica, and the United States ${ }^{1}$}

Shelley Clark, Population Council, New York, NY, USA

Misoprostol is frequently solely perceived as an abortifacient drug. Yet mounting evidence demonstrates that it can be used to treat an array of reproductive health conditions that fall into three main categories: (1) abortion, (2) uterine evacuation, and (3) labor and delivery.

\section{Methods}

To document the off-label use of misoprostol and to capture some of the variation in regimens used in clinical practice, researchers conducted a survey of obstetricians and gynecologists in Brazil, Jamaica, and the United States. From February 1999 to May 2000, 228 obstetricians and gynecologists were interviewed in Brazil ( $n=123)$, Jamaica $(n=53)$, and the United States $(n=52)$. Using tele- phone interviews, researchers asked providers about their knowledge and use of misoprostol for ten distinct reproductive health indications. If a provider reported using misoprostol for a particular reproductive health indication, he or she was asked to describe the regimen used, including dosage amount, number of doses, timing of doses, and route of administration. Providers were also asked to describe commonly observed side effects. They were then asked to estimate the efficacy of misoprostol for the chosen indication and patient acceptability of the drug.

In all three countries, the "snowball" method was used to identify potential respondents. Researchers asked a core of knowledgeable providers to refer other providers who might be willing to participate in the survey. It is important to note that given this method of data collection, this study does not provide an overall estimate of the prevalence of misoprostol use. Rather it shows a range of its use and variation in the regimens prescribed among a nonrepresentative sample of providers.

\section{Uses of misoprostol}

In all three countries, there was a network of providers who had considerable experience using misoprostol. In Brazil and Jamaica there was intense interest in and enthusiasm about misoprostol. In comparison, use of the drug was less common and support for its use more tepid in the United States.

The use of misoprostol for abortion induction was well known among the providers interviewed in all three countries. Between $26 \%$ and $39 \%$ used misoprostol alone for first-trimester abortion. Use of misoprostol for second-trimester abortion, either in combination with dilation and evacuation (D\&E) or to induce labor, was less common. However, the use of misoprostol to prime the cervix prior to surgical abortion was widely practiced in Jamaica (52\%).

Misoprostol appears to be most frequently used for evacuating the uterus following a pregnancy failure. A large percentage of providers in Brazil and Jamaica (73\%) reported using misoprostol for treatment of intrauterine fetal death. Similarly large percentages of providers in these two countries reported using misoprostol to treat 
missed abortion. Reports of use for incomplete spontaneous abortions were rare.

Use of misoprostol during labor and delivery was especially common in Jamaica. A large majority of providers from Jamaica (87\%) reported using misoprostol to induce labor. In contrast, providers in all three countries seldom used misoprostol for prevention or treatment of postpartum hemorrhage (see Table 28).

Misoprostol to induce abortion. Results of the survey demonstrate that providers were exploring a variety of regimens for a range of abortion indications, including first- and second-trimester induction of abortion and cervical priming prior to surgical abortion. For each indication, researchers expressed a strong preference for vaginal administration of the drug. Several providers, particularly in Brazil, however, used a combination of oral and vaginal administration. Providers reported using anywhere from 50- to 900- $\mu$ g doses and an average of three to four doses of misoprostol for firsttrimester induction. In contrast, regimens for cervical priming prior to surgical abortion used about half that dosage.

Overall, providers did not report a large number of side effects with the use of misoprostol for abortion induction. By far the most common side effect reported was gastrointestinal discomfort. A small number of providers also mentioned bleeding, vomiting, nausea, cramps, and pain. In addition, while providers offered a wide range of treat-

TABLE 28 Providers reporting using misoprostol for women's health indications in Brazil, Jamaica, and the United States ( $\mathrm{N}=228$ )

\begin{tabular}{lc}
\hline Indication & $\%$ \\
\hline Induced abortion & 27 \\
First-trimester induction & 23 \\
Second-trimester D\&E & 13 \\
Second-trimester labor induction & 21 \\
Cervical priming prior to surgical abortion & \\
Uterine evacuation & 61 \\
Intrauterine fetal death & 57 \\
Missed abortion & 16 \\
Incomplete abortion & \\
Labor and delivery & 14 \\
Cervical softening & 46 \\
Labor induction & 8 \\
Prevention or treatment of postpartum hemorrhage &
\end{tabular}

ment regimens, they were remarkably consistent in their reports of the drug's efficacy and patient acceptability. Providers typically rated efficacy above $90 \%$ and gauged the acceptability to their patients to be between $80 \%$ and $90 \%$.

Although some regimens were reported to be used commonly in practice, many of them have yet to be tested in the research setting and therefore do not represent recommended treatment regimens. Table 29 compares the most common regimens found in clinical practice in the three countries to those recommended in a recent review article by Goldberg and colleagues. ${ }^{2}$ Although the use of misoprostol for firsttrimester abortion induction is common in all three countries, it was not recommended in the review by Goldberg and colleagues. The review did recommend two regimens for secondtrimester abortion, roughly comparable to the regimens found in clinical practice. The recommendation for cervical priming prior to abortion, however, contrasts sharply with the regimen used in practice, which consists of a much lower dose administered further in advance of the procedure (see Table 29).

In countries like Brazil, where abortion is legally restricted, there are frequent reports documenting women's covert use of the drug. In general, misoprostol is a much safer way to self-induce abortion than other methods women use in these circumstances. Nonetheless, women who use the drug covertly and experience complications may not have access to medical advice or be able to seek prompt care in case of an emergency.

Misoprostol for uterine evacuation after pregnancy failure. More than $60 \%$ of providers who reported using misoprostol for uterine evacuation after pregnancy failure administered the drug vaginally, and nearly a third reported using a regimen combining both vaginal and oral administration. A wide range of regimens was described for each indication, with reported doses ranging from $25 \mu \mathrm{g}$ to $800 \mu \mathrm{g}$ and the average number of doses from three to six.

Overall, providers did not report many side effects with the use of misoprostol for treatment of pregnancy failure. However, one provider reported two cases of uterine rupture in women who were six months pregnant and had experienced IUFD. These women were given 1,200 $\mu \mathrm{g}$, a dose far greater than the recommended dosage of 100-200 $\mu \mathrm{g}$, but consistent with doses cited by other 


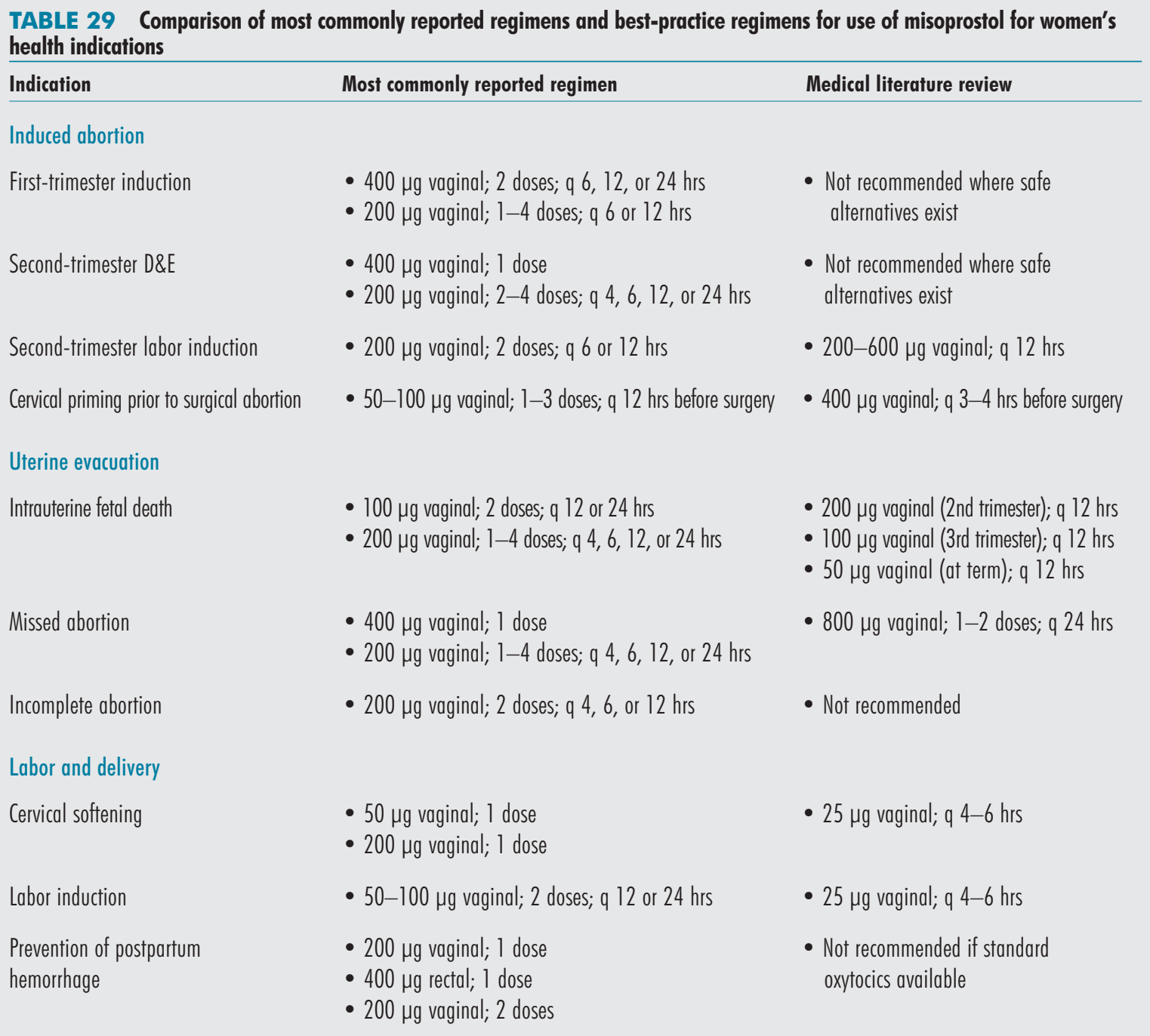

providers in the survey. Providers indicated that misoprostol is more than $90 \%$ effective and $80 \%$ acceptable to women when used to treat pregnancy failure.

Given the variation in reported regimens, it is difficult to identify the most common treatments for uterine evacuation. For early missed abortion, the review article by Goldberg and colleagues recommends one or two doses of $800 \mu \mathrm{g}$ vaginal misoprostol every 24 hours. In practice, the providers surveyed tended to use about half that dose for this indication. Finally, Goldberg and colleagues note that little evidence supports the use of misoprostol for treatment of incomplete spontaneous abortions. Yet a sizable majority of providers in the study reported using two doses of $200 \mu \mathrm{g}$ every 4,6 , or 12 hours for this indication.
Misoprostol for labor and delivery. For labor induction and cervical softening, a majority of providers reported that they administer misoprostol vaginally. While most providers surveyed indicated that they use between $25 \mu \mathrm{g}$ and $50 \mu \mathrm{g}$, others reported using doses as high as $600 \mu \mathrm{g}$. For both labor induction and cervical softening, the amount of misoprostol typically administered is at least double that recommended in the review article by Goldberg and colleagues. Side effects of misoprostol when used for these indications included uterine hyperstimulation, pain, and precipitate labor. Providers consistently judged the drug's efficacy and acceptability as over $80 \%$.

Providers who reported using misoprostol for either prevention or treatment of PPH were divided between those who favored vaginal (53\%) or 
rectal (33\%) administration. For prevention of $\mathrm{PPH}$, providers reported administering between $200 \mu \mathrm{g}$ and $400 \mu \mathrm{g}$, either vaginally or rectally. (The review article by Goldberg and colleagues does not recommend misoprostol for prevention of $\mathrm{PPH}$ if other drugs are available.) A few providers mentioned side effects including cramps, gastrointestinal discomfort, and fever or chills when misoprostol was used for this indication.

\section{Conclusions}

Given the method of data collection, it is not possible to estimate the prevalence of misoprostol use by providers in Brazil, Jamaica, or the United States. Nonetheless, it is clear that there is high demand for misoprostol among obstetricians and gynecologists, especially in Brazil and Jamaica. Providers also reported a high level of perceived efficacy and acceptability for all indications. Owing to a lack of practice guidelines and standard regimens, however, there is tremendous variation in the indications for which misoprostol is used and in the regimens used for each of these indications.

Off-label use of this drug poses several limitations. Some providers may underestimate its potency and give their patients excessively large doses. Many individual providers consistently reported giving much higher doses for the various indications than are currently substantiated in the medical literature. Without proper guidelines detailing when and how misoprostol should be used, providers may use regimens that are not safe or effective. In addition, providers may use misoprostol for indications for which is it not necessary or not the best available treatment. For example, as with other labor-inducing drugs, providers may use misoprostol for their convenience and prescribe it more often than medically necessary to increase the number of "daytime deliveries."

\section{Assessment of Misoprostol Use in Developing Countries}

Elizabeth Westley, EngenderHealth, New York, NY, USA and Jacqueline Sherris, Program for Appropriate Technology in Health, Seattle, WA, USA

EngenderHealth and the Program for Appropriate Technology in Health (PATH) conducted an assessment of misoprostol use, focusing on developing countries and with a particular emphasis on its use for abortion. The study's three primary objectives were to:

- investigate the availability and use of misoprostol;

- explore the potential impact of misoprostol availability on postabortion complications; and

- identify information needs of key stakeholders, including women, providers, and pharmacists.

Following a literature review, researchers conducted a survey of providers in 23 countries and a qualitative assessment of misoprostol use among women, providers, pharmacists, and pharmaceutical representatives in four countries.

\section{Survey of providers}

In collaboration with the field offices of EngenderHealth and PATH, 70 providers from 23 countries were surveyed by mail, fax, or e-mail. The selfadministered survey included questions about providers' knowledge and opinions regarding the availability and use of misoprostol both within and outside the medical establishment.

Respondents from countries where the drug is registered were most likely to report misoprostol use for women's health indications. Respondents from countries where misoprostol is not registered reported very little use, particularly in Africa. Among respondents who reported using misoprostol, commonly reported indications for use were treatment of IUFD and uterine labor induction. Respondents reported high acceptability.

Many reported that self-administration of misoprostol, in order to induce abortion, was a common practice in their communities. Over half of the respondents had treated women with incomplete abortion who appeared to have induced abortion with misoprostol. Reports of women using misoprostol for this purpose were more widespread among providers from Latin America. Almost $90 \%$ of respondents there who reported seeing women who had self-administered misoprostol felt it was as safe as or safer than other available methods to induce abortion. Some respondents reported anecdotally that where misoprostol was available, complications from induced abortion were less severe, resulting in less-frequent mortality or severe morbidity.

\section{Qualitative assessment of misoprostol use in four countries}

An in-depth qualitative assessment of misoprostol use and availability was conducted in two countries 
in Latin America, one country in Asia, and one in Africa. Researchers chose countries where abortion is highly restricted, somewhat restricted yet rarely available, or legal but with limited access. Participants included over 100 women of reproductive age (including 23 women presenting at clinics for treatment of postabortion complications), 83 providers from the formal sector (including obstetricians and gynecologists, general practitioners, and nurses), 19 lay practitioners and traditional healers, 37 pharmacists, and four pharmaceutical representatives. The assessment drawn from their comments offers insight into the use and availability of misoprostol within a variety of legal, social, and economic settings.

In-depth interviews with women. Knowledge of misoprostol was not widespread among the 93 women interviewed in the four countries, although younger and better-educated women were more likely to be aware of the drug. In some cases, women were not able to distinguish between misoprostol, mifepristone, emergency contraceptive pills, and oral contraceptives. Women indicated that they receive information about pregnancy termination primarily from their friends and relatives.

In-depth interviews with women treated for postabortion complications. Over half of the 23 women interviewed reported using misoprostol. Reported doses and regimens varied widely, with doses of as many as eight tablets recommended to them by pharmacists or health care practitioners, to be administered orally, vaginally, or orally and vaginally. (Use of the "three-up/three-down" protocol, in which three tablets are taken orally and three are taken vaginally, was widespread in one country.) Some women reported taking the tablets orally with special teas, and in one case with an injection. Oral administration was recommended to some women so that a provider would not be able to find evidence of the drug if the woman later required treatment.

Many women in the sample expressed fear and confusion about not knowing what to expect when taking misoprostol, and some reported being frightened by the bleeding and pain they experienced. Women who attempted abortion commonly stated that the experience was lonely and frightening, that they usually did not know what to expect, and that they sought assistance only after unsuccessful attempts. These responses are from women who required treatment at a health care facility, and therefore do not represent the opinions of those who had successful abortions and did not present for postabortion care.

In-depth interviews with pharmacists. Results of interviews with women suggest that pharmacists are the front-line providers of misoprostol in countries where misoprostol is available but abortion is illegal or access to abortion is limited.

However, pharmacists were understandably reluctant to describe their experiences providing misoprostol to women seeking to terminate their pregnancies. While pharmacists commonly acknowledged that misoprostol could be used for abortion, they rarely reported providing misoprostol for that indication.

In-depth interviews with pharmaceutical representatives. Three of the four pharmaceutical representatives interviewed acknowledged obstetric and gynecological uses of misoprostol, and all stated that the company that markets and distributes misoprostol cannot and thus does not promote off-label use of the drug.

In-depth interviews with providers. All providers reported using misoprostol for many women's health indications, although obstetricians and gynecologists appeared to use the drug for the widest range of indications. Providers emphasized the need for standardized practice guidelines but seemed reluctant for information about misoprostol to be disseminated to women. They voiced concerns about uterine rupture and other side effects and complications but acknowledged a significant positive impact of use of the drug on women's health, particularly a marked reduction in the number of women presenting with complications of induced abortion.

\section{Summary}

The combination of widespread off-label use of misoprostol and few conclusive large-scale clinical trials leaves policymakers, drug regulators, pharmaceutical companies, providers, and women in an unusual and uncomfortable position. On the one hand, a large and growing group of providers, particularly in developing countries, has discovered a range of uses of misoprostol for improving reproductive health care. On the other hand, pharmaceutical companies have shown no interest in developing misoprostol for any of these women's health indications.

The potential for misoprostol to improve women's health makes its continued use in obstetrics and gynecology almost inevitable. Effective 
information dissemination strategies are therefore essential to ensure safe and effective use of the drug. Practice guidelines should be simple to understand and applicable to a wide range of situations. Materials should be developed in local languages. In addition, providers would benefit from articles published in local medical journals, as they often have limited access to journals from other countries. Because the Internet is a frequently used source of information, accurate, evidencebased information on misoprostol use for women's health indications, including for pregnancy termination, should be made available online. Information dissemination efforts should also target pharmacists who provide misoprostol for preg- nancy termination even where legal restrictions prohibit them from doing so. In settings where abortion is highly restricted, women have few sources for accurate information, and therefore creative dissemination strategies are necessary.

\section{References}

1 Clark, S., J. Blum, K. Blanchard, L. Galvão, H. Fletcher, and B. Winikoff. 2002. "Misoprostol use in obstetrics and gynecology in Brazil, Jamaica, and the United States," International Journal of Gynaecology and Obstetrics 76(1) 65-74.

2 Goldberg, A.B., M.B. Greenberg, and P.D. Darney. 2001. "Misoprostol and pregnancy," New England Journal of Medicine 344(1): 38-47. 


\section{PRIORITIES FOR RESEARCH A N D POLICY}

Meeting participants agreed that a major priority for research and policy is creation of a solid clinical science base for all women's health indications for which misoprostol is effective. A second priority is to ensure the availability of misoprostol by registering it for women's health indications and guaranteeing that its availability is not subject to economic or political factors. Once misoprostol is available and accessible in a country, providers must be trained, guidelines created, and women educated so that use of the drug is safe and effective. Finally, a broader policy strategy is necessary to generate support for needed program development.

\section{Goals}

\section{Overall}

- Create awareness about the potential of misoprostol for women's health indications;

- Generate scientific understanding of misoprostol for women's health indications; and

- Improve safe and effective use of misoprostol for women's health indications.

It is important that:

- women's health and policy groups understand the issues, formulate positions on use of misoprostol, and disseminate these positions;

- medical providers understand the benefits and limitations of misoprostol's use for women's health indications;

- researchers coordinate research plans, drug development, and other efforts critical to creating good practice guidelines; and

- members of all of the above groups present information garnered from research in a standardized way to educate and inform politicians, lawmakers, and other professionals.

\section{Research Priorities}

\section{In general}

- Explore the biology as well as the advantages and disadvantages of various routes of administration: buccal, sublingual, rectal, oral, and vaginal;
- Develop a dose-response curve by gestational age over the entire course of a pregnancy with respect to uterine contractility and cervical softening;

- Determine the feasibility of integrating misoprostol use into a variety of health care service delivery settings;

- Investigate patient and provider acceptability, perceived and actual benefit of treatment, and actual use and practice patterns;

- Establish the effect of pre-administration moistening and $\mathrm{pH}$ on efficacy and absorption of misoprostol when administered vaginally; and

- Determine the feasibility of developing doses smaller than $100 \mu \mathrm{g}$ and $200 \mu \mathrm{g}$.

\section{Induced abortion}

- Identify safe and effective regimens for firstand second-trimester induction with misoprostol; and

- Explore the use of misoprostol for cervical ripening prior to second- and third-trimester dilation and evacuation procedures.

\section{Uterine evacuation after pregnancy failure}

- Compare medical management with surgical and expectant management for treatment of incomplete and missed abortion; and

- Compare medical and surgical management of IUFD.

\section{Labor induction (viable pregnancy)}

- Identify the best regimen for labor induction;

- Define the benefits and risks of labor induction with misoprostol in women with previous cesarean section; and

- Compare the use of misoprostol for labor induction remote from term with current treatment alternatives such as oxytocin or dinoprostone.

\section{Use in the third stage of labor}

- Explore the role of misoprostol in the prevention of PPH in a range of health care delivery settings; 
- Evaluate the use of misoprostol in the treatment of PPH in a range of health care delivery settings; and

- Determine appropriate proxies for measuring morbidity and mortality in studies of treatment and prevention of PPH.

\section{Cervical priming}

- Evaluate the use of misoprostol for cervical priming prior to IUD insertion and hysteroscopy; and

- Identify a regimen for using misoprostol for cervical priming for same-day procedures.

\section{Policy Priorities}

\section{Disseminate information}

- Increase discussion of use of misoprostol for women's health indications in professional forums by:

- building consensus on guidelines for clinical practice;

- fostering and encouraging discussion at national and international meetings; and

- convening informational and technical seminars.

- Train medical providers by:

- creating practice guidelines tailored to local context and type of provider; and
- supporting development of leaders in the field who can provide training and expertise on use of the technology.

- Educate women on the appropriate use of misoprostol for women's health indications by:

- assessing informational needs and appropriate vehicles of information dissemination; and

- employing strategies that allow autonomy in reproductive health decisionmaking in formal and informal settings.

- Generate awareness among key advocacy groups.

\section{Develop a dedicated product}

- Register a misoprostol product for new indications in the United States and abroad; and

- Develop alternate formulations:

- 25 and $50 \mu \mathrm{g}$ tablets; and

- Vaginal, rectal, buccal, and sublingual formulations, where necessary.

\section{Stimulate awareness in the funding community}

- Pursue major investment for low-resource settings where potential cannot be met without generous funding; and

- Generate funding to support research, education, dissemination, and policy efforts. 
This report outlines the potential of misoprostol $\left(\right.$ Cytotec $\left.^{\circledR}\right)$ for a range of women's health indications. A growing body of knowledge supports its use for induced abortion, uterine evacuation after pregnancy failure, cervical priming, labor induction, and management of the third stage of labor.

Meeting participants noted that despite misoprostol's medical and scientific promise, there is an inadequate level of funding support for research from both private and public entities to continue the work outlined here. Some of the challenges faced are common to drugs used in women's health in general and reproductive health in particular. Fears about liability and teratogenicity inhibit research on drugs for use in pregnant women. In addition, controversies surrounding misoprostol have hampered progress toward expanding its use. Stories in the mainstream media have dramatized the rare but tragic fatal outcomes due to misuse of misoprostol in labor induction. And because misoprostol is used to induce abortion, pharmaceutical companies responsible for its development and marketing are not supporting expanded use of the drug. For these reasons, it is imperative that women's health researchers, providers, advocates, policy leaders, and educators assume leadership roles and work together to develop and fulfill a common agenda to encourage research and development.

Misoprostol should not be promoted as "a magic bullet," nor should its potential be lost due to lack of support from industry and governments. Policy discussions must be accompanied by research conclusions from rigorously conducted pharmacologic, clinical, and social science studies. Science, however, must also be realistic about the real-world situations women face. The potential public health importance of this drug in lowresource settings (it is inexpensive, easy to store, and readily available) should be taken into account when assessing the appropriate role of misoprostol in health service delivery. Similarly, research to specify optimal clinical protocols for the use of misoprostol should recognize the importance of simplicity and clarity. It is likely that such protocols will have their most important public health roles in settings that lack sophisticated medical supervision or resources.

Statistical significance should not be the only measure of clinical significance. It is important to disseminate information about the evidence-based uses of this medication. It is also important to continue research on indications that lack adequate scientific evidence but for which the drug is already being used in clinical and lay practice. Presentations at this meeting highlighted the huge variation in the clinical use of misoprostol. The counterintuitive dose-related effects of this drug on the pregnant uterus - a higher dose is needed to trigger uterine contractions early in pregnancy, and a much lower dose is needed in later pregnancy-is essential information for both clinicians and lay people. Similarly the risks of inappropriate use must be part of the medical dialogue among clinicians and lay audiences. Researchers should continue to explore dosing and routes of administration for a wide range of clinical indications.

Financial investment will be required for misoprostol to meet its potential. Such investment could result in the registration of a product for several women's health indications. Funding also is needed for education and information dissemination among professional and lay audiences.

This meeting began a dialogue among researchers, providers, advocates, policy leaders, and educators. Participants affirmed a commitment to continue the work needed to realize the potential of misoprostol as a women's health technology. 
7 May 2001

State-of-the-Art Research

\section{Session 1: Induced Abortion (Misoprostol Alone)}

- Review of first- and second-trimester induced abortion

Speaker: John Jain, University of Southern California, Los Angeles, CA, USA

- First-trimester induced abortion: A life-table analysis

Speaker: Bryna Harwood, University of Southern California, Los Angeles, CA, USA

- First-trimester induced abortion in India Speaker: Kurus Coyaji, K.E.M. Hospital, Pune, India

- Second-trimester induced abortion in Thailand Speaker: Yongyoth Herabutya, Ramathibodi Hospital, Bangkok, Thailand

\section{Session 2: Uterine Evacuation After Pregnancy Failure}

- Incomplete and missed abortion in early pregnancy Speaker: Salina M.W. Pang, Chinese University of Hong Kong, Hong Kong, China

- IUFD in the second and third trimester Speaker: Hazem el-Refaey, Chelsea and Westminster Hospital, London, UK

\section{Session 3: Labor Induction}

- Review of labor induction with misoprostol: Route of administration, efficacy, safety, and potential concerns

Speaker: Allan Templeton, University of Aberdeen, Aberdeen, UK

- Labor induction with complicated labor: Postcesarean delivery, pre-eclampsia, pre-term/term premature rupture of membranes Speaker: Luis Sanchez-Ramos, University of Florida, Jacksonville, FL, USA

\section{Session 4: Postpartum Hemorrhage}

- The WHO trial

Speaker: A. Metin Gulmezoglu, World Health Organization, Geneva, Switzerland

- Overview of research experience: Past and present

Speaker: Justus Hofmeyr, University of the Witwatersrand, Nelspruit, South Africa

- Prevention of postpartum hemorrhage in the home delivery setting in rural Gambia Speaker: Gijs Walraven, Medical Research Council, Farafenni, Gambia

- The pharmacokinetics of rectal misoprostol when used to the prevent postpartum hemorrhage

Speaker: Anthony Bamigboye, University of the Witwatersrand, Nelspruit, South Africa

\section{Session 5: Cervical Ripening for Obstetric and Gynecological Procedures}

- Cervical ripening prior to surgical abortion Speaker: Gillian Penney, University of Aberdeen, Aberdeen, UK

- Cervical ripening prior to hysteroscopy and other gynecological procedures Speaker: Suk Wai Ngai, University of Hong Kong, Hong Kong, China

\section{Current Clinical Practice}

- Results of a survey in Jamaica, Brazil, and the United States

Speaker: Shelley Clark, Population Council, New York, NY, USA

- Route of administration: Considering efficacy and acceptability

Speakers: Bryna Harwood, University of Southern California, Los Angeles, CA, USA; Caitlin Shannon, Population Council, New York, NY, USA 


\section{Misoprostol: An Important Technology for Women's Health}

- Misoprostol in current research and clinical practice

Speaker: Felicia H. Stewart, Center for Reproductive Health Research \& Policy, University of California, San Francisco, CA, USA

- Protecting the potential of misoprostol: Ensuring availability and appropriate use Speaker: Beverly Winikoff, Population Council, New York, NY, USA

\section{Gaps and New Directions in Research}

- What are the most established/promising indications?

- How can we improve upon the regimen for these indications?

- Can we develop safe/effective regimens for the remaining indications?

- Can we develop new indications?

Speakers: Alisa Goldberg, University of California, San Francisco, CA, USA; Kurus Coyaji, K.E.M. Hospital, Pune, India

The Role of Provider Groups in Supporting the Appropriate Use and Development of Misoprostol

- Supporting and providing education and training for health care providers

- Promoting progressive hospital policies

- Protecting providers from potential legal issues Speakers: Vicki Saporta, National Abortion Federation, Washington, DC, USA; Ruth Shaber, Kaiser Permanente Medical Group, Oakland, CA, USA
The Role of NGOs and Other Nonprofit Organizations in Ensuring the Availability and Supporting the Use of Misoprostol

- Creating awareness of the application and appropriate use of misoprostol in clinical practice

Speaker: Kirsten Moore, Reproductive Health Technologies Project, Washington, DC, USA

- From physicians to lay practitioners: Educating providers

Speaker: Jodi Magee, Physicians for Reproductive Choice and Health, New York, NY, USA

- Supporting the availability and use of misoprostol in developing countries Speakers: Elizabeth Westley, EngenderHealth, New York, NY, USA; Jacqueline Sherris, Program for Appropriate Technology in Health, Seattle, WA, USA 
Anthony Bamigboye, M.D.

University of the Witwatersrand

Nelspruit, South Africa

bamigboye@ hotmail.com

Erika Banks, M.D.

Albert Einstein College of Medicine

Bronx, NY, USA

erkbanks@aol.com

Leah Beardsley, M.S.N., N.P.

Planned Parenthood Federation of America

New York, NY, USA

leah.beardsley@ppfa.org

Kelly Blanchard

Population Council

Johannesburg, South Africa

kblanchard@ pcjoburg.org.za

Jennifer Blum

Population Council

New York, NY, USA

jblum@popcouncil.org

Ellen Chesler, Ph.D.

Open Society Institute

New York, NY, USA

echesler@sorosny.org

Shelley Clark, Ph.D.

University of Chicago

(formerly of the Population Council)

Chicago, IL, USA

sclark1@uchicago.edu

Kurus Coyaji, M.D.

K.E.M. Hospital

Pune, India

kurus@vsnl.com

Juan Díaz, M.D.

Population Council

São Paulo, Brazil

jdiaz@popcouncil.org.br
Hazem el-Refaey, M.D.

Chelsea and Westminster Hospital

London, UK

hazem@mac.com

Henry Espinoza, M.D.

Population Council

Mexico City, Mexico

hespinoza@popcouncil.org.mx

Horace Fletcher, M.D.

University of the West Indies

Kingston, Jamaica

hfletchr@cwjamaica.com

Anne Foster-Rosales, M.D., M.P.H.

University of California, San Francisco

San Francisco, CA, USA

anne@ob.ucsf.edu

Sally Girvin, R.N.C., N.P.

Consultant (formerly of EngenderHealth)

NewYork, NY, USA

sallygirvin@hotmail.com

Alisa Goldberg, M.D.

Planned Parenthood League of Massachusetts

(formerly of the University of California,

San Francisco)

Boston, MA, USA

agoldberg@pplm.org

A. Metin Gulmezoglu, M.D.

World Health Organization

Geneva, Switzerland

gulmezoglum@who.int

Saad Harti

Alta Care

Paris, France

harti.saad@hra-pharma.com

Bryna Harwood, M.D.

University of Pittsburgh

(formerly of the University of Southern California)

Pittsburgh, PA, USA

bharwood@mail.magee.edu 
Danielle Hassoun, M.D. Hôpital Delafontaine

Saint Denis, France

d.hassoun@wanadoo.fr

Yongyoth Herabutya, M.D.

Ramathibodi Hospital

Bangkok, Thailand

rayhr@mahidol.ac.th

Justus Hofmeyr, M.D.

University of the Witwatersrand

Nelspruit, South Africa

gjh@global.co.za

John Jain, M.D.

University of Southern California

Los Angeles, CA, USA

jjain@hsc.usc.edu

Unnop Jaisamran, M.D.

Chulalongkorn University

Bangkok, Thailand

fmedujs@md2.md.chula.ac.th

Bonnie Scott Jones

Center for Reproductive Rights (formerly Center for Reproductive Law and Policy)

New York, NY, USA

bonnie.jones@crlp.org

Rachel Jones

Alan Guttmacher Institute

New York, NY, USA

rjones@guttmacher.org

Rehan Khan, M.D.

Chelsea and Westminster Hospital

London, UK

r.khan@ic.ac.uk

Orawan Kiriwat, M.D.

Mahidol University

Bangkok, Thailand

drorawankiriwat@hotmail.com

Ann Leonard

Ipas

Chapel Hill, NC, USA

leonardah@ipas.org

Laura Maclsaac, M.D.

Albert Einstein College of Medicine

Bronx, NY, USA

MDLaura@earthlink.net
Jodi Magee, M.D.

Physicians for Reproductive Choice and Health New York, NY, USA

jodi@prch.org

Kirsten Moore, M.P.A.

Reproductive Health Technologies Project

Washington, DC, USA

kmoore@rhtp.org

Suk Wai Ngai, M.D.

University of Hong Kong

Hong Kong, China

cora@hkucc.hku.hk

Tiana Norgren

Open Society Institute

New York, NY, USA

tnorgren@sorosny.org

Salina M.W. Pang, M.D.

Chinese University of Hong Kong

Hong Kong, China

mwpang@cuhk.edu.hk

Ashlesha Patel, M.D.

University of Illinois at Chicago

Chicago, IL, USA

apatel82@uic.edu

Gillian Penney, M.D.

University of Aberdeen

Aberdeen, UK

g.c.penney@abdn.ac.uk

Patrick S. Ramsey, M.D.

University of Alabama at Birmingham

Birmingham, AL, USA

ramsey_patrick@hotmail.com

Damrong Reinprayoon, M.D.

Chulalongkorn University

Bangkok, Thailand

surasakta@yahoo.com

Allan Rosenfield, M.D.

Columbia University

New York, NY, USA

ar32@columbia.edu

Luis Sanchez-Ramos, M.D.

University of Florida

Jacksonville, FL, USA

luis.sanchez@jax.ufl.edu 
Vicki Saporta

National Abortion Federation

Washington, DC, USA

vsaporta@prochoice.org

Rafaella Schiavon, M.D.

Population Council

Mexico City, Mexico

rcschiavon@popcouncil.org.mx

Ruth Shaber, M.D.

Kaiser Permanente Medical Group

Oakland, CA, USA

ruth.shaber@kp.org

Caitlin Shannon, M.P.H.

Population Council

New York, NY, USA

cshannon@popcouncil.org

Sunita Sharma, M.D.

Chelsea and Westminster Hospital

London, UK

sunita.sharma@ic.ac.uk

Jacqueline Sherris, Ph.D.

Consultant (formerly of Program for Appropriate

Technology in Health)

Seattle, WA, USA

jsherris@path.org

Kuldip Singh, M.D.

National University Hospital

Singapore

obgkuldi@nus.edu.sg

Korakot Sirimai, M.D.

Siriraj Family Health Research Center

Bangkok, Thailand

ksirimai@hotmail.com

Felicia H. Stewart, M.D.

Center for Reproductive Health

Research \& Policy

University of California, San Francisco

San Francisco, CA, USA

fstewar@itsa.ucsf.edu

Allie Stickney

Planned Parenthood Federation of America

New York, NY, USA

allie.stickney@ppfa.org
Phil Stubblefield, M.D.

Boston University School of Medicine

Boston, MA, USA

phillip.stubblefield@bmc.org

Elizabeth Talmont, M.D.

Planned Parenthood Federation of America

New York, NY, USA

elizabeth.talmont@ppfa.org

Surasak Taneepanichskul, M.D.

Chulalongkorn University

Bangkok, Thailand

surasakta@yahoo.com

Allan Templeton, M.D.

University of Aberdeen

Aberdeen, UK

allan.templeton@abdn.ac.uk

Gijs Walraven, M.D.

Medical Research Council

Farafenni, Gambia

gjis_walraven@hotmail.com

Andrew Weeks, M.D.

Royal Liverpool University Hospital

(formerly of Makerere University)

Liverpool, UK

aweeks@doctors.org.uk

Tracy Weitz, M.P.A.

Center for Reproductive Health

Research \& Policy

University of California, San Francisco

San Francisco, CA, USA

weitzt@obgyn.ucsf.edu

Carolyn Westhoff, M.D.

Columbia University

New York, NY, USA

clw3@columbia.edu

Elizabeth Westley, M.P.H.

Family Care International

(formerly of EngenderHealth)

New York, NY, USA

ewestley@familycareintl.org

Beverly Winikoff, M.D., M.P.H.

Gynuity Health Projects

(formerly of the Population Council)

New York, NY, USA

bwinikoff@gynuity.org 
A P P E N D X C :

\section{B I B LIOG RAPHY OF P B LISHED ARTICLES ON USE OF MISOPROSTOL FOR WOMEN'S HEALTH INDICATIONS, $1990-2002$}

\section{Induced abortion}

\section{First trimester-clinical trials}

Bugalho, A., A. Faundes, L. Jamisse, M. Usfa, E. Maria, and C. Bique. 1996. "Evaluation of the effectiveness of vaginal misoprostol to induce first trimester abortion," Contraception 53(4): 244-246.

Bugalho, A., S. Mocumbi, A. Faundes, and E. David. 2000. "Termination of pregnancies of $<6$ weeks gestation with a single dose of 800 microg of vaginal misoprostol," Contraception 61(1): 47-50.

Carbonell, J.L., J. Rodriguez, S. Aragon, A. Velazco, R. Tanda, C. Sanchez, S. Barambio, S. Chami, and F. Valero. 2001. "Vaginal misoprostol 1000 microg for early abortion," Contraception 63(3): 131-136.

Carbonell, J.L., L. Varela, A. Velazco, and C. Fernandez. 1997. "The use of misoprostol for termination of early pregnancy," Contraception 55(3): 165-168.

Carbonell, J.L., L. Varela, A. Velazco, C. Fernandez, and C. Sanchez. 1997. "The use of misoprostol for abortion at $<$ or = 9 weeks' gestation," European Journal of Contraception and Reproductive Health Care 2(3): 181-185.

Carbonell, J.L., L. Varela, A. Velazco, R. Tanda, S. Barambio, and S. Chami. 2000. "Vaginal misoprostol 600 microg for early abortion," European Journal of Contraception and Reproductive Health Care 5(1): 46-51.

Carbonell, J.L., L. Varela, A. Velazco, R. Tanda, and C. Sanchez. 1999. “Vaginal misoprostol for abortion at 10-13 weeks' gestation," European Journal of Contraception and Reproductive Health Care 4(1): 35-40.

Carbonell, J.L., A. Velazco, L. Varela, R. Tanda, C. Sanchez, S. Barambio, S. Chami, F. Valero, S. Aragon, and J. Mari. 2001. "Misoprostol for abortion at 9-12 weeks' gestation in adolescents," European Journal of Contraception and Reproductive Health Care 6(1): 39-45.

Carbonell-Esteve, J.L., L. Varela, A. Velazco, E. Cabezas, R. Tanda, and C. Sanchez. 1998. "Vaginal misoprostol for late first trimester abortion," Contraception 57(5): 329-333.

Carbonell-Esteve, J.L., L. Varela, A. Velazco, R. Tanda, E. Cabezas, and C. Sanchez. 1999. "Early abortion with 800 micrograms of misoprostol by the vaginal route," Contraception 59(4): 219-225.
Coyaji, K., B. Elul, U. Krishna, S. Otiv, S. Ambardekar, A. Bopardikar, V. Raote, C. Ellertson, and B. Winikoff. 2002. "Mifepristone-misoprostol abortion: A trial in rural and urban Maharashtra, India," Contraception 66(1): 33-40.

Crane, J.M., D. Young, K. Butt, M. Delaney, and D. Hutchens. 2001. "Safety and efficacy of misoprostol orally and vaginally: A randomized trial," Obstetrics and Gynecology 98(5 Pt 1): 875-876.

Jain, J.K., C. Dutton, B. Harwood, K.R. Meckstroth, and D.R. Mishell, Jr. 2002. "A prospective randomized, doubleblinded, placebo-controlled trial comparing mifepristone and vaginal misoprostol to vaginal misoprostol alone for elective termination of early pregnancy," Human Reproduction 17(6): 1477-1482.

Jain, J.K., B. Harwood, K.R. Meckstroth, and D.R. Mishell. 2001. "Early pregnancy termination with vaginal misoprostol combined with loperamide and acetaminophen prophylaxis," Contraception 63(4): 217-221.

Jain, J.K., K.R. Meckstroth, and D.R. Mishell, Jr. 1999. “Early pregnancy termination with intravaginally administered sodium chloride solution-moistened misoprostol tablets: Historical comparison with mifepristone and oral misoprostol," American Journal of Obstetrics and Gynecology 181(6): 1386-1391.

Jain, J.K., K.R. Meckstroth, M. Park, and D.R. Mishell, Jr. 1999. "A comparison of tamoxifen and misoprostol to misoprostol alone for early pregnancy termination," Contraception 60(6): 353-356.

Ngai, S.W., O.S. Tang, Y.M. Chan, and P.C. Ho. 2000. “Vaginal misoprostol alone for medical abortion up to 9 weeks of gestation: Efficacy and acceptability," Human Reproduction 15(5): 1159-1162.

Tang, O.S. and P.C. Ho. 2001. "Pilot study on the use of sublingual misoprostol for medical abortion," Contraception 64(5): 315-317.

Tang, O.S., S.W. Lee, and P.C. Ho. 2002. "A prospective randomized study on the measured blood loss in medical termination of early pregnancy by three different misoprostol regimens after pretreatment with mifepristone," Human Reproduction 17(11): 2865-2868.

Tang, O.S., B.Y. Miao, S.W. Lee, and P.C. Ho. 2002. "Pilot study on the use of repeated doses of sublingual misoprostol in termination of pregnancy up to 12 weeks gestation: Efficacy and acceptability," Human Reproduction 17(3): 654-658. 
Tang, O.S., K.S. Wong, L.C. Tang, and P.C. Ho. 1999. “Pilot study on the use of repeated doses of misoprostol in termination of pregnancy at less than 9 weeks of gestation," Advances in Contraception 15(3): 211-216.

Tang, O.S., J. Xu, L. Cheng, S.W. Lee, and P.C. Ho. 2002. “The effect of contraceptive pills on the measured blood loss in medical termination of pregnancy by mifepristone and misoprostol: A randomized placebo controlled trial," Human Reproduction 17(1): 99-102.

Velazco, A., L. Varela, R. Tanda, C. Sanchez, S. Barambio, S. Chami, F. Valero, S. Aragon, J. Mari, and J.L. Carbonell. 2000. "Misoprostol for abortion up to 9 weeks' gestation in adolescents," European Journal of Contraception and Reproductive Health Care 5(4): 227-233.

Westhoff, C., R. Dasmahapatra, and E. Schaff. 2000. "Analgesia during at-home use of misoprostol as part of a medical abortion regimen," Contraception 62(6): 311-314.

Wiebe, E.R. 2001. “Misoprostol administration in medical abortion: A comparison of three regimens," Journal of Reproductive Medicine 46(2): 125-129.

2001. "Pain control in medical abortion," International Journal of Gynaecology and Obstetrics 74(3): 275-280.

Zikopoulos, K.A., E.G. Papanikolaou, S.N. Kalantaridou, G.D. Tsanadis, N.I. Plachouras, N.A. Dalkalitsis, and E.A. Paraskevaidis. 2002. "Early pregnancy termination with vaginal misoprostol before and after 42 days gestation," Human Reproduction 17(12): 3079-3083.

\section{Second trimester-clinical trials}

Autry, A.M., E.C. Hayes, G.F. Jacobson, and R.S. Kirby. 2002. “A comparison of medical induction and dilation and evacuation for second-trimester abortion," American Journal of Obstetrics and Gynecology 187(2): 393-397.

Bebbington, M.W., N. Kent, K. Lim, A. Gagnon, M.F. Delisle, F. Tessier, and R.D. Wilson. 2002. "A randomized controlled trial comparing two protocols for the use of misoprostol in midtrimester pregnancy termination," American Journal of Obstetrics and Gynecology 187(4): 853-857.

Bugalho, A., C. Bique, L. Almeida, and A. Faundes. 1993. “The effectiveness of intravaginal misoprostol (Cytotec) in inducing abortion after eleven weeks of pregnancy," Studies in Family Planning 24(5): 319-323.

Carbonell, J.L., L. Valera, A. Velazco, R. Tanda, and C. Sanchez. 1998. “Vaginal misoprostol for early second-trimester abortion," European Journal of Contraception and Reproductive Health Care 3(2): 93-98.

Dickinson, J.E. and S.F. Evans. 2002. "The optimization of intravaginal misoprostol dosing schedules in secondtrimester pregnancy termination," American Journal of Obstetrics and Gynecology 186(3): 470-474.

Dickinson, J.E., M. Godfrey, and S.F. Evans. 1998. “Efficacy of intravaginal misoprostol in second-trimester pregnancy termination: A randomized controlled trial," Journal of Maternal-Fetal Medicine 7(3): 115-119.
Elsheikh, A., A. Antsaklis, S. Mesogitis, N. Papantoniou, A. Rodolakis, E. Vogas, and S. Michalas. 2001. "Use of misoprostol for the termination of second trimester pregnancies," Archives of Gynecology and Obstetrics 265(4): 204-206.

Eng, N.S. and A.C. Guan. 1997. “Comparative study of intravaginal misoprostol with gemeprost as an abortifacient in second trimester missed abortion," Australian and New Zealand Journal of Obstetrics and Gynaecology 37(3): 331-334.

Ghorab, M.N. and B.A. El Helw. 1998. “Second-trimester termination of pregnancy by extra-amniotic prostaglandin F2alpha or endocervical misoprostol: A comparative study," Acta Obstetricia et Gynecologica Scandinavica 77(4): 429-432.

Gilbert, A. and R. Reid. 2001. "A randomised trial of oral versus vaginal administration of misoprostol for the purpose of mid-trimester termination of pregnancy," Australian and New Zealand Journal of Obstetrics and Gynaecology 41(4): 407-410.

Gonzalez, J.A., S.J. Carlan, and M.W. Alverson. 2001. “Outpatient second trimester pregnancy termination," Contraception 63(2): 89-93.

Herabutya, Y., B. Chanrachakul, and P. Punyavachira. 2001. "Second trimester pregnancy termination: A comparison of 600 and 800 micrograms of intravaginal misoprostol," Journal of Obstetrics and Gynaecology Research 27(3): 125-128.

Hidar, S., M. Fekih, A. Chaieb, M. Bibi, R. Mellouli, and H. Khairi. 2001. "[Oxytocin and misoprostol administered intravaginally for termination of pregnancy at 13 to 29 weeks of amenorrhea: A prospective randomized trial]," Journal de Gynécologie Obstétrique et Biologie de la Reproduction 30(5): 439-443.

Ho, P.C., S.W. Ngai, K.L. Liu, G.C. Wong, and S.W. Lee. 1997. "Vaginal misoprostol compared with oral misoprostol in termination of second-trimester pregnancy," Obstetrics and Gynecology 90(5): 735-738.

Hoffer, M.C., C. Charlier, P.L. Giacalone, L. Zimbris, M. Astruc, and P. Boulot. 1998. "[Evaluation of combination RU 486laminaria tents-misoprostol-peridural anesthesia in second and third trimester induced abortions]," Journal de Gynécologie Obstétrique et Biologie de la Reproduction 27(1): 83-86.

Jain, J.K., J. Kuo, and D.R. Mishell, Jr. 1999. “A comparison of two dosing regimens of intravaginal misoprostol for second-trimester pregnancy termination," Obstetrics and Gynecology 93(4): 571-575.

Jain, J.K. and D.R. Mishell, Jr. 1994. "A comparison of intravaginal misoprostol with prostaglandin E2 for termination of second-trimester pregnancy," New England Journal of Medicine 331(5): 290-293.

. 1996. "A comparison of misoprostol with and without laminaria tents for induction of second-trimester abortion," American Journal of Obstetrics and Gynecology 175(1): 173-177. 
2001. "Misoprostol regimens for termination of second trimester pregnancy," Human Reproduction 16(2): 393.

Leader, J., M. Bujnovsky, S.J. Carlan, T. Triana, and K. Richichi. 2002. "Effect of oral misoprostol after second-trimester delivery: A randomized, blinded study," Obstetrics and Gynecology 100(4): 689-694.

Lim, J.M., E.B. Soh, and S. Raman. 1995. "Intravaginal misoprostol for termination of midtrimester pregnancy," Australian and New Zealand Journal of Obstetrics and Gynaecology 35(1): 54-55.

Mendilcioglu, I., M. Simsek, P.E. Seker, O. Erbay, C.G. Zorlu, and B. Trak. 2002. "Misoprostol in second and early third trimester for termination of pregnancies with fetal anomalies," International Journal of Gynaecology and Obstetrics 79(2): 131-135.

Munthali, J. and J. Moodley. 2001. "The use of misoprostol for mid-trimester therapeutic termination of pregnancy," Tropical Doctor 31(3): 157-161.

Nuutila, M., J. Toivonen, 0. Ylikorkala, and E. Halmesmaki. 1997. "A comparison between two doses of intravaginal misoprostol and gemeprost for induction of secondtrimester abortion," Obstetrics and Gynecology 90(6): 896-900.

Owen, J. and J.C. Hauth. 1999. "Vaginal misoprostol vs. concentrated oxytocin plus low-dose prostaglandin E2 for second trimester pregnancy termination," Journal of Maternal-Fetal Medicine 8(2): 48-50.

Paz, B., G. Ohel, T. Tal, S. Degani, E. Sabo, and Z. Levitan. 2002. "Second trimester abortion by laminaria followed by vaginal misoprostol or intrauterine prostaglandin F2alpha: A randomized trial," Contraception 65(6): 411-413.

Pongsatha, S. and T. Tongsong. 2001. "Second trimester pregnancy termination with $800 \mathrm{mcg}$ vaginal misoprostol," Journal of the Medical Association of Thailand 84(6): 859-863.

Pongsatha, S., T. Tongsong, and 0. Suwannawut. 2001. "Therapeutic termination of second trimester pregnancy with vaginal misoprostol," Journal of the Medical Association of Thailand 84(4): 515-519.

Schaff, E.A., S.L. Fielding, and C. Westhoff. 2002. "Randomized trial of oral versus vaginal misoprostol 2 days after mifepristone $200 \mathrm{mg}$ for abortion up to 63 days of pregnancy," Contraception 66(4): 247-250.

Srisomboon, J., T. Tongsong, and S. Pongpisuttinun. 1997. "Termination of second-trimester pregnancy with intracervicovaginal misoprostol," Journal of the Medical Association of Thailand 80(4): 242-246.

Todd, C.S., M. Soler, L. Castleman, M.K. Rogers, and P.D. Blumenthal. 2002. "Buccal misoprostol as cervical preparation for second trimester pregnancy termination," Contraception 65(6): 415-418.

Wong, K.S., C.S. Ngai, K.S. Chan, L.C. Tang, and P.C. Ho. 1996. "Termination of second trimester pregnancy with geme- prost and misoprostol: A randomized double-blind placebo-controlled trial," Contraception 54(1): 23-25.

Wong, K.S., C.S. Ngai, A.Y. Wong, L.C. Tang, and P.C. Ho. 1998. "Vaginal misoprostol compared with vaginal gemeprost in termination of second trimester pregnancy: A randomized trial," Contraception 58(4): 207-210.

Wong, K.S., C.S. Ngai, E.L. Yeo, L.C. Tang, and P.C. Ho. 2000. “A comparison of two regimens of intravaginal misoprostol for termination of second trimester pregnancy: A randomized comparative trial," Human Reproduction 15(3): 709-712.

\section{Review}

Ashok, P.W., A. Templeton, P.T. Wagaarachchi, and G.M. Flett. 2002. "Factors affecting the outcome of early medical abortion: A review of 4132 consecutive cases," British Journal of Obstetrics and Gynaecology 109(11): 1281-1289.

Baird, D.T. 2002. "Medical abortion in the first trimester," Best Practice and Research: Clinical Obstetrics and Gynaecology 16(2): 221-236.

Blanchard, K., B. Winikoff, K. Coyaji, and T.N. Nguyen. 2000. "Misoprostol alone-A new method of medical abortion?" Journal of the American Medical Women's Association 55(3 Suppl): 189-190.

Blanchard, K., B. Winikoff, and C. Ellertson. 1999. “Misoprostol used alone for the termination of early pregnancy: $A$ review of the evidence," Contraception 59(4): 209-217.

Bugalho, A., C. Bique, L. Almeida, and S. Bergstrom. 1993. "Pregnancy interruption by vaginal misoprostol," Gynecologic and Obstetric Investigation 36(4): 226-229.

Bygdeman, M. and K.G. Danielsson. 2002. “Options for early therapeutic abortion: A comparative review," Drugs 62(17): 2459-2470.

Espinoza, H., C. Ellertson, S. Garcia, R. Schiavon, and A. Langer. 2002. "[Medical methods for pregnancy termination: A review of literature and its potential role in Mexico and Latin America]," Gaceta Médica de México 38(4): 347-356.

Harwood, B. and D.R. Mishell, Jr. 2000. “Use of vaginal misoprostol for abortion," Human Reproduction 15(12): 2686-2688.

Jain, J.K. and D.R. Mishell, Jr. 2000. “Misoprostol regimens for termination of second trimester pregnancy," Human Reproduction 16(2): 393.

Paul, M.E., C.M. Mitchell, A.J. Rogers, M.C. Fox, and E.G. Lackie. 2002. "Early surgical abortion: Efficacy and safety," American Journal of Obstetrics and Gynecology 187(2): 407-411.

Scheepers, H.C., E.J. van Erp, and A.S. van den Bergh. 1999. “Use of misoprostol in first and second trimester abortion: A review," Obstetrical and Gynecological Survey 54(9): 592-600.

Tang, O.S. and P.C. Ho. 2002. "Medical abortion in the second trimester," Best Practice and Research. Clinical Obstetrics and Gynaecology 16(2): 237-246. 


\section{Other}

[No authors listed]. 1991. "Misoprostol and legal medical abortion," Lancet 338(8777): 1241-1242.

Al-Hussaini, T.K. 2001. "Uterine rupture in second trimester abortion in a grand multiparous woman: A complication of misoprostol and oxytocin," European Journal of Obstetrics, Gynecology, and Reproductive Biology 96(2): 218-219.

Berghahn, L., D. Christensen, and S. Droste. 2001. “Uterine rupture during second-trimester abortion associated with misoprostol," Obstetrics and Gynecology 98(5 Pt 2): 976-977.

Bugalho, A., C. Bique, C. Pereira, A.C. Granja, and S. Bergstrom. 1996. "Uterine evacuation by vaginal misoprostol after second trimester pregnancy interruption," Acta Obstetricia et Gynecologica Scandinavica 75(3): 270-273.

Chen, M., J.C. Shih, W.T. Chiu, and F.J. Hsieh. 1999. "Separation of cesarean scar during second-trimester intravaginal misoprostol abortion," Obstetrics and Gynecology 94(5 Pt 2): 840.

Chong, Y.S., S. Chua, and S. Arulkumaran. 2002. "Sublingual misoprostol for first trimester termination of pregnancy: Safety concerns," Human Reproduction 17(10): 2777; author reply 2778.

Coelho, H.L., A.C. Teixeira, A.P. Santos, E.B. Forte, S.M. Morais, C. La Vecchia, G. Tognoni, A. Herxheimer. 1993. "Misoprostol and illegal abortion in Fortaleza, Brazil," Lancet 341(8855): 1261-1263.

Costa, S.H. 1998. “Commercial availability of misoprostol and induced abortion in Brazil," International Journal of Gynaecology and Obstetrics 63(Suppl 1): S131-S139.

Costa, S.H. and M.P. Vessey. 1993. "Misoprostol and illegal abortion in Rio de Janeiro, Brazil," Lancet341(8855): 1258-1261.

Creinin, M.D. 2000. “Randomized comparison of efficacy, acceptability and cost of medical versus surgical abortion," Contraception 62(3): 117-124.

De Nonno, L.J., C. Westhoff, S. Fielding, and E. Schaff. 2000. "Timing of pain and bleeding after mifepristone-induced abortion," Contraception 62(6): 305-309.

Faundes, A., L.C. Santos, M. Carvalho, and C. Gras. 1996. "Postabortion complications after interruption of pregnancy with misoprostol," Advances in Contraception 12(1): 1-9.

Ficicioglu, C., M. Tasdemir, and S. Tasdemir. 1996. “Effect of vaginal misoprostol application for cervical softening in pregnancy interruption before ten weeks of gestation," Acta Obstetricia et Gynecologica Scandinavica 5(1): 54-56.

Herabutya, Y., B. Chanrachakul, and P. Punyavachira. 2000. "Vaginal misoprostol in termination of second trimester pregnancy," Journal of Obstetrics and Gynaecology Research 26(2): 121-125.

Herabutya, Y., P. O-Prasertsawat. 1998. “Second trimester abortion using intravaginal misoprostol," International Journal of Gynaecology and Obstetrics 60(2): 161-165.
Hern, W.M. 2001. “Laminaria, induced fetal demise and misoprostol in late abortion," International Journal of Gynaecology and Obstetrics 75(3): 279-286.

Honkanen, H., S. Ranta, O. Ylikorkala, and 0. Heikinheimo. 2002. "The kinetics of serum hCG and progesterone in response to oral and vaginal administration of misoprostol during medical termination of early pregnancy," Human Reproduction 17(9): 2315-2319.

Jones, M.M. and K. Fraser. 1998. “Misoprostol and attempted self-induction of abortion," Journal of the Royal Society of Medicine 91(4): 204-205.

Jwarah, E. and J.0. Greenhalf. 2000. “Rupture of the uterus after 800 micrograms misoprostol given vaginally for termination of pregnancy," British Journal of Obstetrics and Gynaecology 107(6): 807.

Koopersmith, T.B. and D.R. Mishell, Jr. 1996. "The use of misoprostol for termination of early pregnancy," Contraception 53(4): 238-242.

Li, Y.T. and C.S. Yin. 2001. “Delivery of retained placenta by misoprostol in second trimester abortion" International Journal of Gynaecology and Obstetrics 74(2): 215-216.

Norel, G. 2002. "[Voluntary pharmacologic termination of pregnancy]," Revue Médicale de Bruxelles 23(1): A52-A53.

Pongsatha, S., N. Morakot, and T. Tongsong. 2002. “Demographic characteristics of women with self use of misoprostol for pregnancy interruption attending Maharaj Nakorn Chiang Mai Hospital," Journal of the Medical Association of Thailand 85(10): 1074-1080.

Rae, D.W., F.W. Smith, and A.A. Templeton. 2001. “Magnetic resonance imaging of the human cervix: A study of the effects of prostaglandins in the first trimester," Human Reproduction 16(8): 1744-1747.

Ramsey, P.S., B.B. Hogg, K.G. Savage, D.D. Winkler, and J. Owen. 2000. "Cardiovascular effects of intravaginal misoprostol in the mid trimester of pregnancy," American Journal of Obstetrics and Gynecology 183(5): 1100-1102.

Rosenfield, A. 1994. "The difficult issue of second-trimester abortion," New England Journal of Medicine 331(5): 324-325.

Rosenman, S. and G. Kleinman. 2002. “Cervical pregnancy: Two case reports," Connecticut Medicine 66(2): 71-72.

Rosing, M.A. and C.D. Archbald. 2000. "The knowledge, acceptability, and use of misoprostol for self-induced medical abortion in an urban US population," Journal of the American Medical Women's Association 55(3 Suppl): 183-185.

Sirimai, K., 0. Kiriwat, S. Neungton, and S. Suvanichchati. 2002. "Misoprostol use for therapeutic abortion in Siriraj Hospital: The year 2000," Journal of the Medical Association of Thailand 85(4): 416-423.

Tang, 0.S. 2002. "Sublingual misoprostol for first trimester termination of pregnancy: Safety concerns," Human Reproduction 17(10): 2778. 
Tsai, E.M., C.H. Yang, and J.N. Lee. 2002. “Medical abortion with mifepristone and misoprostol: A clinical trial in Taiwanese women," Journal of the Formosan Medical Association 101(4): 277-282.

Whitecar, P.W., A. Zweifel, and K.J. Moise. 1999. “Failed second-trimester misoprostol termination responding to vaginal instillation of citric acid," Obstetrics and Gynecology 94(5 Pt 2): 839.

Wright-Francis, D.L., B.D. Raynor, and G.W. Webb. 1998. "Misoprostol in second trimester termination of pregnancy," Primary Care Update for Ob/Gyns 5(4): 176.

Young, J.M. 1994. "Second trimester abortion," New England Journal of Medicine 331(25): 1716.

Zahradnik, H.P. 1992. "[Misuse of misoprostol in abortion induction]," Deutsche Medizinische Wochenschrift 117(45): 1735-1736.

\section{Uterine Evacuation After Pregnancy Failure}

\section{Early pregnancy failure-clinical trials}

Autry, A., G. Jacobson, R. Sandhu, and K. Isbill. 1999. “Medical management of non-viable early first trimester pregnancy," International Journal of Gynaecology and Obstetrics 67(1): 9-13.

Ayres-de-Campos, D., J. Teixeira-da-Silva, I. Campos, and B. Patricio. 2000. "Vaginal misoprostol in the management of first-trimester missed abortions," International Journal of Gynaecology and Obstetrics 71(1): 53-57.

Chung, T.K., L.P. Cheung, T.Y. Leung, C.J. Haines, and A.M. Chang. 1995. "Misoprostol in the management of spontaneous abortion," British Journal of Obstetrics and Gynaecology 102(10): 832-835.

Chung, T.K., D.T. Lee, L.P. Cheung, C.J. Haines, and A.M. Chang. 1999. "Spontaneous abortion: A randomized, controlled trial comparing surgical evacuation with conservative management using misoprostol," Fertility and Sterility 71(6): 1054-1059.

Chung, T., P. Leung, L.P. Cheung, C. Haines, and A.M. Chang. 1997. "A medical approach to management of spontaneous abortion using misoprostol: Extending misoprostol treatment to a maximum of 48 hours can further improve evacuation of retained products of conception in spontaneous abortion," Acta Obstetricia et Gynecologica Scandinavica 76(3): 248-251.

Creinin, M.D., B. Harwood, and R.S. Guido. 2002. “Medical management of missed abortion: A randomized clinical trial," Obstetrics and Gynecology 100(2): 382-383.

de Jonge, E.T., J.D. Makin, E. Manefeldt, G.H. De Wet, and R.C. Pattinson. 1995. "Randomised clinical trial of medical evacuation and surgical curettage for incomplete miscarriage," British Medical Journal311(7006): 662.
Demetroulis, C., E. Saridogan, D. Kunde, and A.A. Naftalin. 2001. "A prospective randomized control trial comparing medical and surgical treatment for early pregnancy failure," Human Reproduction 16(2): 365-369.

Gronlund, A., L. Gronlund, L. Clevin, B. Andersen, N. Palmgren, and 0. Lidegaard. 2002. "Management of missed abortion: Comparison of medical treatment with either mifepristone + misoprostol or misoprostol alone with surgical evacuation: A multi-center trial in Copenhagen county, Denmark," Acta Obstetricia et Gynecologica Scandinavica 81(11): 1060-1065.

Gronlund, L., A.L. Gronlund, L. Clevin, B. Andersen, N. Palmgren, and 0. Lidegaard. 2002. "Spontaneous abortion: Expectant management, medical treatment or surgical evacuation," Acta Obstetricia et Gynecologica Scandinavica 81(8): 781-782.

Henshaw, R.C., K. Cooper, H. el-Refaey, N.C. Smith, and A.A. Templeton. 1993. "Medical management of miscarriage: Non-surgical uterine evacuation of incomplete and inevitable spontaneous abortion," British Medical Journal 306(6882): 894-895.

Kovavisarach, E. and U. Sathapanachai. 2002. “Intravaginal 400 microg misoprostol for pregnancy termination in cases of blighted ovum: A randomised controlled trial," Australian and New Zealand Journal of Obstetrics and Gynaecology 42(2): 161-163.

Muffley, P.E., M.L. Stitely, and R.B. Gherman. 2002. “Early intrauterine pregnancy failure: A randomized trial of medical versus surgical treatment," American Journal of Obstetrics and Gynecology 187(2): 321-325; discussion 325-326.

Ngai, S.W., Y.M. Chan, O.S. Tang, and P.C. Ho. 2001. “Vaginal misoprostol as medical treatment for first trimester spontaneous miscarriage," Human Reproduction 16(7): 1493-1496.

Nielsen, S., M. Hahlin, and J. Platz-Christensen. 1999. "Randomized trial comparing expectant with medical management for first trimester miscarriages," British Journal of Obstetrics and Gynaecology 106(8): 804-807.

Pandian, Z., P. Ashok, and A. Templeton. 2001. “The treatment of incomplete miscarriage with oral misoprostol," British Journal of Obstetrics and Gynaecology 108(2): 213-214.

Pang, M.W., T.S. Lee, and T.K. Chung. 2001. “Incomplete miscarriage: A randomized controlled trial comparing oral with vaginal misoprostol for medical evacuation," Human Reproduction 16(11): 2283-2287.

Sahin, H.G., H.A. Sahin, and M. Kocer. 2001. “Randomized outpatient clinical trial of medical evacuation and surgical curettage in incomplete miscarriage," European Journal of Contraception and Reproductive Health Care 6(3): 141-144.

Wagaarachchi, P.T., P.W. Ashok, N. Narvekar, N.C. Smith, and A. Templeton. 2001. “Medical management of early fetal demise using a combination of mifepristone and misoprostol," Human Reproduction 16(9): 1849-1853.

Wagaarachchi, P.T., P.W. Ashok, N.C. Smith, and A. Templeton. 2002. "Medical management of early fetal demise using sublingual misoprostol," British Journal of Obstetrics and Gynaecology 109(4): 462-465. 
Wagaarachchi, P., P. Ashok, and A. Templeton. 2002. “Medical management of missed abortion: A randomized clinical trial," Obstetrics and Gynecology 100(2): 383.

Wakabayashi, M., M. Tretiak, T. Kosasa, S. Sharma, T. Aeby, L. Kamemoto, and L. Diniega. 1998. "Intravaginal misoprostol for medical evacuation of first trimester missed abortion," Primary Care Update for Ob/Gyns 5(4): 176.

Wood, S.L. and P.H. Brain. 2002. "Medical management of missed abortion: A randomized clinical trial," Obstetrics and Gynecology 99(4): 563-566.

Zalanyi, S. 1998. "Vaginal misoprostol alone is effective in the treatment of missed abortion," British Journal of Obstetrics and Gynaecology 105(9): 1026-1028.

\section{IUFD-clinical trials}

Bugalho, A., C. Bique, L. Almeida, and S. Bergstrom. 1994. "Application of vaginal misoprostol before cervical dilatation to facilitate first-trimester pregnancy interruption," Obstetrics and Gynecology 83(5 Pt 1): 729-731.

Bugalho, A., C. Bique, F. Machungo, and S. Bergstrom. 1995. "Vaginal misoprostol as an alternative to oxytocin for induction of labor in women with late fetal death," Acta Obstetricia et Gynecologica Scandinavica 74(3): 194-198.

Bugalho, A., C. Bique, F. Machungo, and A. Faundes. 1994. "Induction of labor with intravaginal misoprostol in intrauterine fetal death," American Journal of Obstetrics and Gynecology 171(2): 538-541.

Eng, N.S. and A.C. Guan. 1997. “Comparative study of intravaginal misoprostol with gemeprost as an abortifacient in second trimester missed abortion," Australian and New Zealand Journal of Obstetrics and Gynaecology 37(3): 331-334.

Merrell, D.A. and M.A.T. Koch. 1995. “Induction of labor with intravaginal misoprostol in the second and third trimester of pregnancy," South African Medical Journal 85(10 Suppl): 1088-1090.

Srisomboon, J. and S. Pongpisuttinun. 1998. “Efficacy of intracervicovaginal misoprostol in second-trimester pregnancy termination: A comparison between live and dead fetuses," Journal of Obstetrics and Gynaecology Research 24(1): 1-5.

Wagaarachchi, P.T., P.W. Ashok, N.N. Narvekar, N.C. Smith, and A. Templeton. 2002. "Medical management of late intrauterine death using a combination of mifepristone and misoprostol," British Journal of Obstetrics and Gynaecology 109(4): 443-447.

Yapar, E.G., S. Senoz, M. Urkutur, S. Batioglu, and O. Gokmen. 1996. "Second trimester pregnancy termination including fetal death: Comparison of five different methods," European Journal of Obstetrics, Gynecology, and Reproductive Biology 69(2): 97-102.

\section{Review}

Creinin, M.D., J.L. Schwartz, R.S. Guido, and H.C. Pymar. 2001. "Early pregnancy failure-Current management concepts," Obstetrical and Gynecological Survey 56(2): 105-113.

\section{Other}

Bygdeman, M. 1994. "[Treatment in miscarriage and abortion: Widened use of drugs has many advantages]," Läkartidningen 91(14): 1396-1397.

Creinin, M.D., R. Moyer, and R. Guido. 1997. “Misoprostol for medical evacuation of early pregnancy failure," Obstetrics and Gynecology 89(5 Pt 1): 768-772.

el-Refaey, H. and A. Templeton. 1998. “Unsuccessful treatment of missed abortion," British Journal of Obstetrics and Gynaecology 105(5): 567-568.

Haberal, A., H. Celikkanat, and S. Batioglu. 1996. “Oral misoprostol use in early complicated pregnancy," Advances in Contraception 12(2): 139-143.

Jurkovic, D. 1998. “Modern management of miscarriage: Is there a place for non-surgical treatment?" Ultrasound in Obstetrics and Gynecology 11(3): 161-163.

Macrow, P. and M. Elstein. 1993. “Managing miscarriage medically," British Medical Journal 306(6882): 876.

Wood, S. 2000. "Management of spontaneous abortionMedical or surgical," Fertility and Sterility 73(3): 652.

\section{Labor Induction}

\section{Clinical trials}

Aboulfalah, A., T. Chraibi, K. el Mouatacim, N. Samouh, and A. Himmi. 2001. "Induction of labour with intravaginal misoprostol after prior cesarean delivery," African Journal of Reproductive Health 5(2): 139-142.

Abramovici, D., S. Goldwasser, B.C. Mabie, B.M. Mercer, R. Goldwasser, and B.M. Sibai. 1999. "A randomized comparison of oral misoprostol versus Foley catheter and oxytocin for induction of labor at term," American Journal of Obstetrics and Gynecology 181(5 Pt 1): 1108-1112.

Adair, C.D., J.W. Weeks, S. Barrilleaux, M. Edwards, K. Burlison, and D.F. Lewis. 2002. “Oral or vaginal misoprostol administration for induction of labor: A randomized, double-blind trial," Obstetrics and Gynecology 92(5): 810-813.

Barrilleaux, P.S., J.A. Bofill, D.A. Terrone, E.F. Magann, W.L. May, and J.C. Morrison. 2002. “Cervical ripening and induction of labor with misoprostol, dinoprostone gel, and a Foley catheter: A randomized trial of 3 techniques," American Journal of Obstetrics and Gynecology 186(6): 1124-1129.

Bartha, J.L., R. Comino-Delgado, F. Garcia-Benasach, P. Martinez-Del-Fresno, and L.J. Moreno-Corral. 2000. “Oral misoprostol and intracervical dinoprostone for cervical ripening and labor induction: A randomized comparison," Obstetrics and Gynecology 96(3): 465-469.

Belfrage, P., E. Smedvig, L. Gjessing, T.M. Eggebo, and I. Okland. 2000. "A randomized prospective study of misoprostol and dinoprostone for induction of labor," Acta Obstetricia et Gynecologica Scandinavica 79(12): 1065-1068. 
Benchimol, M., J. Gondry, J.E. Mention, O. Gagneur, and J.C. Boulanger. 2001. "[Role of misoprostol in the delivery outcome]," Journal de Gynécologie Obstétrique et Biologie de la Reproduction 30(6): 576-583.

Bennett, K.A., K. Butt, J.M. Crane, D. Hutchens, and D.C. Young. 1998. "A masked randomized comparison of oral and vaginal administration of misoprostol for labor induction," Obstetrics and Gynecology 92(4 Pt 1): 481-486.

Blanchette, H.A., S. Nayak, and S. Erasmus. 1999. “Comparison of the safety and efficacy of intravaginal misoprostol (prostaglandin E1) with those of dinoprostone (prostaglandin E2) for cervical ripening and induction of labor in a community hospital," American Journal of Obstetrics and Gynecology 180(6 Pt 1): 1551-1559.

Bower, D.J. and L.N. Meurer. 1999. “Oral versus vaginal administration of misoprostol for labor induction," Journal of Family Practice 48(1): 9-10.

Browning, J. and R.B. Gherman. 2000. “Oral misoprostol versus intravaginal prostaglandin $\mathrm{E}(2)$ for preinduction cervical ripening: A randomized trial," Obstetrics and Gynecology 95(4 Suppl 1): S76.

Bugalho, A., C. Bique, F. Machungo, and S. Bergstrom. 1995 "A comparative study of vaginal misoprostol and intravenous oxytocin for induction of labour," Gynecologic and Obstetric Investigation 39(4): 252-256.

Bugalho, A., C. Bique, F. Machungo, and A. Faundes. 1995. "Low-dose vaginal misoprostol for induction of labor with a live fetus," International Journal of Gynaecology and Obstetrics 49(2): 149-155.

Buser, D., G. Mora, and F. Arias. 1997. "A randomized comparison between misoprostol and dinoprostone for cervical ripening and labor induction in patients with unfavorable cervices," Obstetrics and Gynecology 89(4): 581-585.

Butt, K.D., K.A. Bennett, J.M. Crane, D. Hutchens, and D.C. Young. 1999. "Randomized comparison of oral misoprostol and oxytocin for labor induction in term prelabor membrane rupture," Obstetrics and Gynecology 94(6): 994-999.

Campos, G.A., S. Guzman, J.G. Rodriguez, L.S. Voto, and M. Margulies. 1994. "[Misoprostol-A PGE1 analog for induction of labor at term: Comparative and randomized study with oxytocin]," Revista Chilena de Obstetricia y Ginecología 59(3): 190-195; discussion 195-196.

Carlan, S.J., S. Bouldin, D. Blust, and W.F. O'Brien. 2001. “Safety and efficacy of misoprostol orally and vaginally: A randomized trial," Obstetrics and Gynecology 98(1): 107-112.

Chang, C.H. and F.M. Chang. 1997. “Randomized comparison of misoprostol and dinoprostone for preinduction cervical ripening and labor induction," Journal of the Formosan Medical Association 96(5): 366-369.

Chanrachakul, B., Y. Herabutya, and P. Punyavachira. 2002. "Randomized trial of isosorbide mononitrate versus misoprostol for cervical ripening at term," International Journal of Gynaecology and Obstetrics 78(2): 139-145.
Charoenkul, S. and M. Sripramote. 2000. "A randomized comparison of one single dose of vaginal 50 microg misoprostol with $3 \mathrm{mg}$ dinoprostone in pre-induction cervical ripening," Journal of the Medical Association of Thailand 83(9): 1026-1034.

Choy-Hee, L. and B.D. Raynor. 2001. "Misoprostol induction of labor among women with a history of cesarean delivery," American Journal of Obstetrics and Gynecology 184(6): $1115-1117$

Chraibi, T., A. Aboulfalah, W. Bisbis, M. Noun, N. Matar, N. Samouh, and A. Himmi. 1999. "[Induction of labor by misoprostol, an analog of PGE1: A prospective study of 200 cases]," Santé 9(6): 345-349.

Chuck, F.J. and B.J. Huffaker. 1995. “Labor induction with intravaginal misoprostol versus intracervical prostaglandin E2 gel (Prepidil gel): Randomized comparison," American Journal of Obstetrics and Gynecology 173(4): 1137-1142.

Cullen, M. 2001. "Use of Cytotec (misoprostol) for labor induction," Journal of Obstetric, Gynecologic, and Neonatal Nursing 30(1): 11.

Echeverria, E. and M. Rocha. 1995. "[Randomized comparative study of induced labor with oxytocin and misoprostol in prolonged pregnancies]," Revista Chilena de Obstetricia y Ginecología 60(2): 108-111.

el-Refaey, H., R. Nooh, P. O'Brien, M. Abdalla, M. Geary, J. Walder, and C. Rodeck. 2000. “The misoprostol third stage of labour study: A randomised controlled comparison between orally administered misoprostol and standard management," British Journal of Obstetrics and Gynaecology 107(9): 1104-1110.

El-Sherbiny, M.T., I.H. El-Gharieb, and H.A. Gewely. 2001. "Vaginal misoprostol for induction of labor: 25 vs. 50 microg dose regimen," International Journal of Gynaecology and Obstetrics 72(1): 25-30.

Escudero, F. and H. Contreras. 1997. "A comparative trial of labor induction with misoprostol versus oxytocin," International Journal of Gynaecology and Obstetrics 57(2): 139-143.

Farah, L.A., L. Sanchez-Ramos, C. Rosa, G.O. Del Valle, F.L. Gaudier, I. Delke, and A.M. Kaunitz. 1997. "Randomized trial of two doses of the prostaglandin E1 analog misoprostol for labor induction," American Journal of Obstetrics and Gynecology 177(2): 364-369; discussion 369-371.

Feingold, M. and S. Ghamande. 1997. "A randomized trial of misoprostol and oxytocin for induction of labor: Safety and efficacy," Obstetrics and Gynecology 90(1): 155.

Ferguson, J.E. 2nd, B.H. Head, F.H. Frank, M.L. Frank, J.S. Singer, T. Stefos, and G. Mari. 2002. “Misoprostol versus low-dose oxytocin for cervical ripening: A prospective, randomized, double-masked trial," American Journal of Obstetrics and Gynecology 187(2): 273-279; discussion 279-280. 
Fisher, S.A., V.P. Mackenzie, and G.A. Davies. 2001. “Oral versus vaginal misoprostol for induction of labor: A doubleblind randomized controlled trial," American Journal of Obstetrics and Gynecology 185(4): 906-910.

Frohn, W.E., S. Simmons, and S.J. Carlan. 2002. “Prostaglandin E2 gel versus misoprostol for cervical ripening in patients with premature rupture of membranes after 34 weeks," Obstetrics and Gynecology 99(2): 206-210.

Gherman, R.B., J. Browning, A. O'Boyle, and T.M. Goodwin. 2001. “Oral misoprostol vs. intravaginal prostaglandin E2 for preinduction cervical ripening: A randomized trial," Journal of Reproductive Medicine 46(7): 641-646.

Ghidini, A., C.Y. Spong, V. Korker, and E. Mariani. 2001. "Randomized controlled trial of 50 and $100 \mathrm{mcg}$ of misoprostol for induction of labor at term," Archives of Gynecology and Obstetrics 265(3): 128-130.

Goedken, J., S. Poehlmann, and M. Paul. 2000. “A blinded randomized controlled trial of misoprostol, dinoprostone, and oxytocin for labor induction," Obstetrics and Gynecology 95(4 Suppl): S73.

Gottschall, D.S., A.F. Borgida, J.J. Mihalek, F. Sauer, and J.F. Rodis. 1997. "A randomized clinical trial comparing misoprostol with prostaglandin E2 gel for preinduction cervical ripening," American Journal of Obstetrics and Gynecology 177(5): 1067-1070.

Hall, R., M. Duarte-Gardea, and F. Harlass. 2002. “Oral versus vaginal misoprostol for labor induction," Obstetrics and Gynecology 99(6): 1044-1048.

Has, R., C. Batukan, H. Ermis, E. Cevher, A. Araman, G. Kilic, and L. Ibrahimoglu. 2002. "Comparison of 25 and 50 microg vaginally administered misoprostol for preinduction of cervical ripening and labor induction," Gynecologic and Obstetric Investigation 53(1): 16-21.

Herabutya, Y., P. O-Prasertsawat, and J. Pokpirom. 1997. “A comparison of intravaginal misoprostol and intracervical prostaglandin E2 gel for ripening of unfavorable cervix and labor induction," Journal of Obstetrics and Gynaecology Research 23(4): 369-374.

Hoffmann, R.A., J. Anthony, and S. Fawcus. 2001. “Oral misoprostol vs. placebo in the management of prelabor rupture of membranes at term," International Journal of Gynaecology and Obstetrics 72(3): 215-221.

Hofmeyr, G.J. 2001. "Induction of labour with misoprostol," Current Opinion in Obstetrics and Gynecology 13(6): 577-581.

Hofmeyr, G.J., Z. Alfirevic, B. Matonhodze, P. Brocklehurst, E. Campbell, and V.C. Nikodem. 2001. “Titrated oral misoprostol solution for induction of labour: A multi-centre, randomised trial," British Journal of Obstetrics and Gynaecology 108(9): 952-959.

How, H.Y., L. Leaseburge, J.C. Khoury, T.A. Siddiqi, J.A. Spinnato, and B.M. Sibai. 2001. "A comparison of various routes and dosages of misoprostol for cervical ripening and the induction of labor," American Journal of Obstetrics and Gynecology 185(4): 911-915.

Jackson, N. and S. Paterson-Brown. 2000. "Labour characteristics and uterine activity: Misoprostol compared with oxytocin in women at term with prelabour rupture of the membranes," British Journal of Obstetrics and Gynaecology 107(9): 1181-1182.

Jouatte, F., D. Subtil, P. Marquis, J.L. Plennevaux, and F. Puech. "[Medical indications of labor induction: A comparison between intravaginal misoprostol and intravenous dinoprostone]," Journal de Gynécologie Obstétrique et Biologie de la Reproduction 29(8): 763-771.

Kadanali, S., T. Kucukozkan, N. Zor, and Y. Kumtepe. 1996. "Comparison of labor induction with misoprostol vs. oxytocin/prostaglandin E2 in term pregnancy," International Journal of Gynaecology and Obstetrics 55(2): 99-104.

Khoury, A.N., Q.P. Zhou, D.M. Gorenberg, B.M. Nies, G.E. Manley, and F.E. Mecklenburg. 2001. "A comparison of intermittent vaginal administration of two different doses of misoprostol suppositories with continuous dinoprostone for cervical ripening and labor induction," Journal of Maternal-Fetal Medicine 10(3): 186-192.

Kramer, R.L., G.J. Gilson, D.S. Morrison, D. Martin, J.L. Gonzales, and C.R. Qualls. 1997. "A randomized trial of misoprostol and oxytocin for induction of labor: Safety and efficacy," Obstetrics and Gynecology 89(3): 387-391.

Kwon, J.S., G.A. Davies, and V.P. Mackenzie. 2001. “A comparison of oral and vaginal misoprostol for induction of labour at term: A randomised trial," British Journal of Obstetrics and Gynaecology 108(1): 23-26.

le Roux, P.A., J.O. Olarogun, J. Penny, and J. Anthony. 2002. "Oral and vaginal misoprostol compared with dinoprostone for induction of labor: A randomized controlled trial," Obstetrics and Gynecology 99(2): 201-205.

Ledger, W.J. 1997. “Labor induction with intravaginal misoprostol in term premature rupture of membranes: $A$ randomized study," Obstetrics and Gynecology 90(4 Pt 1): 644.

Lee, H.Y. 1997. "A randomised double-blind study of vaginal misoprostol vs dinoprostone for cervical ripening and labour induction in prolonged pregnancy," Singapore Medical Journal 38(7): 292-294.

Majoko, F., M. Zwizwai, G. Lindmark, and L. Nystrom. 2002. "Labor induction with vaginal misoprostol and extraamniotic prostaglandin F2alpha gel," International Journal of Gynaecology and Obstetrics 76(2): 127-133.

Mullin, P.M., M. House, R.H. Paul, and D.A. Wing. 2002. “A comparison of vaginally administered misoprostol with extra-amniotic saline solution infusion for cervical ripening and labor induction," American Journal of Obstetrics and Gynecology 187(4): 847-852. 
Mundle, W.R. and D.C Young. 1996. "Vaginal misoprostol for induction of labor: A randomized controlled trial," Obstetrics and Gynecology 88(4 Pt 1): 521-525.

Neiger, R. and P.C. Greaves. 2001. “Comparison between vaginal misoprostol and cervical dinoprostone for cervical ripening and labor induction," Tennessee Medicine 94(1): 25-27.

Nunes, F., R. Rodrigues, and M. Meirinho. 1999. “Randomized comparison between intravaginal misoprostol and dinoprostone for cervical ripening and induction of labor," American Journal of Obstetrics and Gynecology 181(3): 626-629.

O'Flaherty, L. 2001. “Oral misoprostol and intracervical dinoprostone for cervical ripening and labor induction: A randomized comparison," Journal of Midwifery and Women's Health 46(3): 203-204.

Ozan, H., G. Uncu, V. Yildirim, M. Omak, H.F. Kara, and M. Tufekci. 2001. "Misoprostol in labor induction," Journal of Obstetrics and Gynaecology Research 27(1): 17-20.

Ozden, S., M.N. Delikara, A. Avci, and C. Ficicioglu. 2002. “Intravaginal misoprostol vs. expectant management in premature rupture of membranes with low Bishop scores at term," International Journal of Gynaecology and Obstetrics 77(2): 109-115.

Ozgur, K., A. Kizilates, M. Uner, O. Erman, and B. Trak. 1997. "Induction of labor with intravaginal misoprostol versus intracervical dinoprostone," Archives of Gynecology and Obstetrics 261(1): 9-13.

Pajak, J., M. Tomialowicz, J. Florjanski, J. Heimrath, G. Myszczyszyn, J. Zalewski, and J. Woyton. 2001. "[Comparison of vaginal misoprostol and oxytocin for labor induction in post-term pregnancy]," Ginekologia Polska 72(12A): 1300-1304.

Pandis, G.K., A.T. Papageorghiou, C.M. Otigbah, R.J. Howard, and K.H. Nicolaides. 2001. "Randomized study of vaginal misoprostol (PGE(1)) and dinoprostone gel (PGE(2)) for induction of labor at term," Ultrasound in Obstetrics and Gynecology 18(6): 629-635.

Pongsatha, S., T. Tongsong, and T. Somsak. 2001. “A comparison between $50 \mathrm{mcg}$ oral misoprostol every 4 hours and 6 hours for labor induction: A prospective randomized controlled trial," Journal of the Medical Association of Thailand 84(7): 989-994.

Rowlands, S., R. Bell, S. Donath, S. Morrow, and B.J. Trudinger. 2001. "Misoprostol versus dinoprostone for cervical priming prior to induction of labour in term pregnancy: A randomised controlled trial," Australian and New Zealand Journal of Obstetrics and Gynaecology 41(2): 145-152.

Rozenberg, P., S. Chevret, F. Goffinet, I. Durand-Zaleski, Y. Ville, C. Vayssiere, A. Roberto, Z. Lahna, I. Nisand, C. Fisch, P. Chaumet-Riffaud, and C. Chastang. 2001. "Induction of labour with a viable infant: A randomised clinical trial comparing intravaginal misoprostol and intravaginal dinoprostone," British Journal of Obstetrics and Gynaecology 108(12): 1255-1262.
Rust, O.A., M. Greybush, R.O. Atlas, K.J. Jones, and J. Balducci. 2001. "Preinduction cervical ripening: A randomized trial of intravaginal misoprostol alone vs. a combination of transcervical Foley balloon and intravaginal misoprostol," Journal of Reproductive Medicine 46(10): 899-904.

Sahin, H.G., H.A. Sahin, and M. Kocer. 2002. “Induction of labor in toxemia with misoprostol," Acta Obstetricia et Gynecologica Scandinavica 1(3): 252-257.

Sahin, H.G., H.A. Sahin, R. Surucu, and M. Guvercinci. 2001. “A study of intravaginal misoprostol for induction of labor in toxemia of pregnancy," International Journal of Gynaecology and Obstetrics 75(1): 3-9.

Sanchez-Ramos, L., A.H. Chen, A.M. Kaunitz, F.L. Gaudier, and I. Delke. 1997. "Labor induction with intravaginal misoprostol in term premature rupture of membranes: A randomized study," Obstetrics and Gynecology 89(6): 909-912.

Sanchez-Ramos, L., C.J. Danner, I. Delke, and A.M. Kaunitz. 2002. "The effect of tablet moistening on labor induction with intravaginal misoprostol: A randomized trial," Obstetrics and Gynecology 99(6): 1080-1084.

Sanchez-Ramos, L. and A.M. Kaunitz. 1997. “Oral administration of misoprostol for labor induction: A randomized controlled trial," Obstetrics and Gynecology 90(1): 153-154.

. 2001. "Outpatient cervical ripening with intravaginal misoprostol," Obstetrics and Gynecology 97(2): 325-326.

Sanchez-Ramos, L., A.M. Kaunitz, G.O. Del Valle, I. Delke, P. Schroeder, and D.K. Briones. 1993. “Labor induction with the prostaglandin E1 methyl analogue misoprostol versus oxytocin: A randomized trial," Obstetrics and Gynecology 81(3): 332-336.

Sanchez-Ramos, L., D.E. Peterson, I. Delke, F.L. Gaudier, and A.M. Kaunitz. 1998. “Labor induction with prostaglandin E1 misoprostol compared with dinoprostone vaginal insert: A randomized trial," Obstetrics and Gynecology 91(3): 401-405.

Sciscione, A.C., L. Nguyen, J. Manley, M. Pollock, B. Maas, and G. Colmorgen. 2001. "A randomized comparison of transcervical Foley catheter to intravaginal misoprostol for preinduction cervical ripening," Obstetrics and Gynecology 97(4): 603-607.

Shetty, A., P. Danielian, and A. Templeton. 2001. “A comparison of oral and vaginal misoprostol tablets in induction of labour at term," British Journal of Obstetrics and Gynaecology 108(3): 238-243.

- 2002. "Sublingual misoprostol for the induction of labor at term," American Journal of Obstetrics and Gynecology 186(1): 72-76.

Shetty, A., L. Mackie, P. Danielian, P. Rice, and A. Templeton. 2002. "Sublingual compared with oral misoprostol in term labour induction: A randomized controlled trial," British Journal of Obstetrics and Gynaecology 109(6): 645-650. 
Shetty, A., R. Martin, P. Danielian, and A. Templeton. 2002. “A comparison of two dosage regimens of oral misoprostol for labor induction at term," Acta Obstetricia et Gynecologica Scandinavica 81(4): 337-342.

Shetty, A., K. Stewart, G. Stewart, P. Rice, P. Danielian, and A. Templeton. 2002. "Active management of term prelabour rupture of membranes with oral misoprostol," British Journal of Obstetrics and Gynaecology 109(12): 1354-1358.

Srisomboon, J., W. Piyamongkol, and P. Aiewsakul. 1997. “Comparison of intracervical and intravaginal misoprostol for cervical ripening and labour induction in patients with an unfavourable cervix," Journal of the Medical Association of Thailand 80(3): 189-194.

Srisomboon, J. and S. Pongpisuttinun. 1998. “Efficacy of intracervicovaginal misoprostol in second-trimester pregnancy termination: A comparison between live and dead fetuses," Journal of Obstetrics and Gynaecology Research 24(1): 1-5.

Stitely, M.L., J. Browning, M. Fowler, R.T. Gendron, and R.B. Gherman. 2000. “Outpatient cervical ripening with intravaginal misoprostol," Obstetrics and Gynecology 96(5 Pt 1): 684-688.

Surbek, D.V., H. Boesiger, I. Hoesli, N. Pavic, and W. Holzgreve. 1997. "A double-blind comparison of the safety and efficacy of intravaginal misoprostol and prostaglandin E2 to induce labor," American Journal of Obstetrics and Gynecology 177(5): 1018-1023.

Thulasimani, M. and S. Ramaswamy. 2000. “Comparison of oral misoprostol and oxytocin for labor induction," Obstetrics and Gynecology 95(5): 786.

Varaklis, K., R. Gumina, and P.G. Stubblefield. 1995. “Randomized controlled trial of vaginal misoprostol and intracervical prostaglandin E2 gel for induction of labor at term," Obstetrics and Gynecology 86(4 Pt 1): 541-544.

Vengalil, S.R., D.A. Guinn, N.F. Olabi, L.I. Burd, and J. Owen. 1998. "A randomized trial of misoprostol and extra-amniotic saline infusion for cervical ripening and labor induction," Obstetrics and Gynecology 91(5 Pt 1): 774-779.

Walley, R.L., J.B. Wilson, J.M. Crane, K. Matthews, E. Sawyer, and D. Hutchens. 2000. "A double-blind placebo controlled randomised trial of misoprostol and oxytocin in the management of the third stage of labour," British Journal of Obstetrics and Gynaecology 107(9): 1111-1115.

Wang, H., L. Li, and L. Pu. 1998. "[The effect of 25 micrograms misoprostol on induction of labor in late pregnancy]," Zhonghua Fu Chan Ke Za Zhi 33(8): 469-571.

Wang, L., C. Shi, and G. Yang. 1997. "[Comparison of misoprostol and ricinus oil meal for cervical ripening and labor induction]," Zhonghua Fu Chan Ke Za Zhi32(11): 666-668.

Wang, Z., W. Li, and W. Ouyang. 1997. "[Safety and efficacy of intravaginal misoprostol for cervical ripening in the third trimester of pregnancy]," Zhonghua Fu Chan Ke Za Zhi 32(6): 326-328.
Wang, Z., W. Li, W. Ouyang, Y. Ding, F. Wang, L. Xu, and X. Su. 1998. "Cervical ripening in the third trimester of pregnancy with intravaginal misoprostol: A double-blind, randomized, placebo-controlled study," Journal of Tongji Medical University 18(3): 183-186.

Wilk, M., T. Jureczko, R. Poreba, and A. Sipinski. 2001. "[Misoprostol and oxytocin in induction of labour in women with prolonged pregnancy-Safety and effectiveness comparison]," Wiadomosci Lekarskie 54(11-12): 662-667.

Wilk, M., R. Poreba, A. Sipinski, and T. Jureczko. 2000. “[The use of misoprostol preparation (Cytotec) in induction of labor at prolonged pregnancy]," Ginekologia Polska 71(4): 322-326.

Windrim, R., K. Bennett, W. Mundle, and D.C. Young. 1997. "Oral administration of misoprostol for labor induction: $A$ randomized controlled trial," Obstetrics and Gynecology 89(3): 392-397.

Wing, D.A., D. Ham, and R.H. Paul. 1999. "A comparison of orally administered misoprostol with vaginally administered misoprostol for cervical ripening and labor induction," American Journal of Obstetrics and Gynecology 180(5): 1155-1160.

Wing, D.A., M.M. Jones, A. Rahall, T.M. Goodwin, and R.H. Paul. 1995. "A comparison of misoprostol and prostaglandin E2 gel for preinduction cervical ripening and labor induction," American Journal of Obstetrics and Gynecology 172(6): 1804-1810.

Wing, D.A., G. Ortiz-Omphroy, and R.H. Paul. 1997. “A comparison of intermittent vaginal administration of misoprostol with continuous dinoprostone for cervical ripening and labor induction," American Journal of Obstetrics and Gynecology 177(3): 612-618.

Wing, D.A., M.R. Park, and R.H. Paul. 2000. "A randomized comparison of oral and intravaginal misoprostol for labor induction," Obstetrics and Gynecology 95(6 Pt 1): 905-908.

Wing, D.A. and R.H. Paul. 1996. "A comparison of differing dosing regimens of vaginally administered misoprostol for preinduction cervical ripening and labor induction," American Journal of Obstetrics and Gynecology 175(1): 158-164.

. 1998. "Induction of labor with misoprostol for premature rupture of membranes beyond thirty-six weeks' gestation," American Journal of Obstetrics and Gynecology 179(1): 94-99.

Wing, D.A., S. Tran, and R.H. Paul. 2002. “Factors affecting the likelihood of successful induction after intravaginal misoprostol application for cervical ripening and labor induction," American Journal of Obstetrics and Gynecology 186(6): 1237-1240; discussion 1240-1243.

\section{Review}

Alfirevic, Z. 2000. "Oral misoprostol for induction of labor," Cochrane Database of Systematic Reviews (4): CD001338. 
Alfirevic, Z., G. Howarth, and A. Gaussmann. 2000. "Oral misoprostol for induction of labour with a viable fetus," Cochrane Database of Systematic Reviews (2): CD001338.

Apgar, B.S. 1999. “Current trends in cervical ripening and labor induction," American Family Physician 60(2): 418-420.

Bauer, T.A., D.L. Brown, and L.K. Chai. 1997. “Vaginal misoprostol for term labor induction," Annals of Pharmacotherapy 31(11): 1391-1393.

Boulvain, M., A. Kelly, C. Lohse, C. Stan, and O. Irion. 2001. "Mechanical methods for induction of labour," Cochrane Database of Systematic Reviews (4): CD001233.

Brennand, J. and I. Greer. 1998. "Induction of labor: New horizons," Hospital Medicine 59(11): 856-860.

Bugnon, A., A.E. Paniagua, G. Postiglione, and J.L. Lardizabal. 1994. "[Induction of labor with misoprostol]," Ginecología y Obstetricia de México 62: 407-414.

Crane, J.M. and K.A. Bennett. 2000. "A meta-analysis of controlled-release prostaglandin for cervical ripening and labour induction," Journal of the Society of Obstetricians and Gynaecologists of Canada 22(9): 692-698.

el-Refaey, H. and E. Jauniaux. 1997. "Methods of induction of labour," Current Opinion in Obstetrics and Gynecology 9(6): 375-378.

Enoch, J. 1999. “Misoprostol (Cytotec): A new method of inducing labor," Midwifery Today with International Midwife Spring(49): 22-30.

Fletcher, H. and S. Hutchinson. 2001. "A retrospective review of pregnancy outcome after misoprostol (prostaglandin E1) induction of labour," West Indian Medical Journal 50(1): 47-49.

Harman, J.H. and A. Kim. 1999. “Current trends in cervical ripening and labor induction," American Family Physician 60(2): 477-484.

Hofmeyr, G.J. and A.M. Gulmezoglu. 1999. “Vaginal misoprostol for cervical ripening and labour induction in late pregnancy," Birth 26(4): 264.

- 2000. "Vaginal misoprostol for cervical ripening and labour induction in late pregnancy," Cochrane Database of Systematic Reviews (2): CD000941.

_. 2001. "Vaginal misoprostol for cervical ripening and induction of labour," Cochrane Database of Systematic Reviews (3): CD000941.

Hofmeyr, G.J, A.M. Gulmezoglu, and Z. Alfirevic. 1999. "Misoprostol for induction of labour: A systematic review," British Journal of Obstetrics and Gynaecology 106(8): 798-803.

Kelly, A.J., J. Kavanagh, and J. Thomas. 2001. “Vaginal prostaglandin (PGE2 and PGF2a) for induction of labour at term," Cochrane Database of Systematic Reviews (2): CD003101.

Leszczynska-Gorzelak, B., M. Laskowska, and J. Oleszczuk. 2001. “Comparative analysis of the effectiveness of misoprostol and prostaglandin $\mathrm{E}(2)$ in the preinduction and induction of labor," Medical Science Monitor 7(5): 1023-1028.

Rayburn, W.F. 2002. “Preinduction cervical ripening: Basis and methods of current practice," Obstetrical and Gynecological Survey 57(10): 683-692.

Reichler, A., Y. Romem, and M.Y. Divon. 1995. “Induction of labor," Current Opinion in Obstetrics and Gynecology 7(6): 432-426.

Sanchez-Ramos, L. and A.M. Kaunitz. 2000. “Misoprostol for cervical ripening and labor induction: A systematic review of the literature," Clinical Obstetrics and Gynecology 43(3): 475-488.

Sanchez-Ramos, L., A.M. Kaunitz, and I. Delke. 2002. “Labor induction with 25 microg versus 50 microg intravaginal misoprostol: A systematic review," Obstetrics and Gynecology 99(1): 145-151.

Sanchez-Ramos, L., A.M. Kaunitz, R.L. Wears, I. Delke, and F.L. Gaudier. 1997. "Misoprostol for cervical ripening and labor induction: A meta-analysis," Obstetrics and Gynecology 89(4): 633-642.

Summers, L. 1997. "Methods of cervical ripening and labor induction," Journal of Nurse-Midwifery 42(2): 71-85.

Wing, D.A. 1999. "Labor induction with misoprostol," American Journal of Obstetrics and Gynecology 181(2): 339-345.

2002. "A benefit-risk assessment of misoprostol for cervical ripening and labour induction," Drug Safety 25(9): 665-676.

\section{Other}

ACOG Committee on Obstetrics. 1995. Induction of Labor, American College of Obstetricians and Gynecologists Technical Bulletin no. 217. Washington, DC: American College of Obstetricians and Gynecologists.

Akhan, S.E., A.C. Iyibozkurt, and A. Turfanda. 2001. “Unscarred uterine rupture after induction of labor with misoprostol: A case report," Clinical and Experimental Obstetrics and Gynecology 28(2): 118-120.

Akhan, S.E., A. Yidirim, A.C. lyibozkurt, and A. Turfanda. 2000. "The evaluation of misoprostol-related tachysystole in normal and high risk pregnancies," Clinical and Experimental Obstetrics and Gynecology 27(3-4): 207-211.

Bennett, B.B. 1997. “Uterine rupture during induction of labor at term with intravaginal misoprostol," Obstetrics and Gynecology 89(5 Pt 2): 832-833.

Bique, C., A. Bugalho, and S. Bergstrom. 1999. "Labor induction by vaginal misoprostol in grand multiparous women," Acta Obstetricia et Gynecologica Scandinavica 78(3): 198-201.

Chao, A., Y.Y. El-Sayed, and A.M. Sapugay. 2002. “Does nifedipine prevent the tachysystole associated with misoprostol induction?" Journal of Maternal-Fetal and Neonatal Medicine 11(4): 266-269. 
Crane, J.M., D.C. Young, K.D. Butt, K.A. Bennett, and D. Hutchens. 2001. "Excessive uterine activity accompanying induced labor," Obstetrics and Gynecology 97(6): 926-931.

Cunha, M., A. Bugalho, C. Bique, and S. Bergstrom. 1999. "Induction of labor by vaginal misoprostol in patients with previous cesarean delivery," Acta Obstetricia et Gynecologica Scandinavica 78(7): 653-654.

Danielian, P., B. Porter, N. Ferri, J. Summers, and A. Templeton. 1999. "Misoprostol for induction of labor at term: A more effective agent than dinoprostone vaginal gel," British Journal of Obstetrics and Gynaecology 106(8): 793-797.

Day, L., A. Tailor, R. Howard, and S. Burrell. 2000. “Misoprostol for induction of labor at term," British Journal of Obstetrics and Gynaecology 107(4): 576-577.

Del Valle, G.O., L. Sanchez-Ramos, C. Jordan, F.L. Gaudier, and I. Delke. 1996. “Use of misoprostol (prostaglandin E1 methyl analog) to expedite delivery in severe preeclampsia remote from term," Journal of Maternal-Fetal Medicine 5(1): 39-40.

Ferroni, K.M. 1997. “Induction of labor: A clinician's viewpoint," Annals of Pharmacotherapy 31(11): 1401-1402.

Fletcher, H., S. Mitchell, J. Frederick, D. Simeon, and D. Brown. 1994. "Intravaginal misoprostol versus dinoprostone as cervical ripening and labor-inducing agents," Obstetrics and Gynecology 83(2): 244-247.

Flynn, C.A. 1997. “Intravaginal misoprostol: A new option for labor induction?" Journal of Family Practice 44(1): 31.

Gherman, R.B., S. McBrayer, and J. Browning. 2000. “Uterine rupture associated with vaginal birth after cesarean section: A complication of intravaginal misoprostol?" Gynecologic and Obstetric Investigation 50(3): 212-213.

Goer, H. 2000. "Misoprostol and uterine rupture," Birth 27(3): 224-225.

Goffinet, F., R. Humbert, P. Clerson, H.J. Philippe, G. Breart, and D. Cabrol. "[National survey on the use of induced labor by obstetricians: Study Group on Induced Labor]," Journal de Gynécologie Obstétrique et Biologie de la Reproduction 28(4): 319-329.

Gonzalez Pena, J.C. 1996. "Misoprostol for induction of labor," American Journal of Obstetrics and Gynecology 174(2): 797.

Greybush, M., C. Singleton, R.O. Atlas, J. Balducci, and O.A. Rust. 2001. "Preinduction cervical ripening techniques compared," Journal of Reproductive Medicine 46(1): 11-17.

Griggs, B.C., S.J. Carlan, and D.L. Blust. 2000. “The effect of maternal weight on efficacy of intravaginal misoprostol for cervical ripening," Obstetrics and Gynecology 95(4 Suppl 1): S70.

Gunalp, S. and I. Bildirici. 2000. “The effect of vaginal pH on the efficacy of vaginal misoprostol for induction of labor," Acta Obstetricia et Gynecologica Scandinavica 79(4): 283-285.

Hill, D.A., R.A. Chez, J. Quinlan, A. Fuentes, and J. LaCombe. 2000. “Uterine rupture and dehiscence associated with intravaginal misoprostol cervical ripening," Journal of Reproductive Medicine 45(10): 823-826.

Hofmeyr, G.J., B.B. Matonhodze, Z. Alfirevic, E. Campbell, M. de Jager, and C. Nikodem. 2001. "Titrated oral misoprostol solution-A new method of labour induction," South African Medical Journal 91(9): 775-776.

Howarth, G.R., L. Pistorius, G. Mantel, M. Funk, and R.C. Pattinson. 1996. "Induction of labour at termMisoprostol, efficacy, economics and ethics," South African Medical Journal 86(9 Suppl): 1174, 1176.

Hsieh, Y.Y., H.D. Tsai, C.C. Chang, L.S. Yeh, T.C. Yang, and T.Y. Hsu. 2000. "Precipitate delivery and postpartum hemorrhage after term induction with 200 micrograms misoprostol," Zhonghua Yi Xue Za Zhi 63(1): 58-61.

Humphrey, R.G., S.J. Carlan, and T.D. O'Leary. 2000. "Misoprostol for cervical ripening in patients with previous cesarean delivery," Obstetrics and Gynecology 95(4 Suppl 1): S70.

Incerpi, M.H., M.J. Fassett, S.L. Kjos, S.H. Tran, and D.A. Wing. 2001. “Vaginally administered misoprostol for outpatient cervical ripening in pregnancies complicated by diabetes mellitus," American Journal of Obstetrics and Gynecology 185(4): 916-919.

Katz, V.L., R.M. Farmer, C.A. Dean, and M.E. Carpenter. 2000. "Use of misoprostol for cervical ripening," Southern Medical Journal 93(9): 881-884.

Khabbaz, A.Y., I.M. Usta, M.I. El-Hajj, A. Abu-Musa, M. Seoud, and A.H. Nassar. 2001. "Rupture of an unscarred uterus with misoprostol induction: Case report and review of the literature," Journal of Maternal-Fetal Medicine 10(2): 141-145.

Khosla, A.H., D. Sirohiwal, and K. Sangwan. 2002. “A still birth and uterine rupture during induction of labour with oral misoprostol," Australian and New Zealand Journal of Obstetrics and Gynaecology 42(4): 412.

Kolderup, L., L. McLean, K. Grullon, K. Safford, and S.J. Kilpatrick. 1999. "Misoprostol is more efficacious for labor induction than prostaglandin E2, but is it associated with more risk?" American Journal of Obstetrics and Gynecology 180(6 Pt 1): 1543-1550.

Lemancewicz, A., R. Urban, M.Z. Skotnicki, A. Karpiuk, and J. Urban. 1999. "Uterine and fetal Doppler flow changes after misoprostol and oxytocin therapy for induction of labor in post-term pregnancies," International Journal of Gynaecology and Obstetrics 67(3): 139-145.

Leszczynska-Gorzelak, B., M. Laskowska, and J. Oleszczuk. 1999. "[Use of misoprostol for preinduction and induction of labor in term pregnancy]," Ginekologia Polska 70(12): 881-889.

Letourneur, B., O. Parant, V. Tofani, and A. Berrebi. 2002. "[Uterine rupture on unscarred uterus following labor induction for 2(nd) trimester termination of pregnancy with oral misoprostol: Conservative management]," Journal de Gynécologie Obstétrique et Biologie de la Reproduction 31(4): $371-373$ 
Li, L., W. Gao, and S. Chen. 1996. "[Labour induction in women at term with mifepristone and misoprostol]," Zhonghua Fu Chan Ke Za Zhi 31(11): 681-684.

Liu, H.S., T.Y. Chu, Y.K. Chang, M.H. Yu, and W.H. Chen. 1999. "Intracervical misoprostol as an effective method of labor induction at term," International Journal of Gynaecology and Obstetrics 64(1): 49-53.

Matonhodze, B.B., L.C. Katsoulis, and G.J. Hofmeyr. 2002. "Labor induction and meconium: In vitro effects of oxytocin, dinoprostone and misoprostol on rat ileum relative to myometrium," Journal of Perinatal Medicine 30(5): 405-410.

Patel, A., J.M. Gilles, D. Moffett, R. Mahram, M. Diro, and G. Burkett. 2000. “Can misoprostol be interchanged with oxytocin for augmentation of labor?" Obstetrics and Gynecology 95(4 Suppl 1): S10.

Pavlista, D. and P. Krepelka. “[Misoprostol—A new prostaglandin for induction of labor?]" Ceska Gynekologie 62(5): 312-313.

Plaut, M.M., M.L. Schwartz, and S.L. Lubarsky. 1999. “Uterine rupture associated with the use of misoprostol in the gravid patient with a previous cesarean section," American Journal of Obstetrics and Gynecology 180(6 Pt 1): $1535-1542$.

Raio, L., F. Ghezzi, E. Di Naro, H. Bruhwiler, and K.P. Luscher 2001. "[Shorter delivery time after induction with misoprostol]," Zeitschrift für Geburtshilfe und Neonatologie 205(4): 147-151.

Ramsey, P.S., D.Y. Harris, P.L. Ogburn, R.H. Heise, P.M. Magtibay, and K.D. Ramin. 1998. "Comparative cost analysis of prostaglandin analogues dinoprostone and misoprostol as labor preinduction agents," Primary Care Update for Ob/Gyns 5(4): 182.

Rodrigues, R., F. Nunes, D. Tiago, T. Avillez, A. Vieira, and M. Meirinho. 1998. "Induction of labor with intravaginal administration of misoprostol," International Journal of Gynaecology and Obstetrics 60(3): 233-237.

Sanchez-Ramos, L. and I. Delke. 1999. "Induction of labor with misoprostol for premature rupture of membranes beyond thirty-six weeks' gestation," American Journal of Obstetrics and Gynecology 180(1 Pt 1): 253-254.

Sanchez-Ramos, L. and A.M. Kaunitz. 1994. “Intravaginal misoprostol versus dinoprostone as cervical ripening and labor-inducing agents," Obstetrics and Gynecology 83(5 Pt 1): 799-801.

_. 2000. "Perinatal morbidity associated with misoprostol-induced labor," American Journal of Obstetrics and Gynecology 182(3): 749-750.

. 2000. "Uterine rupture associated with the use of prostaglandin E1 in patients with previous cesarean delivery," American Journal of Obstetrics and Gynecology 182(4): 990-991.

Sciscione, A.C., L. Nguyen, J.S. Manley, P.A. Shlossman, and G.H. Colmorgen. 1998. "Uterine rupture during preinduction cervical ripening with misoprostol in a patient with a previ- ous caesarean delivery," Australian and New Zealand Journal of Obstetrics and Gynaecology 38(1): 96-97.

Toppozada, M.K., M.Y. Anwar, H.A. Hassan, and W.S. elGazaerly. 1997. “Oral or vaginal misoprostol for induction of labor," International Journal of Gynaecology and Obstetrics 56(2): 135-139.

Votipka, J.R. 1997. “Misoprostol for cervical ripening and labor induction," Journal of Family Practice 45(1): 20.

Wagner, M. 1999. “Misoprostol (Cytotec) for labor induction: A cautionary tale," Midwifery Today with International Midwife Spring(49): 31-33.

Wilson, C. 2000. "The nurse's role in misoprostol induction: A proposed protocol," Journal of Obstetric, Gynecologic, and Neonatal Nursing 29(6): 574-583.

Wing, D.A., K. Lovett, and R.H. Paul. 1998. “Disruption of prior uterine incision following misoprostol for labor induction in women with previous cesarean delivery," Obstetrics and Gynecology 91(5 Pt 2): 828-830.

Wing, D.A., A. Rahall, M.M. Jones, T.M. Goodwin, and R.H. Paul. 1995. "Misoprostol: An effective agent for cervical ripening and labor induction," American Journal of Obstetrics and Gynecology 172(6): 1811-1816.

Yulzari-Roll, V., M. Hod, and J. Bar. 2002. “[New developments in labor induction]," Harefuah 141(4): 369-373, 408.

\section{Postpartum Hemorrhage}

\section{Clinical trials}

Abdel-Aleem, H., I. El-Nashar, and A. Abdel-Aleem. 2001. "Management of severe postpartum hemorrhage with misoprostol," International Journal of Gynaecology and Obstetrics 72(1): 75-76.

Acharya, G., M.T. Al-Sammarai, N. Patel, A. Al-Habib, and T. Kiserud. 2001. “A randomized, controlled trial comparing effect of oral misoprostol and intravenous syntocinon on intra-operative blood loss during cesarean section," Acta Obstetricia et Gynecologica Scandinavica 80(3): 245-250.

Adekanmi, 0.A., S. Purmessur, G. Edwards, and J.W. Barrington. 2001. "Intrauterine misoprostol for the treatment of severe recurrent atonic secondary postpartum haemorrhage," British Journal of Obstetrics and Gynaecology 108(5): 541-542.

Amant, F. 2001. “The misoprostol third stage study: A randomised controlled comparison between orally administered misoprostol and standard management-A doubleblind placebo controlled randomised trial of misoprostol and oxytocin in the management of the third stage labour," British Journal of Obstetrics and Gynaecology 108(3): 338.

Amant, F., B. Spitz, D. Timmerman, A. Corremans, and F.A. Van Assche. 1999. “Misoprostol compared with methylergometrine for the prevention of postpartum hemorrhage: A double blind randomised trial," British Journal of Obstetrics and Gynaecology 106(10): 1066-1070. 
Bamigboye, A.A., G.J. Hofmeyr, and D.A. Merrell. 1998. “Rectal misoprostol in the prevention of postpartum hemorrhage: A placebo-controlled trial," American Journal of Obstetrics and Gynecology 179(4): 1043-1046.

Bamigboye, A.A., D.A. Merrell, G.J. Hofmeyr, and R. Mitchell. 1998. "Randomized comparison of rectal misoprostol with syntometrine for management of third stage of labor," Acta Obstetricia et Gynecologica Scandinavica 77(2): 178-181.

Bugalho, A., A. Daniel, A. Faundes, and M. Cunha. 2001. “Misoprostol for prevention of postpartum hemorrhage," International Journal of Gynaecology and Obstetrics 73(1): 1-6.

Caliskan, E., M.M. Meydanli, B. Dilbaz, B. Aykan, M. Sonmezer, and A. Haberal. 2002. "Is rectal misoprostol really effective in the treatment of third stage of labor? A randomized controlled trial," American Journal of Obstetrics and Gynecology 187(4): 1038-1045.

Cook, C.M., B. Spurrett, and H. Murray. 1999. "A randomized clinical trial comparing oral misoprostol with synthetic oxytocin or syntometrine in the third stage of labor," Australian and New Zealand Journal of Obstetrics and Gynaecology 39(4): 414-419.

Diab, K.M., A.R. Ramy, and M.A. Yehia. 1999. “The use of rectal misoprostol as active pharmacological management of the third stage of labor," Journal of Obstetrics and Gynaecology Research 25(5): 327-332.

el-Refaey, H., R. Nooh, P. O'Brien, M. Abdalla, M. Geary, J. Walder, and C. Rodeck. 2000. “The misoprostol third stage of labour study: A randomised controlled comparison between orally administered misoprostol and standard management," British Journal of Obstetrics and Gynaecology 107(9): 1104-1110.

el-Refaey, H., P. O'Brien, W. Morafa, J. Walder, and C. Rodeck. 1997. "Use of oral misoprostol in the prevention of postpartum haemorrhage," British Journal of Obstetrics and Gynaecology 104(3): 336-339.

Gerstenfeld, T.S. and D.A. Wing. 2001. “Rectal misoprostol versus intravenous oxytocin for the prevention of postpartum hemorrhage after vaginal delivery," American Journal of Obstetrics and Gynecology 185(4): 878-882.

Gulmezoglu, A.M., J. Villar, N.T. Ngoc, G. Piaggio, G. Carroli, L. Adetoro, H. Abdel-Aleem, L. Cheng, G. Hofmeyr, P. Lumbiganon, C. Unger, W. Prendiville, A. Pinol, D. Elbourne, H. el-Refaey, and K. Schulz. 2001. “WHO multicentre randomised trial of misoprostol in the management of the third stage of labour," Lancet 358(9283): 689-695.

Hofmeyr, G.J., V.C. Nikodem, M. de Jager, and A. Drakely. 2001. "Side-effects of oral misoprostol in the third stage of labour-A randomized placebo-controlled trial," South African Medical Journal 91(5): 432-435.

Hofmeyr, G.J., V.C. Nikodem, M. de Jager, and B.R. Gelbart. 1998. "A randomised placebo controlled trial of oral misoprostol in the third stage of labor," British Journal of Obstetrics and Gynaecology 105(9): 971-975.
Karkanis, S.G., D. Caloia, M.E. Salenieks, J. Kingdom, M. Walker, F. Meffe, and R. Windrim. 2002. "Randomized controlled trial of rectal misoprostol versus oxytocin in third stage management," Journal of Obstetrics and Gynaecology Canada 24(2): 149-154.

Kundodyiwa, T.W., F. Majoko, and S. Rusakaniko. 2001. “Misoprostol versus oxytocin in the third stage of labor," International Journal of Gynaecology and Obstetrics 75(3): 235-241.

Lokugamage, A.U., M. Paine, K. Bassaw-Balroop, K.R. Sullivan, H. el-Refaey, and C.H. Rodeck. 2001. "Active management of the third stage at caesarean section: A randomized controlled trial of misoprostol versus syntocinon," Australian and New Zealand Journal of Obstetrics and Gynaecology 41(4): 411-414.

Lokugamage, A.U., K.R. Sullivan, I. Niculescu, P. Tigere, F. Onyangunga, H. el-Refaey, J. Moodley, and C.H. Rodeck. 2001. "A randomized study comparing rectally administered misoprostol versus syntometrine combined with an oxytocin infusion for the cessation of primary post partum hemorrhage," Acta Obstetricia et Gynecologica Scandinavica 80(9): 835-839.

Lumbiganon, P., J. Hofmeyr, A.M. Gulmezoglu, A. Pinol, and J. Villar. 1999. “Misoprostol dose-related shivering and pyrexia in the third stage of labour: WHO Collaborative Trial of Misoprostol in the Management of the Third Stage of Labour," British Journal of Obstetrics and Gynaecology 106(4): 304-308.

Lumbiganon, P., J. Villar, G. Piaggio, A.M. Gulmezoglu, L. Adetoro, and G. Carroli. 2002. "Side effects of oral misoprostol during the first 24 hours after administration in the third stage of labour," British Journal of Obstetrics and Gynaecology 109(11): 1222-1226.

Ng, P.S., A.S. Chan, W.K. Sin, L.C. Tang, K.B. Cheung, and P.M. Yuen. 2001. "A multicentre randomized controlled trial of oral misoprostol and I.M. syntometrine in the management of the third stage of labour," Human Reproduction 16(1): 31-35.

O'Brien, P., H. el-Refaey, A. Gordon, M. Geary, and C.H. Rodeck. 1998. "Rectally administered misoprostol for the treatment of postpartum hemorrhage unresponsive to oxytocin and ergometrine: A descriptive study," Obstetrics and Gynecology 92(2): 212-214.

Olufowobi, 0., M. Afnan, 0. Sorinola, S. Papaioannou, and K. Sharif. 2002. "A randomized study comparing rectally administered misoprostol versus syntometrine combined with an oxytocin infusion for the cessation of primary postpartum hemorrhage," Acta Obstetricia et Gynecologica Scandinavica 81(10): 993; discussion 994.

Ramsey, P.S. and K.D. Ramin. 1999. “Rectally administered misoprostol for the treatment of postpartum hemorrhage unresponsive to oxytocin and ergometrine: A descriptive study," Obstetrics and Gynecology 93(1): 157-158.

Ramsey, P.S., K.D. Ramin, and S.S. Bradley. 1999. "Rectal misoprostol in the prevention of postpartum hemorrhage," American Journal of Obstetrics and Gynecology 180(6 Pt 1): 1601-1602. 
Shojai, R., L. Piechon, C. d'Ercole, L. Boubli, and J.E. Ponties. 2001 "[Rectal administration of misoprostol for delivery induced hemorrhage: Preliminary study]," Journal de Gynécologie Obstétrique et Biologie de la Reproduction 30(6): 572-575.

Surbek, D.V., P.M. Fehr, I. Hosli, and W. Holzgreve. 1999. “Oral misoprostol for third stage of labor: A randomized placebocontrolled trial," Obstetrics and Gynecology 94(2): 255-258.

Walley, R.L., J.B. Wilson, J.M. Crane, K. Matthews, E. Sawyer, and D. Hutchens. 2000. "A double-blind placebo controlled randomised trial of misoprostol and oxytocin in the management of the third stage of labor," British Journal of Obstetrics and Gynaecology 107(9): 1111-1115.

\section{Review}

Gulmezoglu, A.M. 2000. "Prostaglandins for prevention of postpartum hemorrhage," Cochrane Database of Systematic Reviews (2): CD000494.

Gulmezoglu, A.M., F. Forna, J. Villar, and G.J. Hofmeyr. 2002. "Prostaglandins for prevention of postpartum haemorrhage," Cochrane Database of Systematic Reviews (3): CD000494.

Mategrano, V.A. and M.P. Gabay. 2001. "Misoprostol in the prevention of postpartum hemorrhage," Annals of Pharmacotherapy 35(12): 1648-1652.

McCormick, M.L., H.C. Sanghvi, B. Kinzie, and N. McIntosh. 2002. "Preventing postpartum hemorrhage in lowresource settings," International Journal of Gynaecology and Obstetrics 77(3): 267-275.

Villar, J., A.M. Gulmezoglu, G.J. Hofmeyr, and F. Forna. 2002. "Systematic review of randomized controlled trials of misoprostol to prevent postpartum hemorrhage," Obstetrics and Gynecology 100(6): 1301-1312.

\section{Other}

Chong, Y.S., S. Chua, H. el-Refaey, W.L. Choo, B. Chanrachakul, B.C. Tai, C. Rodeck, and S. Arulkumaran. 2001.

"Postpartum intrauterine pressure studies of the uterotonic effect of oral misoprostol and intramuscular syntometrine," British Journal of Obstetrics and Gynaecology 108(1): 41-47.

el-Refaey, H. 2002. "Use of misoprostol in third stage of labour," Lancet 359(9307): 707-708; discussion 709-710.

el-Refaey, H., P. O'Brien, W. Morafa, J. Walder, and C. Rodeck. 1996. "Misoprostol for third stage of labor," Lancet 347(9010): 1257.

Khan, R. and S. Sharma. 2002. "Use of misoprostol in third stage of labour," Lancet 359(9307): 708-709; discussion 709-710.

Li, Y.T., C.S. Yin, and F.M. Chen. 2001. "Rectal administration of misoprostol for the management of retained placenta- $A$ preliminary report," Zhonghua Yi Xue Za Zhi64(12): 721-724.

O'Brien, P., A.U. Lokugamage, J. Guillebaud, and C.H. Rodeck. 2002. "Use of misoprostol in third stage of labour," Lancet 359(9307): 708; discussion 709-710.
Ozan, H., T. Bilgin, N. Ozsarac, R.K. Ozerkan, and C. Cengiz. 2000. "Misoprostol in uterine atony: A report of 2 cases," Clinical and Experimental Obstetrics and Gynecology 27(3-4): 221-222.

Shannon, C. and B. Winikoff. 2002. "Use of misoprostol in third stage of labour," Lancet 359(9307): 709; discussion 709-710.

Walder, J. 1997. “Misoprostol: Preventing postpartum hemorrhage," Modern Midwife 7(9): 23-27.

Zhao, Y., X. Li, and Y. Peng. 1998. "[Clinical study on reduction of postpartum bleeding in cesarean section by misoprostol]," Zhonghua Fu Chan Ke Za Zhi 33(7): 403-405.

\section{Cervical Ripening for Obstetric and Gynecological Procedures}

\section{Surgical abortion-clinical trials}

Ashok, P.W., G.M. Flett, and A. Templeton. 2000. “Mifepristone versus vaginally administered misoprostol for cervical priming before first-trimester termination of pregnancy: A randomized, controlled study," American Journal of Obstetrics and Gynecology 183(4): 998-1002.

Bokstrom, H., P. Atterfelt, M. Alexandersson, M. Brannstrom, and A. Norstrom. 1998. "Preoperative cervical softening before first trimester legal abortion by mifepristone and misoprostol: A double-blind, randomized, clinical biochemical and immunohistochemical study," Contraception 58(3): 157-163.

Bugalho, A., C. Bique, L. Almeida, and S. Bergstrom. 1994 "Application of vaginal misoprostol before cervical dilatation to facilitate first-trimester pregnancy interruption," Obstetrics and Gynecology 83(5 Pt 1): 729-731.

Carbonell, J.L., A. Velazco, Y. Rodriguez, R. Tanda, C. Sanchez, S. Barambio, L. Valera, S. Chami, F. Valero, S. Aragon, and J. Mari. 2001. “Oral versus vaginal misoprostol for cervical priming in first-trimester abortion: A randomized trial," European Journal of Contraception and Reproductive Health Care 6(3): 134-140.

Carlan, S.J., D. Blust, and W.F. O'Brien. 2002. “Buccal versus intravaginal misoprostol administration for cervical ripening," American Journal of Obstetrics and Gynecology 186(2): 229-233.

de Jonge, E.T., R. Jewkes, J. Levin, and H. Rees. 2000. “Randomised controlled trial of the efficacy of misoprostol used as a cervical ripening agent prior to termination of pregnancy in the first trimester," South African Medical Journal 90(3): 256-262.

Edwards, D., R.E. Aitken, A.F. Begg, P.M. MacKay, and R.M. Marchant. 1994. "Predilatation of the cervix before suction curettage for therapeutic abortion in early pregnancy," Australian and New Zealand Journal of Obstetrics and Gynaecology 34(1): 103-104.

Fong, Y.F., K. Singh, and R.N. Prasad. 1998. "A comparative study using two dose regimens (200 microg or 400 microg) of vaginal misoprostol for pre-operative cervical dilatation 
in first trimester nulliparae," British Journal of Obstetrics and Gynaecology 105(4): 413-417.

Henry, A.M. and M. Haukkamaa. 1999. “Comparison of vaginal misoprostol and gemeprost as pre-treatment in first trimester pregnancy interruption," British Journal of Obstetrics and Gynaecology 106(6): 540-543.

Lawrie, A., G. Penney, and A. Templeton. 1996. "A randomized comparison of oral and vaginal misoprostol for cervical priming before suction termination of pregnancy," British Journal of Obstetrics and Gynaecology 103(11): 1117-1119.

Ledingham, M.A., A.J. Thomson, C.B. Lunan, I.A. Greer, and J.E. Norman. 2001. "A comparison of isosorbide mononitrate, misoprostol and combination therapy for first trimester pre-operative cervical ripening: A randomised controlled trial," British Journal of Obstetrics and Gynaecology 108(3): 276-280.

Maclsaac, L., D. Grossman, E. Balistreri, and P. Darney. 1999. "A randomized controlled trial of laminaria, oral misoprostol, and vaginal misoprostol before abortion," Obstetrics and Gynecology 93(5 Pt 1): 766-770.

Morgan, M. and H. Stokes. 2000. “Comparison of vaginal misoprostol and gemeprost as pre-treatment in first trimester pregnancy interruption," British Journal of Obstetrics and Gynaecology 107(1): 145-146.

Ngai, S.W., Y.M. Chan, O.S. Tang, and P.C. Ho. 1999. “The use of misoprostol for pre-operative cervical dilatation prior to vacuum aspiration: A randomized trial," Human Reproduction 14(8): 2139-2142.

Ngai, S.W., O.S. Tang, T. Lao, P.C. Ho, and H.K. Ma. 1995. “Oral misoprostol versus placebo for cervical dilatation before vacuum aspiration in first trimester pregnancy," Human Reproduction 10(5): 1220-1222.

Ngai, S.W., K.C. Yeung, T. Lao, and P.C. Ho. 1995. “Oral misoprostol versus vaginal gemeprost for cervical dilatation prior to vacuum aspiration in women in the sixth to twelfth week of gestation," Contraception 51(6): 347-350.

1996. “Oral misoprostol versus mifepristone for cervical dilatation before vacuum aspiration in first trimester nulliparous pregnancy: A double blind prospective randomised study," British Journal of Obstetrics and Gynaecology 103(11): 1120-1123.

Okanlomo, K.A., D. Ngotho, and J. Moodley. 1999. “Effect of misoprostol for cervical ripening prior to pregnancy interruption before twelve weeks of gestation," East African Medical Journal 76(10): 552-555.

Singh, K., Y.F. Fong, R.N. Prasad, and F. Dong. 1998. “Randomized trial to determine optimal dose of vaginal misoprostol for preabortion cervical priming," Obstetrics and Gynecology 92(5): 795-798.

- 1999. "Evacuation interval after vaginal misoprostol for preabortion cervical priming: A randomized trial," Obstetrics and Gynecology 94(3): 431-434.
1999. “Vaginal misoprostol for pre-abortion cervical priming: Is there an optimal evacuation time interval?" British Journal of Obstetrics and Gynaecology 106(3): 266-269.

Sparrow, M.J., J.D. Tait, and P.R. Stone. 1998. “Vaginal dinoprostone versus oral misoprostol for predilatation of the cervix in first trimester surgical abortion," Australian and New Zealand Journal of Obstetrics and Gynaecology 38(1): 64-68.

Sperling, A.L. 1999. “A randomized controlled trial of laminaria, oral misoprostol, and vaginal misoprostol before abortion," Obstetrics and Gynecology 94(4): 637.

Stitely, M.L., J. Browning, M. Fowler, R.T. Gendron, and R.B. Gherman. 2000. “Outpatient cervical ripening with intravaginal misoprostol," Obstetrics and Gynecology 96(5 Pt 1): 684-688.

Wiebe, E.R. and M.J. Rawling. 1998. “Vaginal misoprostol before first trimester abortion," International Journal of Gynaecology and Obstetrics 60(2): 175-176.

\section{Hysteroscopy and other gynecological procedures-clinical trials}

Fung, T.M., M.H. Lam, S.F. Wong, and L.C. Ho. 2002. “A randomised placebo-controlled trial of vaginal misoprostol for cervical priming before hysteroscopy in postmenopausal women," British Journal of Obstetrics and Gynaecology 109(5): 561-565.

Ngai, S.W., Y.M. Chan, and P.C. Ho. 2001. “The use of misoprostol prior to hysteroscopy in postmenopausal women," Human Reproduction 16(7): 1486-1488.

Ngai, S.W., Y.M. Chan, K.L. Liu, and P.C. Ho. 1997. “Oral misoprostol for cervical priming in non-pregnant women," Human Reproduction 12(11): 2373-2375.

Preutthipan, S. and Y. Herabutya. 1999. "A randomized controlled trial of vaginal misoprostol for cervical priming before hysteroscopy," Obstetrics and Gynecology 94(3): 427-430.

. 2000. "Vaginal misoprostol for cervical priming before operative hysteroscopy: A randomized controlled trial," Obstetrics and Gynecology 96(6): 890-894.

Scott, P. and A. Magos. 2001. “Vaginal misoprostol for cervical priming before operative hysteroscopy: A randomized controlled trial," Obstetrics and Gynecology 97(4): 640-641.

Thomas, J.A., N. Leyland, N. Durand, and R.C. Windrim. 2002. “The use of oral misoprostol as a cervical ripening agent in operative hysteroscopy: A double-blind, placebo-controlled trial," American Journal of Obstetrics and Gynecology 186(5): 876-879.

\section{Review}

Ginath, S. and H.V. Zakut. 2001. “Misoprostol—for cervical ripening?" European Journal of Obstetrics, Gynecology, and Reproductive Biology 99(2): 152-153. 
Poma, P.A. 1999. “Cervical ripening. A review and recommendations for clinical practice," Journal of Reproductive Medicine 44(8): 657-668.

Singh, K. and Y.F. Fong. 2000. "Preparation of the cervix for surgical termination of pregnancy in the first trimester," Human Reproduction Update 6(5): 442-448.

\section{Other}

Barik, S. and P. Stewart. 1997. “Oral versus vaginal misoprostol for cervical priming," British Journal of Obstetrics and Gynaecology 104(5): 644

Carlan, S.J., S. Bouldin, and W.F. O'Brien. 1997. "Extemporaneous preparation of misoprostol gel for cervical ripening: A randomized trial," Obstetrics and Gynecology 90(6): 911-915.

el-Refaey, H., L. Calder, D.N. Wheatley, and A. Templeton. 1994. “Cervical priming with prostaglandin E1 analogues, misoprostol and gemeprost," Lancet 343(8907): 1207-1209.

Fletcher, H.M., S. Mitchell, D. Simeon, J. Frederick, and D. Brown. 1993. "Intravaginal misoprostol as a cervical ripening agent," British Journal of Obstetrics and Gynaecology 100(7): 641-644.

Fong, Y.F., K. Singh, and R.N. Prasad. 1999. “Severe hyperthermia following use of vaginal misoprostol for pre-operative cervical priming," International Journal of Gynaecology and Obstetrics 64(1): 73-74.

Katz, V.L., R.M. Farmer, C.A. Dean, and M.E. Carpenter. 2000. "Use of misoprostol for cervical ripening," Southern Medical Journal 93(9): 881-884.

Perry, K.G., J.E. Larmon, W.L. May, L.G. Robinette, and R.W. Martin. 1998. “Cervical ripening: A randomized comparison between intravaginal misoprostol and an intracervical balloon catheter combined with intravaginal dinoprostone," American Journal of Obstetrics and Gynecology 178(6): 1333-1340.

Platz-Christensen, J.J., S. Nielsen, and L. Hamberger. 1995. "Is misoprostol the drug of choice for induced cervical ripening in early pregnancy termination?" Acta Obstetricia et Gynecologica Scandinavica 74(10): 809-812.

Singh, K., Y.F. Fong, R.N. Prasad, and F. Dong. 1999. “Does an acidic medium enhance the efficacy of vaginal misoprostol for pre-abortion cervical priming?" Human Reproduction 14(6): 1635-1637.

\section{Other}

Austin, J., M.D. Ford, A. Rouse, and E. Hanna. 1997. "Acute intravaginal misoprostol toxicity with fetal demise," Journal of Emergency Medicine 15(1): 61-64.

Barroso, G., S. Karchmer, E. Castelazo, E. Carballo, and A. Kably. 2001. "[A prospective randomized trial of the impact of misoprostol ( $\mathrm{PgE} 1$ ) on pregnancy rate after intrauterine insemination (IUI) therapy: A preliminary report]," Ginecología y Obstetricia de México 69: 346-350.

Bechard de Spirlet, M. "[Use of misoprostol in gynecology and obstetrics]," Gynécologie Obstétrique et Fertilité 30(4): 317-324.

Bisharah, M. and T. Tulandi. 2002. "Side-effects of sublingual misoprostol and insemination terminate study," Reproductive Biomedicine Online 5(1): 92.

Blanchard, K., S. Clark, B. Winikoff, G. Gaines, G. Kabani, and C. Shannon. "Misoprostol for women's health: A review," Obstetrics and Gynecology 99(2): 316-332.

Bond, G.R. and A. Van Zee. 1994. “Overdosage of misoprostol in pregnancy," American Journal of Obstetrics and Gynecology 171(2): 561-562.

Brown, S.E., J.P. Toner, J.A Schnorr, S.C Williams, W.E. Gibbons, D. de Ziegler, and S. Oehninger. 2001. "Vaginal misoprostol enhances intrauterine insemination," Human Reproduction 16(1): 96-101.

Bygdeman, M. 1998 “[Misoprostol may cause fetal malformations]," Läkartidningen 95(30-31): 3268-3269.

Castilla, E.E. and I.M. Orioli. 1994. “Teratogenicity of misoprostol: Data from the Latin-American Collaborative Study of Congenital Malformations (ECLAMC)," American Journal of Medical Genetics 51(2): 161-162.

Chong, Y.S., S. Chua, H. el-Refaey, W.L. Choo, B. Chanrachakul, B.C. Tai, C. Rodeck, and S. Arulkumaran. 2001. “Postpartum intrauterine pressure studies of the uterotonic effect of oral misoprostol and intramuscular syntometrine," British Journal of Obstetrics and Gynaecology 108(1): 41-47.

Clark, S., J. Blum, K. Blanchard, L. Galvao, H. Fletcher, and B. Winikoff. 2002. "Misoprostol use in obstetrics and gynecology in Brazil, Jamaica, and the United States," International Journal of Gynaecology and Obstetrics 76(1): 65-74.

Coelho, H.L., A.C. Teixeira, M. de Fatima Cruz, S.L. Gonzaga, P.S. Arrais, L. Luchini, C. La Vecchia, and G. Tognoni. 1994. "Misoprostol: The experience of women in Fortaleza, Brazil," Contraception 49(2): 101-110.

Coelho, K.E., M.F. Sarmento, C.M. Veiga, C.E. Speck-Martins, H.P. Safatle, C.V. Castro, and N. Niikawa. 2000.

“Misoprostol embryotoxicity: Clinical evaluation of fifteen patients with arthrogryposis," American Journal of Medical Genetics 95(4): 297-301.

Cooper, K.G., S.B. Pinion, S. Bhattacharya, and D.E. Parkin. 1996. "The effects of the gonadotrophin releasing hormone analogue (goserelin) and prostaglandin E1 (misoprostol) on cervical resistance prior to transcervical resection of the endometrium," British Journal of Obstetrics and Gynaecology 103(4): 375-378.

Cox, M.M. 2001. "Misoprostol and pregnancy," Journal of Family Planning and Reproductive Health Care 27(3): 174.

Daisley, H. 2000. "Maternal mortality following the use of misoprostol," Medicine, Science, and the Law 40(1): 78-82. 
Danielsson, K.G., L. Marions, A. Rodriguez, B.W. Spur, P.Y. Wong, and M. Bygdeman. 1999. “Comparison between oral and vaginal administration of misoprostol on uterine contractility," Obstetrics and Gynecology 93(2): 275-280.

Darney, P.D. 2001. “Misoprostol: A boon to safe motherhood ... or not?" Lancet 358(9283): 682-683.

Davies, N.M., J. Longstreth, and F. Jamali. 2001. “Misoprostol therapeutics revisited," Pharmacotherapy 21(1): 60-73.

de la Torre, S., G.J. Gilson, S. Flores, L.B. Curet, C.E. Qualls, and W.F. Rayburn. "Is high-dose misoprostol able to lower the incidence of cesarean section? A randomized controlled trial," Journal of Maternal-Fetal Medicine 10(2): 85-90.

de Poncheville, L., H. Marret, F. Perrotin, J. Lansac, and G. Body. 2002. "[Spontaneous abortions of first trimester pregnancy: Is uterine aspiration still in line?]" Gynécologie Obstétrique et Fertilité 30(10): 799-806.

Downie, W.W. 1991. "Misuse of misoprostol," Lancet 338(8761): 247.

Ferreira, S.M., A.G. Ferreira, M. de Lourdes Contente Gomes, A. da Costa Linhares, and L.V. Decourt. 1999. “Detection of cardiovascular abnormalities in the nursery of a general hospital in the Amazon region: Correlation with potential risk factors," Cardiology in the Young 9(2): 163-168.

Fonseca, W., A.J. Alencar, F.S. Mota, and H.L. Coelho. 1991. "Misoprostol and congenital malformations," Lancet 338(8758): 56

Friedman, M.A. 2001. “Manufacturer's warning regarding unapproved uses of misoprostol," New England Journal of Medicine 344(1): 61.

Gaskin, I.M. 1999. “The problem with Cytotec is that it has not been approved for obstetrical use," Birth Gazette 15(2): 3.

Gebhardt, D.0. 2001. "Misoprostol in a topsy-turvy world," Journal of Medical Ethics 27(3): 205.

Genest, D.R., D. Di Salvo, M.J. Rosenblatt, and L.B. Holmes. 1999. "Terminal transverse limb defects with tethering and omphalocele in a 17 week fetus following first trimester misoprostol exposure," Clinical Dysmorphology 8(1): 53-58.

Goldberg, A.B., M.B. Greenberg, and P.D. Darney. 2001. “Misoprostol and pregnancy," New England Journal of Medicine 344(1): 38-47.

Gonzalez, C.H., M.J. Marques-Dias, C.A. Kim, S.M. Sugayama, J.A. Da Paz, S.M. Huson, and L.B. Holmes. 1998 “Congenital abnormalities in Brazilian children associated with misoprostol misuse in first trimester of pregnancy," Lancet 351(9116): 1624-1627.

Gonzalez, C.H., F.R. Vargas, A.B. Perez, C.A. Kim, D. Brunoni, M.J. Marques-Dias, C.R. Leone, J. Correa Neto, J.C. Llerena, Jr., and J.C. de Almeida. 1993. "Limb deficiency with or without Mobius sequence in seven Brazilian children associated with misoprostol use in the first trimester of pregnancy," American Journal of Medical Genetics 47(1): 59-64.
Graf, W.D. and T.H. Shepard. 1997. "Uterine contraction in the development of Mobius syndrome," Journal of Child Neurology 12(3): 225-227.

Hale, R.W. and S. Zinberg. 2001. “Use of misoprostol in pregnancy," New England Journal of Medicine 344(1): 59-60.

Hofmeyr, G.J. 1998. "Misoprostol in obstetrics and gynaecology: Unregistered, dangerous and essential," South African Medical Journal 88(5): 535-536.

Hofmeyr, G.J., D. Milos, V.C. Nikodem, and M. de Jager. 1998. "Limb reduction anomaly after failed misoprostol abortion," South African Medical Journal 88(5): 566-567.

Katsulov, A. and T. Todorova. 1998. "[Misoprostol: A new prostaglandin in obstetrical practice]," Akusherstvo $i$ Ginekologiia 37(2): 59-66.

Lutescia, L. and H. Coelho. 1998. "[Misoprostol: The solution is not so easy]," Revista de Salud Publica 32(4): 394-395.

Mackenzie, W.E. 2001. "Misoprostol and the politics of fear," Lancet 357(9264): 1296.

McLean, M.T. 1999. “Misoprostol," Midwifery Today with International Midwife Autumn(51): 5.

Nunes, M.L., M.A. Friedrich, and L.F. Loch. 1999. “Association of misoprostol, Moebius syndrome and congenital central alveolar hypoventilation: Case report," Arquivos de Neuro-psiquiatria 57(1): 88-91.

Orioli, I.M. and E.E. Castilla. 2000. “Epidemiological assessment of misoprostol teratogenicity," British Journal of Obstetrics and Gynaecology 107(4): 519-523.

Pastuszak, A.L., L. Schuler, C.E. Speck-Martins, K.E. Coelho, S.M. Cordello, F. Vargas, D. Brunoni, I.V. Schwarz, M. Larrandaburu, H. Safattle, V.F. Meloni, and G. Koren. 1998. "Use of misoprostol during pregnancy and Mobius' syndrome in infants," New England Journal of Medicine 338(26): 1881-1885.

Politz, L.B., R.A. Chez, M.T. Parsons, and K. Huffman. 2001. "The effect of a pill inserter on vaginal misoprostol dosing," Journal of Maternal-Fetal Medicine 10(5): 332-334.

Pottie, K. 1999. “Is misoprostol teratogenic? Misoprostol use during early pregnancy and its association with Mobius' syndrome," Canadian Family Physician 45: 315-316.

Ramsey, P.S., B.B. Hogg, K.G. Savage, D.D. Winkler, and J. Owen. 2000. "Cardiovascular effects of intravaginal misoprostol in the mid trimester of pregnancy," American Journal of Obstetrics and Gynecology 183(5): 1100-1102.

Rocha, J. 1994. "Brazil investigates drug's possible link with birth defects," British Medical Journal 309(6957): 757-758.

Schuler, L., P.W. Ashton, and M.T. Sanseverino. 1992. “Teratogenicity of misoprostol," Lancet 339(8790): 437.

Schuler, L., A. Pastuszak, T.V. Sanseverino, I.M. Orioli, D. Brunoni, P. Ashton-Prolla, F. Silva da Costa, R. Giugliani, A.M. Couto, S.B. Brandao, and G. Koren. 1999. "Pregnancy outcome after exposure to misoprostol in Brazil: A prospective, controlled study," Reproductive Toxicology 13(2): 147-151. 
Shepard, T.H. 1995. "Mobius syndrome after misoprostol: A possible teratogenic mechanism," Lancet 346(8977): 780.

Song, J. 2000. "Use of misoprostol in obstetrics and gynecology," Obstetrical and Gynecological Survey 55(8): 503-510.

Stitely, M.L. and A.J. Satin. 2002. “Cervical ripening agents and uterine stimulants," Clinical Obstetrics and Gynecology 45(1): 114-124.

Tang, O.S., P.P. Gao, L. Cheng, S. Lee, and P.C. Ho. 1998. “Pilot study on the use of a two-week course of oral misoprostol in patients after termination of pregnancy with mifepristone and misoprostol," Contraception 57(2): 89-91.

Tang, O.S., H. Schweer, H.W. Seyberth, S.W. Lee, and P.C. Ho. 2002. "Pharmacokinetics of different routes of administration of misoprostol," Human Reproduction 17(2): 332-336.

Templeton, A. 1998. "Misoprostol for all?" British Journal of Obstetrics and Gynaecology 105(9): 937-939.

Toner, J., D. de Ziegler, S. Brown, W.E. Gibbons, S. Oehninger, J.A. Schnorr, and S.C. Williams. 2001. "High rates of cramping with misoprostol administration for intrauterine insemination," Human Reproduction 16(5): 1051.

van Look, P.F. and H. von Hertzen. 1995. “Misoprostol and birth defects," British Medical Journal 310(6972): 128.

Vargas, F.R., L. Schuler-Faccini, D. Brunoni, C. Kim, V.F. Meloni, S.M. Sugayama, L. Albano, J.C. Llerena, Jr., J.C. Almeida, A. Duarte, D.P. Cavalcanti, E. Goloni-Bertollo, A. Conte, G. Koren, and A. Addis. 2000. "Prenatal exposure to misoprostol and vascular disruption defects: A case-control study," American Journal of Medical Genetics 95(4): 302-306.

Wagner, M. 1999. "Misoprostol," Midwifery Today with International Midwife Autumn(51): 4-5.

2001. "Misoprostol and the politics of convenience," Lancet 357(9274): 2142.

Wheeler, M., P. O'Meara, and M. Stanford. 2002. “Fetal methotrexate and misoprostol exposure: The past revisited," Teratology 66(2): 73-76.

Williams, M.C., J.C. Tsibris, G. Davis, J. Baiano, and W.F. 0 'Brien. 2002. "Dose variation that is associated with approximated one-quarter tablet doses of misoprostol," American Journal of Obstetrics and Gynecology 187(3): 615-619.

Yip, S.K., A.O. Tse, C.J. Haines, and T.K. Chung. 2000. “Misoprostol's effect on uterine arterial blood flow and fetal heart rate in early pregnancy," Obstetrics and Gynecology 95(2): 232-235.

Yu, J., J. Zhang, and Y. Song. 1998. "[Clinical uses of misoprostol in obstetrics and gynecology]," Zhonghua Fu Chan Ke Za Zhi 33(1): 55-57.

Zieman, M., S.K. Fong, N.L. Benowitz, D. Banskter, and P.D. Darney. 1997. "Absorption kinetics of misoprostol with oral or vaginal administration," Obstetrics and Gynecology 90(1): 88-92.

Zust, S., I. Hosli, D. Surbek, and W. Holzgreve. 2001. “[Adverse effects of misoprostol in pregnancy]," Zeitschrift für Geburtshilfe und Neonatologie 205(2): 43-48. 


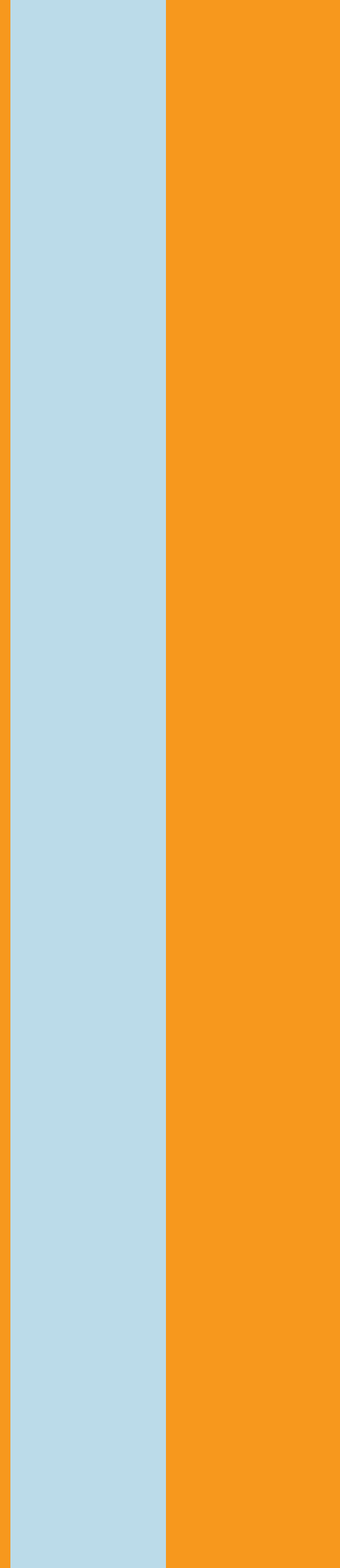

